\title{
HANS-JOCHEN SCHIEWER
}

Ein ris ich dar vmbe abe brach/Von sinem wunder bovme

Beobachtungen zur Überlieferung des nachklassischen Artusromans im 13. und 14. Jahrhundert 
Ein ris ich dar vmbe abe brach/Von sinem wunder bovme. Beobachtungen zur Überlieferung des nachklassischen Artusromans im 13. und 14. Jahrhundert ${ }^{1}$

„Zuerst erblühte die Poesie überall in einer Ausdehnung, wie sie anderwärts selten angetroffen wird. (...) Kein Wunder, dass sich der Geschmack der Heldendichtung in alle Burgen, unter alle Grossen des Landes verbreitete. Man legte kostbare Sammlungen von Handschriften an, in welchen die deutschen Nationaldichtungen auf das zierlichste verzeichnet waren, und die gewöhnliche Hauslektüre des Adels bildete. Die merkwürdigsten Bibliotheken dieser Art fand man zu Amras, Runglstein und Annaberg in Vintschgau. (...) Man fand darin (...) ausgedehnte Sammlungen von Minneliedern in der köstlichsten Reinschrift auf allerfeinstem Pergament in so grosser Fülle, dass man schon im 15. Jahrhundert die Gerichtsverhöre damit einzubinden anfing, wie namentlich im Meranerarchive noch zu sehen ist." ${ }^{2}$

Mit diesen Worten beschreibt BEDA WeBER 1837 den Umgang mit mittelalterlicher Literatur in Tirol. IgNAZ Victor ZINGERLE ließ sich dadurch anregen. ${ }^{3} \mathrm{Er}$ fand im Meraner Gerichtsarchiv jedoch keine Minnelieder, sondern Fragmente des Pleierschen ,Garel' und nicht als Einband spätmittelalterlicher Gerichtsverhöre, sondern als ,Umschlag von Gerichtsprotokollen und Verfachbüchern aus den Jahren 1617-1641'.

Auf zwei grundlegende Phänomene verweist dieses Zitat: Wir haben es, wenn wir uns mit der Überlieferung des nachklassischen Artusromans bis 1400 be-

\footnotetext{
${ }^{1}$ Der Vortrag wurde um ein Kapitel zur ,Wigalois'-Überlieferung und eine kommentierte Tabelle mit wesentlichen kodikologischen Daten der besprochenen Handschriften erweitert. Außerdem wurde bei der Überarbeitung die ,Parzival'-Überlieferung und die Überlieferung der arthurischen Versromane des romanischen Raums berücksichtigt. Erst nach dem Vortrag wurden ein ,Edolanz'-Fragment (Nr. 3), ein ,Gauriel'-Fragment (Nr. 9a), ein Garel-Fragment (Nr. 13) und ein ,Segremors'-Fragment (Nr. 19, Weimar) wiederentdeckt. Herrn Palmer verdanke ich den Hinweis auf neue Fragmente der ,Wigalois'-Hs. Nr. 44 (s. dazu die Hss.tabelle). - Ich danke den in der Tabelle genannten Bibliotheken für die Anfertigung von Mikrofilmen und Kopien sowie bereitwillig erteilte Auskünfte. Mein besonderer Dank gilt den folgenden Bibliotheken, die mir die Erlaubnis zur Reproduktion ihrer Handschriften gaben: Gotha, Forschungsbibl.; Kopenhagen, Kongelige Bibliotek; Krakau, Biblioteka Jagiellońska; Loccum, Klosterbibl.; München, Staatsbibliothek; Schwaz, Bibl. d. Franziskanerklosters; Seitenstetten, Stiftsbibl.; Weimar, Staatsarchiv; Wien, ÖNB. Für Anregungen und Hilfe bedanke ich mich besonders bei Hartmut Beckers (Münster), Kurt Gärtner (Trier), Nikolaus Henkel (Regensburg), Nigel F. Palmer (Oxford) und Karin Schneider (München).

${ }^{2}$ Beda Weber, Das Land Tirol mit einem Anhange Vorarlberg. Ein Handbuch für Reisende. Bd. 1-3. Innsbruck 1837-1838, Bd. I, S. 172.

${ }^{3}$ IgnAZ Victor Zingerle, Zu Pleier's Garel. Die Bruchstücke der Meraner Handschrift. WSB 50 (1865), S. 449-558.
} 
schäftigen, hauptsächlich mit Fragmenten zu tun (6 Handschriften stehen 63 Fragmenten aus 53 Handschriften gegenüber) und die meisten Fragmente bescherte uns der Sammeleifer des 19. und frühen 20. Jahrhunderts (50), dessen Interesse sich fast ausschließlich auf die Archivierung des Textes richtete, d.h., die Fragmente sind, wenn nicht verschollen, so doch in vielen Fällen ohne genaue Fundortangaben überliefert worden.

Die Neubewertung des nachklassischen Artusromans, eingeleitet durch die Arbeiten von RuH, ${ }^{4}$ Cormeau, ${ }^{5} \mathrm{KeRN}^{6}$ und Haug, ${ }^{7}$ hat mich zu dieser Arbeit angeregt. Die zeitliche Grenze um 1400 bezeichnet zwar keine deutliche Zäsur, trennt den Untersuchungszeitraum aber von der „Ritterrenaissance“ und den bibliophilen Interessen des 15. Jahrhunderts. Die von Cormeau und Kern herausgearbeiteten Strukturmerkmale der Gattung rechtfertigen ebenso wie die unergiebige Einzelüberlieferung einen gattungsweiten Überblick. Im Gegensatz zu den bisherigen Untersuchungen beziehe ich nicht nur die vollständigen, sondern auch die fragmentarisch überlieferten Werke mit ein. Der eigentlich pejorative Begriff „nachklassisch“ dient mir nur zur Abgrenzung von den Werken Hartmanns, Wolframs und Gottfrieds, deren Fortsetzungen ebenso wie die strophischen Dichtungen (Albrechts ,Jüngerer Titurel', ,Lohengrin', ,Tirol und Fridebrant ${ }^{\circ}$ ) ausgeschlossen werden.

Die bisherigen, stark strukturalistisch geprägten Untersuchungen führten uns das enge Beziehungsgeflecht der Gattung Artusroman vor Augen. Jeder neue Gattungsvertreter knüpfte an seine Vorläufer und deren Entwurf einer arthurischen Welt an, baute ihn weiter aus. Dieser Befund ließ mich die Frage stellen, welche Aussagen die Überlieferung zu Verbreitung und Resonanz des nachklassischen Artusromans erlaubt.

$\mathrm{Zu}$ diesem Zweck will ich in einem ersten Durchgang die Werke - falls notwendig - vorstellen, die Überlieferungszahlen miteinander und mit denen der klassischen Romane konfrontieren, die geographische und chronologische Verteilung anhand dialektaler und paläographischer Kriterien ${ }^{8}$ beschreiben und

\footnotetext{
${ }^{4}$ Kurt Ruh, Der ,Lanzelet' Ulrichs von Zatzikhofen. Modell oder Kompilation? In: Deutsche Literatur des späten Mittelalters. Hamburger Colloquium 1973. Hg. von Wolfgang Harms und L. P. Johnson. Berlin 1975, S. 47-55. Bei diesem Roman geht der Zusatz „nachklassisch“ gänzlich fehl, allenfalls „vorklassisch“ wäre hier zulässig. Seine Behandlung nicht nur bis zu RuHs Neubewertung rechtfertigt aber seine Einbeziehung.

${ }^{5}$ Christoph Cormeau, ,Wigalois' und ,Diu Crone‘. Zwei Kapitel zur Gattungsgeschichte des nachklassischen Aventiureromans. München 1977 (MTU 57).

${ }^{6}$ Peter Kern, Die Artusromane des Pleier. Berlin 1981 (Philol. Studien u. Qu. H. 100).

${ }^{7}$ Walter Haug, Paradigmatische Poesie. Der spätere deutsche Artusroman auf dem Weg zu einer nachklassischen Ästhetik. DVjs 54 (1980), S. 204-231. Im übrigen verweise ich nur auf die Weiterführung des Gesprächs in den beiden jüngst erschienenen Tagungsbänden: Artusrittertum im späten Mittelalter. Ethos und Ideologie. Hg. von Friedrich WolfzetTel. Gießen 1984; Spätmittelalterliche Artusliteratur. Ein Symposion. Hg. von Karl Heinz Göller. Paderborn [u. a.] 1984 (Beitr. zur englischen und amerikanischen Literatur. Bd. 3).

${ }^{8}$ Bei der dialektalen Einordnung und der zeitlichen Bestimmung nach paläographischen Kriterien stütze ich mich auf die bisherige Forschung. Eine Überprüfung und Neubestimmung konnte angesichts der Materialfülle nur bei extrem abweichenden Einschätzungen innerhalb der Forschung vorgenommen werden.
} 
auf mögliche Zusammenhänge zwischen Überlieferung und den bekannten Daten über Autor, Abfassungszeit und -ort sowie Auftraggeber verweisen. Das folgende Kapitel wird der, Wigalois'-Überlieferung gewidmet sein.

Das dritte Kapitel geht den Fundorten der Fragmente nach, um der Makulierungszeit auf die Spur zu kommen. Den Abschluß des Aufsatzes bilden eine kommentierte Tabelle mit den wichtigsten kodikologischen Daten der Handschriften, Karten zur Verbreitung der Texte und Abbildungen zur handschriftlichen Überlieferung der fragmentarischen Artusromane. Im Kommentar wird der Versuch gemacht, durch einen Vergleich der kodikologischen Daten Überlieferungstypen zu ermitteln. Ein Vergleich mit der Überlieferung altfranzösischer arthurischer Texte soll dann zeigen, ob im heuristischen Bereich Parallelentwicklungen vorliegen. Parallelen in der Gattungsentwicklung erschloß jüngst Cormeau. ${ }^{9}$

I.

Stünden uns für alle bekannten nachklassischen Artusromane des 13. Jahrhunderts Überlieferungszeugen aus der Zeit bis 1400 zur Verfügung, so hätten wir es mit 24 Texten zu tun, ${ }^{10} \mathrm{zu}$ denen ich die bruchstückhaft erhaltene Dichtung

${ }^{9}$ Christoph Cormeau, Zur Gattungsentwicklung des Artusromans nach Wolframs ,Parzival‘. In: Spätmittelalterliche Artusliteratur [Anm. 7], S. 119-131. Beim Vergleich der deutschen Entwicklung mit den von Beate Schmolke-Hasselmann (Der arthurische Versroman von Chrestien bis Froissart. Tübingen 1980, ZfromPh. Beih. Bd. 177) für die altfranzösischen Texte gewonnenen Ergebnissen kommt er zu dem Fazit: „In beiden Literaturen muß also geschlossen werden, daß der Artusroman im 13. Jahrhundert sich in erster Linie an ein informiertes, kennerhaftes - und damit begrenztes - Publikum wandte, dem Wiederholung und Nuancierung bekannter Konstellationen mindestens ebenso wichtig waren wie neue Fabeln oder Problemstellungen.“ (S. 125).

${ }^{10}$ Einen Überblick über die vor 1400 überlieferten Artusromane erlaubt die Tabelle im Anhang. Der ,Daniel“ des Stricker und Pleiers ,Meleranz' sind erst nach 1400 handschriftlich belegt. Albrechts von Scharfenberg, Merlin' und ,Seifrid de Ardemont' kennen wir nur aus der Bearbeitung durch Ulrich Füetrer im ,Buch der Abenteuer', das noch die anonymen und sonst nicht überlieferten Romane ,Persibein', ,Poitislier und ,Flordimar“ enthält. Unberücksichtigt bleibt eine fragmentarisch überlieferte ,Vita Merlini‘ aus dem nordmittelfränkischen Sprachraum, da die kurze Darstellung auf die Person Merlins und seine Prophezeiungen beschränkt ist, ohne im Handlungszusammenhang eines Artusromans zu stehen. Hartmut Beckers, dem ich den Hinweis auf dieses Fragment verdanke, wird demnächst im Rahmen einer monographischen Behandlung des Fragments durch mehrere Bearbeiter einen neuen Textabdruck dieser, Merlin'-Dichtung vorlegen, die zusammen mit einer ,Lüthild'-Legende überliefert wird. Vgl. dazu ders., , Merlin' und ,Lüthild‘. ${ }^{2}$ VL6, 1986, Sp. 447-449. Einziger Abdruck bisher von Johannes Franck, Westdt. Zs. f. Geschichte u. Kunst 21 (1902), S. 284-316. Außerdem erfahren wir durch Rudolf von Ems im nach 1235 entstandenen, Willehalm von Orlens“ (Hg. von Victor JuNk. Berlin 1905. Neudruck: Dublin/ Zürich 1967) (=WvO), daß En Gotfrit von Hohnloch [...] Die werden ritter úber al/ Die bi Artuses jaren/ In sinem hove waren/ Fúr die werdesten erkant [...] wislichen genant habe (V. 2234-2239). Erstaunlich ist bei dieser Erwähnung die fehlende Nennung eines Titelhelden. In vergleichbarer Weise zitiert Rudolf nur die ,Crône' Heinrichs von dem Türlin im ,Alexander' ( $\mathrm{Hg}$. von VICTOR Junk. Berlin 1928-1929. Neudruck: Darmstadt 1970, V. 3219ff.) (= Alex.). Mit der Nennung des Werktitels im ersten Vers setzt er aber ein deutliches Erkennungssignal: Allr Aventiure krone 
,Abor und das Meerweib“ (MB, S. 180-183) zähle, die zwar von minne und aventiure handelt, aber in den überlieferten Partien keinen Hinweis auf Artus und seine Ritter enthält. ${ }^{11}$ Trotzdem glaube ich, diesen Text in die Untersuchung mit einbeziehen zu können, denn Artus und sein Hof werden im Laufe der Gattungsentwicklung immer stärker an den Rand des Geschehens gedrängt, so daß der ausbleibende Hinweis auf Artus und seine Ritter nicht genügt, um dieses Fragment auszuschließen. Ähnlich verhält es sich mit dem ,Manuel und Amande'Fragment (MB, S. 151-154): Manuel von Griechenland und Amande von Spanien tauchen sonst im arthurischen Bereich nicht auf, nur der, Cligès' bietet mit dem Kaisersohn Alexander eine Person aus dem byzantinischen Reich. Über den Handlungsverlauf des Romans wissen wir wenig, doch wird hier der pseudohistorische Minne- und Aventiureroman Pate gestanden haben, in dem der adlige Held nach verwickelten Abenteuern die Dame seines Herzens erwirbt. Die Hochzeit findet am Artushof statt und bildet den Abschluß des Romans, der uns in zwei Einzel- und drei Doppelblättern aus dem Franziskanerkloster Schwaz überliefert ist. ${ }^{12}$ Der unbekannte Verfasser beschließt die Handlung mit einem Hinweis auf die vorlagenunabhängige Verfügbarkeit des Artusstoffes und die fast unerschöpflichen Kombinationsmöglichkeiten:

\author{
Ich mohte iv fremede mere \\ von deme wunderere \\ Vil vnde ane mazen sagen, \\ wan ime ofte in sinen tagen \\ Aventivren vil geschach. \\ ein ris ich dar vmbe abe brach \\ Von sinem wunder bovme, \\ ob man des nicht engoume \\ Vnde ob ieman iehe \\ daz er daz gerne sehe, \\ Daz ich der este breche mer. (MB, S. 153, V. 123-133)
}

(V. 3219). Vielleicht handelte es sich bei dem Werk eines Gottfried von Hohenlohe um eine Aufzählung bekannter Artusritter ähnlich wie im ,Spruch von den Tafelrundern' (Hg. von $\mathrm{H}$. MenhardT, PBB [Tüb.] 77 (1955), S. 136-164 u. 316-332) aus dem späten 15. Jahrhundert. Solange wir nichts Genaues über diese verlorene Dichtung wissen, müssen wir sie trotz der vorgetragenen Bedenken als verlorenen Artusroman ansetzen. - Noch weniger Anhaltspunkte ergeben sich bei dem ebenfalls verlorenen Werk Heinrichs von Leinau (Rudolf von Ems, WvO, V. 2226; Alex., V. 3254), in dem das Motiv des Sperberkampfes auftaucht (WvO, V. 7100-7148). Zu den Wolfenbütteler, Erec'-Fragmenten s. Anm. 25.

${ }^{11}$ Bis auf das ,Loccumer Artusromanfragment', den ,Cligès' und den ,Parcheval' sind alle fragmentarischen Artusromane abgedruckt in: Mittelhochdeutsche Übungsstücke zusammengestellt von Heinrich Meyer-Benfey. 2. Aufl. Halle a. S. 1920 (künftig MB mit Seiten- und Versangabe), hier S. $180-183$.

12 Oswald Zingerle, Manuel und Amande. Bruchstücke eines Artusromans. ZfdA 26 (1882), S. 297-307; Hans-Hugo Steinhoff, Ein neues Fragment von ,Manuel und Amande‘. ZfdA 113 (1984), S. 242-245 (mit Faksimile); ders., Manuel und Amande. ${ }^{2}$ VL 5, 1985, Sp. $1225 f$. 
Offenbar bestätigte sich die Hoffnung des Verfassers nicht, weitere Aufträge für Artusromane zu bekommen, denn alle Bruchstücke gehören zu einer Handschrift. Zeitgenossen wie Nachfolger erwähnen weder Werk noch Verfasser.

Neben dem Pleierschen ,Meleranz' ist der einzige vollständig erhaltene, aber vor 1400 nicht überlieferte Artusroman der, Daniel vom blühenden Tal des Stricker. Von ihm besitzen wir fünf Handschriften des 15. Jahrhunderts, die alle aus dem alemannischen Raum stammen oder dort ihren Ursprung haben. Die Verbreitung und Resonanz des ,Daniel' im 13. Jahrhundert belegen hingegen Rudolf von Ems (WvO, V. 2230-2233) im Südwesten und die Gegenreaktion des Pleiers, der ,Garel von dem blühenden Tal', im Südosten. Im ,Gauriel von Muntabel ' des Konrad von Stoffeln ${ }^{13}$ und im ,Friedrich von Schwaben ${ }^{14}$ tritt der Daniel neben titelgebenden Artusrittern auf. Möglicherweise verdrängte der nur im Südosten überlieferte ,Garel' des Pleier den Strickerschen Roman aus dem bairisch-österreichischen Sprachgebiet. Reaktionen und Erwähnungen sprechen also für eine Kenntnis des Werks im 13. und 14. Jahrhundert bei Autoren und artusbegeisterten Hörern und Lesern. ${ }^{15}$

,Abor und das Meerweib', ein mittelhochdeutscher, Cligès' und der ,Edolanz', das ,Loccumer Artusromanfragment', der ,Parcheval' und der ,Segremors“ sind die nur bruchstückhaft überlieferten Artusromane.

Von ,Abor und das Meerweib“ besitzen wir ein Fragment aus der 1. Hälfte des 14. Jahrhunderts (Nr. 1 u. Abb. 1-2), dessen Sprache bairische Merkmale aufweist, das aber auf eine ostfränkische oder mitteldeutsche (thüringische) Vorlage zurückgeht. ${ }^{16}$ Wir hören von einem wigant namens Abor, der - ermattet an einem Jungbrunnen aufgefunden - von einem merwip gepflegt, geliebt und beschenkt wird, bis deren Mann aus der Stadt omlatin zurückkehrt. Hier bricht das Fragment $\mathrm{ab}$.

${ }^{13}$ Konrad von Stoffeln, Gauriel von Muntabel. Hg. von Ferdinand Khull. Mit e. Nachw. u. Lit.verz. von Alexander Hildebrand. Neudruck d. Ausg. 1885. Osnabrück 1969, V. 3867. $(=\mathrm{GvM})$

${ }^{14}$ Friedrich von Schwaben. Hg. von Max J. JellineK. Berlin 1904 (DTM 1), V. 4819.

${ }^{15}$ Anders äußert sich Werner SCHröDer, Der Text von Strickers ,Daniel ' und seine Überlieferung. ZfdA 114 (1985), S. 46-70. Ausgehend von der spät einsetzenden handschriftlichen Überlieferung kommt ScHRÖDER zu dem Schluß: „Es sieht so aus, als sei er schon im 13. wenig verbreitet gewesen und als habe er nur in einer Handschrift überlebt, die im 15. Jh. zum Ausgangspunkt einer Wiederbelebung geworden ist." (S. 60). Dabei berücksichtigt Schröder allerdings nicht die genannten literarischen Zeugnisse und die Zusammensetzung des Publikums der ersten Stunde, das sicherlich aus Kennern der Gattung bestand. Solche Kennerschaft verlangten der augenscheinlich erfolgreichere ,Karl' und die maeren nicht von ihrem Publikum. Zur Beurteilung von Erfolg oder Mißerfolg vieler mittelalterlicher Dichtungen muß man sich von der Beeinflussung durch neuzeitliche Marktgesetze frei machen. Der ,Daniel“ war eine für einen bestimmten Kreis von Kennern konzipierte Auftragsdichtung wie die gesamte spätere Artusepik, und in diesem Kreis genügten wenige Exemplare, um eine Dichtung bekannt zu machen. Vgl. dazu auch XENJA vON ERTZDORfF, Strickers ,Daniel vom blühenden Tal‘. Ein Artus-Roman des 13. Jahrhunderts im Ambiente des 15. Jahrhunderts. In: Fs. f. Siegfried Grosse. Hg. von Werner Besch [u.a.]. Göppingen 1984 (GAG 423), S. 371-382.

${ }^{16} \mathrm{Hg}$. von Jacob Grimm. ZfdA 5 (1845), S. 6-10; Edward Schröder, ,Abor und das Meerweib“. GGA (1925), S. 161-165; Ludwig Denecke. ${ }^{2}$ VL 1, 1978, Sp. 10-11. 
Die drei bekannten ,Cligès'-Bruchstücke (Nr. 2) gehören zu einer am Beginn des 14. Jahrhunderts im Bairischen entstandenen Handschrift. ${ }^{17}$ Vermutlich Thomasin und sicher Rudolf von Ems (WvO, V. 2256ff., V. 4390ff.) erwähnen eine mittelhochdeutsche Fassung des Chrestienschen ,Cligès'. ${ }^{18}$ Konrad Fleck (Alex., V. 3240ff.) und Ulrich von Türheim werden von Rudolf als Verfasser genannt. Seit der Publikation der Kalocsaer Fragmente durch András Vizkelety wird die Dichtung Ulrich von Türheim aufgrund der darin enthaltenen Verfassernennung (Vlrich [von Tur]ehein auf f. $1^{\text {rb }}$ ) zugewiesen. ${ }^{19}$

Vom ,Edolanz' (MB, S. 145-150) besitzen wir ein Fragment aus dem späten 13. Jahrhundert (Nr. 3 u. Abb. 3-4) (20 $^{20}$ und ein Fragment aus der Mitte des 14. Jahrhunderts (Nr. 4 u. Abb. 5-7), beide Fragmente zeigen bairische Eigenheiten. Dieser Befund wird durch die Nennung des ,Edolanz' in der überwiegend südbairischen Überlieferungsgruppe II des ,Jüngeren Titurel ${ }^{\star}$ ergänzt: ${ }^{21}$ Beim Fest des Königs Artus auf Florischanze läßt Albrecht viele bekannte Schönheiten der Artusliteratur auftreten, die Frauengestalten Wolframs, Gottfrieds, Hartmanns, Ulrichs, Wirnts und am Schluß eine Karfeiten. die Edolantz erchos im zu ainer traute..$^{22}$ In den Bruchstücken taucht diese Karfite nicht auf, wir hören nur: Edolanz besteht einen Riesenkampf, befreit dadurch Gawein und eine Königin, trifft auf einen rehbockreitenden Zwerg, kämpft zugunsten einer Stadt gegen den Pontschur, den er in einem Sperberkampf vor dem Artushof besiegt.

In den niederdeutschen Sprachraum führt uns das ,Loccumer Artusromanfragment' (Nr. 10 u. Abb. 8). Es stammt aus einer kaum nach 1300 entstandenen

${ }^{17}$ Hans Gröchenig u. Peter Hans Pascher, Ulrich von Türheim, Cligès. Ausgabe der bisher bekannten Fragmente vermehrt um den Neufund aus St. Paul im Lavanttal. Einleitung und buchkundliche Beschreibung. Klagenfurt 1984 (Armarium. 2) [mit, wenn auch schlechten Abb.].

${ }^{18}$ Thomasin von Zirclaria, Der Wälsche Gast. Hg. von Heinrich RüCKert. Nachdruck d. Ausg. 1852. Mit e. Einl. u. e. Register von Friedrich Neumann. Berlin 1965, V. 1026-1052. (= Thomasin).

${ }^{19}$ András Vizkelety, Neue Fragmente des mhd. ,Cligès'-Epos aus Kalocsa (Ungarn). ZfdPh 88 (1969), S. 409-432. Die Zuweisung an Ulrich von Türheim übergeht die chronologischen Probleme: Die Nennung bei Thomasin sowie die nur aus dem zweiten Teil der Dichtung stammenden Bruchstücke lassen LachmanNs Vermutung (Vizkelety, S. 410) einer Fortsetzertätigkeit Ulrichs noch gültig bleiben.

${ }^{20}$ Eine gezielte Nachfrage in Seitenstetten ergab, daß das verschollen geglaubte Fragment (so CHRISTOPH CORMEAu ${ }^{2}$ VL 2, 1980, Sp. 359) noch immer dort aufbewahrt wird. Zu den kodikologischen Daten s. Tabelle Nr. 3.

${ }^{21}$ Konrad Borchling, Der jüngere Titurel und sein Verhältnis zu Wolfram von Eschenbach. Göttingen 1897, S. 37, 41f.; Albrecht (von Scharfenberg), Jüngerer Titurel. Hg. von Werner Wolf. Bd. I, II, 1-2. Berlin 1955-1968 (DTM 45, 55, 61), Str. 1632 (H 1598)-1646 (H 1612); Bd III/1. Nach den Grundsätzen von WerNer WOLF krit. hg. von KURT NyHOLM. Berlin 1985 (DTM 73), Str. 4569 (H 4539): Her hartmann von Owe, nu sprecht, daz iu gevalle / Enite iur werden vrowe, der dienaer muz hie slichen sam si alle, / und Edolantze, den ein Provencale / prüft fur die werden alle, die twanc der Grahardois der vluht zemale. - Da die Ausgabe eine Wiedergabe der Überlieferungsgruppe I auf der Basis von Handschrift B (Heidelberg, UB, cod. pal. germ. 383) ist, wird Edolanz auch in diesem Überlieferungszweig genannt und dürfte somit nicht nur dem Redaktor R, sondern auch Albrecht bekannt gewesen sein, vgl. WaLTER RölL, Studien zu Text und Überlieferung des sogenannten Jüngeren Titurel. Heidelberg 1964, S. 97.

${ }^{22}$ Jüngerer Titurel [Anm. 21], Str. 1644 (H 1610) nach Hs. X. 
Handschrift, deren ursprüngliches Oktavformat aus buchbinderischen Gründen auf Duodez reduziert wurde. Folglich ist der Text nur noch sehr rudimentär erhalten. Hartmut BeCKers, der das Fragment erstmals ausführlich würdigte, erkannte deutliche Beziehungen zum Wolframschen Gahmuret-Teil und im Anschluß an Ludwig WolfF die Übernahme einer Versgruppe aus Hartmanns, Armem Heinrich ${ }^{623}$ Der sprachliche Befund weist die Fragmente nach Westfalen.

Die schon vorgestellte Dichtung von ,Manuel und Amande“ ist in drei Fragmenten (Nr. 11 u. Abb. 20ff.) einer Handschrift erhalten, die um 1300 am nordöstlichen Rand des oberdeutschen Sprachgebiets entstand. ${ }^{24}$

Aus dem mittelfränkischen Sprachraum stammen die in der 2. Hälfte des 13. Jahrhunderts entstandenen ,Parcheval'-Fragmente (Nr. 12), die eine Übersetzung der ebenfalls nur bruchstückhaften mittelniederländischen Fassung von Chrestiens ,Contes del graal' repräsentieren. ${ }^{25}$ Sie bieten eine Passage aus dem Karfreitagserlebnis (Pz. IX. Buch, 446ff.) und setzen mit der Wegweisung zum Klausner ein.

Die aus dem thüringischen Sprachraum stammenden drei Fragmente einer Dichtung um den seit Hartmanns ,Erec' bekannten Artusritter Segremors (Erec, V. 1665; MB, S. 166-180) gehören zu zwei Handschriften aus der Zeit um 1300 (Nr. 20 u. Abb. 15-16) und der 1. Hälfte des 14. Jahrhunderts (Nr. 19 u. Abb. 9-14). Der unbekannte Verfasser bezieht die Handlungsstruktur aus einer französischen Vorlage (Raoul de Houdenc, ,Meraugis de Portlesguez') und die Namen aus der deutschsprachigen Gattungstradition oder schafft sie in Wolframscher Manier neu. ${ }^{26}$

${ }^{23}$ Hartmut Beckers, Ein vergessenes mittelniederdeutsches Artuseposfragment (Loccum, Klosterbibliothek, Ms. 20). Niederdt. Wort 14 (1974), S. 23-52; ders., Loccumer Artusroman. ${ }^{2}$ VL 5, 1985, Sp. 886-888.

${ }^{24}$ S. Anm. 12.

${ }^{25}$ LeOPOLD ZATočIL, Prager Bruchstück einer bisher unbekannten mittelfränkischen Übertragung der mittelniederländischen Versbearbeitung von Chrétiens de Troyes Percevalroman (Li contes del graal). In: L. Z., Germanistische Studien und Texte. I. Brünn 1968, S. 247-280 (mit Faksimile). Die Aufnahme der,Parcheval'-Dichtung ist durch ihre gesicherte Unabhängigkeit von Wolfram gerechtfertigt. Aus diesem Grunde werden die Wolfenbütteler ,Erec'-Fragmente nicht aufgenommen, weil die Kontroverse über deren Unabhängigkeit von der Hartmannschen Fassung noch nicht beendet ist. Eine eigene begründete Stellungnahme kann in diesem Rahmen nicht gegeben werden. Vgl. dazu Eberhard Nellmann, Ein zweiter ,Erec'-Roman? Zu den neugefundenen Wolfenbütteler Fragmenten. ZfdPh 112 (1982), S. 28-78, bes. S. 63ff.; KuRT GärTnER, Der Text der Wolfenbütteler ,Erec'-Fragmente und seine Bedeutung für die ,Erec'-Forschung. PBB 104 (1982), S. 207-230 u. 359-430, bes. 413-415.

${ }^{26}$ Paul Gerhardt Beyer, Die mitteldeutschen Segremorsfragmente. Untersuchung und Ausgabe. Marburg, Phil. Diss. 1909, S. 79-96; S. 116f. - Den einzigen Hinweis, der sich auf eine, Segremors'-Dichtung beziehen ließe, enthält der ,Welsche Gast' Thomasins von Zirclaere in der Jugendlehre: lât niht verderben iuwer jugent:/ gedenket an Alexanders tugent, / an gevuoc volgt ir Tristande,/ Seigrimos, Kâlogriande. (V. 1049-1052). - Einerseits spricht die hier zugewiesene Vorbildfunktion eher für das Vorhandensein einer größeren Erzählung um die Segremorsgestalt gerade wegen der eher unauffälligen Erscheinung von Segremors in den bekannten Artusromanen, andererseits nennt ihn Thomasin hier neben Kalogreant, der zwar eine eigene Geschichte, aber nur innerhalb von Hartmanns, Iwein' hat. Beide Gestalten treten als literarische Decknamen bei der Artusfahrt Ulrichs von Lichtenstein auf $(\mathrm{Hg}$. von Reinhold Bechstein. Bd. 2. Leipzig 1888, Str. 1416, 5; 
Die aus dem Staatsarchiv Weimar und der Forschungsbibliothek Gotha stammenden Fragmente einer ,Segremors'-Handschrift (Nr. 19 und Abb. 9-14) stellen eine Ausnahmeerscheinung innerhalb der Überlieferung des nachklassischen Artusromans dar. Die äußeren Abmessungen der beschnittenen Pergamentblätter (Weimar: $435 \times 330 \mathrm{~mm}$; Gotha: $475 \times 365 \mathrm{~mm}$ ) und der thüringische Dialekt mit niederdeutschen Spuren $^{27}$ rücken sie in die Nähe der ,Jenaer Liederhandschrift'. Ein Vergleich der übergroßen Schrift beider Handschriften bestätigt diese Vermutung. Ohne daß man hier schon mit Sicherheit auf eine Identität beider Schreiber schließen könnte, besteht doch zumindest Werkstatt- oder Schulgemeinschaft. ${ }^{28}$ Dieser Befund gilt auch für den Initialenschmuck.

Format, Schriftdialekt und Schrift verbinden die ,Jenaer Liederhandschrift" mit den ,Segremors'-Fragmenten auf das engste, so da $ß$ die Vermutung nahe liegt, da $ß$ es sich hierbei um zwei Schwesterhandschriften handeln könnte: auf der einen Seite ein Liederbuch, auf der anderen Seite der ,Segremors'. Das wäre allerdings kein ausgeglichenes Verhältnis. Mehr Wahrscheinlichkeit hat die Annahme, daß sich hinter den ,Segremors'-Fragmenten eine Epensammlung verbirgt. Diese Annahme stützen ,Parzival'Fragmente der Forschungsbibliothek Gotha Memb. I 130, deren kodikologische Daten zu denen der ,Segremors'-Fragmente passen. ${ }^{29}$ Sie dienten als Einbandmaterial für Akten, die das Amt Wassenburg beim thüringischen Arnstadt betrafen. Nach den Einträgen dürfte die Makulierung 1541-1542 erfolgt sein. Dazu passen die Vermerke auf den ,Segremors'-Fragmenten: Weimar, $1^{\mathrm{r}}$ Wassennburgk; Gotha, $2^{\mathrm{v}}$ 1543. ampt wassennburgh. Somit verbinden nicht nur die äußeren Merkmale, sondern auch Fundort und Makulierungszeit die ,Segremors'- und ,Parzival'-Fragmente.

Arnstadt und Burg und Amt Wachsenburg gehörten seit der Mitte des 13. Jahrhunderts zum Herrschaftsbereich der Wettiner. Dialekt, Fundort und Ausstattung legen die

1439,2 u. ö.). Die räumliche und zeitliche Entfernung zu den Segremorsfragmenten spricht eher gegen die Zitierung eines titelgebenden Romanhelden, die man wohl nur für den ,Prosa-Lancelot ernsthaft erwägen könnte. Im, Gauriel von Muntabel' taucht er nicht in einem Zug mit titelgebenden Romanhelden auf, im ,Friedrich von Schwaben' gar nicht. Erst unter den Autoritäten aus der Dichtung erscheint Segremors in ,Bollstatters Spruchsammlung' (London, BM, Ms. Add. 16 581, $146^{r}$ ) wieder und findet am Ende des 15. Jh.s einen Platz im "Spruch von den Tafelrundern“ (s. Anm. 10, V. 50). Aber hier befinden wir uns im Umfeld von Sammlern ritterlicher Epen.

${ }^{27}$ Beyer [Anm. 26], S. 30-41.

${ }^{28}$ Ein Vergleich der Abb. 9-14 mit der Faksimileausgabe der ,Jenaer Liederhandschrift ${ }^{\star}(\mathrm{Hg}$. von Helmut Tervooren u. Ulrich Müller, Göppingen 1972, Litterae 10.) zeigt den vollkommen gleichen Schreibduktus. Unterschiede in der Spaltenanlage sind gattungsbedingt, d.h., ein Hervorziehen des Anverses jedes Reimpaares entfällt bei strophischen Texten. Die durchgängige $t z i^{\circ}-$ Graphie in der ,Jenaer Liederhandschrift' gegenüber $z \dot{v}$ in den ,Segremors'-Fragmenten kann vorlagenbedingt sein. Frau Dr. K. Schneider hat mir die Zusammengehörigkeit der beiden Handschriften bestätigt und nimmt auf jeden Fall Werkstattgemeinschaft an.

${ }^{29}$ Bernd SChirok, Parzivalrezeption im Mittelalter. Darmstadt 1982 (Erträge der Forschung 174), S. 33, Nr. 13. Die Identität beider Schreiber stellte schon Otto BeHAGHel (Arnstädter Bruchstükke II. Germania 35 [1890], S. 388-390) fest. Im Gegensatz zu Behaghel hält Hartl die Handschrift nicht für zwei-, sondern dreispaltig (Wolfram von Eschenbach, Parzival. Hg. von KARL Lachmann. 7. Ausg. Neu bearb. von Eduard Hartl. Bd. 1. Berlin 1952, S. XlVIIf.). Autopsie ergab, daß die Hahdschrift zweispaltig ist und genau mit den ,Segremors'-Fragmenten zusammenpaßt. Die Arnstädter ,Parzival'-Bruchstücke, die SCHIROK wegen ihrer Zusammengehörigkeit mit den Gothaer Fragmenten ebenfalls unter Nr. 13 erwähnt, befinden sich nicht in Gotha und müssen vorerst als verschollen gelten. Die Blattgröße der Gothaer Fragmente beträgt $440 \times 340$, die der Spalte $330 \times 110-115 \mathrm{~mm}$. Die Spaltengröße der Weimarer Bruchstücke liegt bei $310 \times 108-113 \mathrm{~mm}$. 
Vermutung nahe, daß die zu einer Epensammlung gehörenden fragmentarischen Handschriften im Auftrag der Landgrafen von Thüringen (Friedrich der Ernsthafte von Thüringen-Meißen?, 1324-1349) entstanden sein könnten. Damit rückt die eng verwandte ,Jenaer Liederhandschrift' wieder in die Nähe der Wettiner. ${ }^{30}$

Wir kennen von den genannten bruchstückhaften Werken weder Verfasser, noch Auftraggeber oder Entstehungszeit. Wir können uns nur am paläographischen und dialektalen Befund orientieren: Das älteste Werk dürfte wohl der mittelhochdeutsche ,Cligès' sein, nicht wegen des Überlieferungsbefundes, sondern wegen der frühen Bezeugung bei Thomasin und Rudolf von Ems. Beide möglichen Verfasser, Konrad Fleck und Ulrich von Türheim, waren alemannische Dichter. Die alten Fragmente P von Flecks ,Flore und Blanscheflur' stammen jedoch ebenso wie die ,Cligès'-Fragmente aus einer bairisch-österreichischen Handschrift (1. Hälfte des 13. Jahrhunderts). ${ }^{31}$ Das zeugt von dem schnellen Literaturaustausch zwischen Südwest und Südost in der 1. Hälfte des 13. Jahrhunderts ebenso wie die um 1205 entstandenen ,Iwein'-Fresken auf der Burg Rodenegg des bischöflich-brixnerischen Ministerialen Arnold von Rodank. ${ }^{32}$ Die übrigen Romane werden - soweit ich weiß - von Zeitgenossen und Nachfolgern bis 1400 nicht erwähnt. Der ,Segremors' ist doppelt im Thüringischen überliefert, ,Abor und das Meerweib' unikal im ostfränkisch-nordbairisch-mitteldeutschen Dreieck, aus ostfränkischem oder thüringischem Gebiet einwandernd. ,Manuel und Amande' ist unikal im ostfränkischen, der ,Parcheval' ebenfalls unikal im mittelfränkischen Dialekt belegt. Einen Reflex der sonst verlorenen rheinischen Artusepik sieht Hartmut BeCKers im , Loccumer Artusromanfragment ${ }^{\circ}{ }^{33}$ Das Interesse in diesem geographischen Gebiet dokumentiert neben dem ,Parcheval ${ }^{\star}$

${ }^{30}$ Im Jahre 1302 erfolgte eine Lehensauftragung gräflich Schwarzburgischen Besitzes in und um Arnstadt und der Wachsenburg an die Landgrafen von Thüringen, die diese Besitzungen als Lehen an die Honsteiner und die Grafen von Orlamünde ausgaben. Otto IV. von Orlamünde verkaufte die Wachsenburg, Arnstadt und Ilmenau kurze Zeit später an die Linie Schwarzburg-Blankenburg. 1366/1368 erwarb Landgraf Friedrich III. der Strenge die Wachsenburg (Urkundenbuch der Stadt Arnstadt 704-1495. Hg. von C. A. Burkhardt. Jena 1883, S. 38, Nr. 67; Geschichte Thüringens. Hg. von Hans Patze u. Walter Schlesinger. Bd. II/1. Köln/Wien 1974, S. 87, 105, 149, 152). Im 16. Jahrhundert war die Wachsenburg Sitz eines landesfürstlichen Amtes, das auch für die Führung der Türkensteuerverzeichnisse zuständig war (ebd. III, 1967, S. 152f.). Die Weimarer ,Segremors'-Fragmente fand der Herausgeber des Urkundenbuches im Sächsisch-Ernestinischen Hauptarchiv (ReinHOld KöHLER, Germania 10 [1860], S. 461-463). - Endgültige Aussagen zu den Beziehungen zwischen der ,Jenaer Liederhandschrift' und der hier skizzierten Epenhandschrift müssen einer detaillierten Untersuchung vorbehalten bleiben, jedoch ist deren Verwandtschaft unleugbar. Vorläufig relativiert diese Beziehung die Vermutung von ERDMUTE Pickerodt-Uthleb (Die Jenaer Liederhandschrift. Metrische und musikalische Untersuchungen. Göppingen 1975, S. 250-252), daß die Askanier, d. h. Rudolf I. (1298-1365), Auftraggeber der Handschrift gewesen sein müßten.

${ }^{31}$ Prag, Státní knihovna, cod. XVII. D. 31 fragm 6. Vgl. dazu Peter Ganz. ${ }^{2}$ VL2, 1980, Sp. 744-747.

32 ACHim Masser, Die ,Iwein'-Fresken von Burg Rodenegg in Südtirol und der zeitgenössische Ritterhelm. ZfdA 112 (1983), S. 177-198, hier bes. S. 198.

${ }^{33}$ BeCKers [Anm. 23], 1974, S. 51. 
auch der ,Prosa-Lancelot', dessen ältestes Fragment mutmaßlich (Nr. 18) aus dem ripuarischen Bereich kommt. ${ }^{34}$ Nicht zuletzt gehört das mittelfränkische Lancelot-Bruchstück m (Nr. 17) aus der Mitte des 14. Jahrhunderts hierher. Es ist neben dem neu gefundenen, Gauriel'- Bruchstück (9a) das einzige arthurische Papierfragment und stammt aus dem Gräflich Waldeckschen Archiv. ${ }^{35}$

Trotz dieser unbefriedigenden Überlieferungslage legt der Überlieferungsbefund im Verein mit der fehlenden literarischen Resonanz nahe, daß diese Bruchstücke kaum die Dialektgrenzen ihres Entstehungsgebietes überschritten haben und in ihrer Verbreitung begrenzt waren. Das gilt auch für den im Südosten zweifach überlieferten ,Edolanz', ausnehmen möchte ich nur den, Cligès'.

Sucht man nun nach möglichen Gönnern für diese Romane, kommt man über Hypothesen kaum hinaus. JоАснім Bumkes Gönner-Topographie erlaubt es aber, einige Vermutungen zu äußern: ${ }^{36}$,Segremors' und ,Abor und das Meerweib' müßte man dann sprachlich dem Kreis um Markgraf Heinrich III. von Meißen (vor 1216-1288) oder seinen unmittelbaren Nachfolgern bzw. seinen Söhnen Albrecht, seit 1262 Landgraf von Thüringen, und Dietrich als Markgraf von Landsberg zuordnen. Heinrich, Albert und Dietrich gelten zu recht seit DE Boors Aufsatz als die drei Fürsten (JT, Str. 64,1), der mitte wol uf diutscher terre (JT, 5768,3), die Albrecht im ,Jüngeren Titurel' als Auftraggeber nennt. ${ }^{37}$

Im Südosten stehen auf der Gönnerkarte Herzog Ludwig II. von Bayern und Herzog Heinrich XIII. von Niederbayern. Ludwig förderte den , Jüngeren Titurel', der ,Edolanz' wird darin einmal, im dominant bairischen Überlieferungszweig II zweimal erwähnt. - Im mittelfränkischen und westfälischen Raum ist BuMKes Gönnerkarte „weiß“.

Wechseln wir nun die Szenerie, und betrachten wir die Überlieferung der vollständig überlieferten Texte. Ulrichs ,Lanzelet' überliefern vor 1400 eine vollständige Handschrift (Nr. 24) und drei Fragmente (Nr. 21-23); ebenso wie die einzige Handschrift des 15. Jahrhunderts sind sie in alemannischem Schriftdialekt abgefaßt. ${ }^{38}$ Dieser Befund paßt zum vermuteten Entstehungsraum des Werkes, widerspricht aber dem tatsächlichen Wirkungsgrad. Der, Lanzelet' beeinflußte sämtliche vollständigen nachklassischen Artusromane, Wirnts, Wigalois' ausgenommen. In Heinrichs ,Crône' und im Pleierschen , Tandareis` vermischen sich,

${ }^{34}$ Penti Tilvis, Prosa-Lancelot-Studien. 1.2. Helsinki 1957 (Annales Academiae Scientiarum Fennicae, B. 110), S. 132.

${ }^{35}$ Lancelot. Hg. von Reinhold Kluge. Bd. 1-3. Berlin 1948-1974 (DTM 42, 47, 63), hier Bd. 1, S. XLI-XLII. Im Waldecker Archiv fand man auch ein allerdings alemannisches ,Parzival'-Fragment, vgl. Schirok [Anm. 29], S. 54, Nr. 82.

36 JoAchim Bumke, Mäzene im Mittelalter. München 1979, S. 176-229.

${ }^{37}$ Helmut de Boor, Drei Fürsten im mittleren Deutschland. In: Fs. f. Ingeborg Schröbler. Hg. von Dietrich Schmidtke u. Helga Schüppert. Tübingen 1973 (PBB Bd. 95. Sonderh.), S. 238-257. Der Tannhäuser nennt Heinrich, Albrecht und Dietrich im VI. Leich ebenfalls, daneben noch die Grafen von Brehna (Dietrich u. Konrad) sowie Graf Hermann I. von Henneberg.

${ }^{38}$ Rosemary N. Combridge, Das Fragment B des Lanzelet Ulrichs von Zazikhoven. Euphorion 57 (1963), S. 200-209; dies., The problems of a new edition of Ulrich von Zatzikhoven's Lanzelet. In: Probleme mittelalterlicher Überlieferung und Textkritik. Oxforder Colloquium 1966. Hg. von Peter F. Ganz u. Werner Schröder. Berlin 1968, S. 67-80, hier S. 68. 
wie Christoph Cormeau und Peter Kern feststellten, ${ }^{39}$ Lancelot- und LanzeletGeschichte. Diese offenkundige Koexistenz verschiedener Lancelot-Traditionen dokumentiert Püterich von Reichertshausen in seinem ,Ehrenbrief", dort nennt er neben fünf Lancelot-Romanen Ulrichs ,Lanzelet' zusätzlich. ${ }^{40}$

Heinrichs ,Crône' kennen wir vor 1400 nur aus vier, wenn auch in einem Fall (Nr. 8) sehr umfangreichen Bruchstücken. ${ }^{41}$ Sie stammen aus der Zeit um 1300 bis gegen 1350 und mit einer Ausnahme aus dem Süd- und Mittelosten, d. h., sie sind mittelbairisch (Nr. 8) und zweimal ostfränkisch-mitteldeutsch Richtung Deutschböhmen (Nr. 5 u. 7), also am Nordrand des Oberdeutschen beheimatet. Eine Ausnahme bildet jedoch das Fragment K (Nr. 6), das die Abschrift einer oberdeutschen Vorlage in Niederdeutschland repräsentiert. Eine singuläre Erscheinung, der nur die, Wigalois'-Überlieferung etwas Vergleichbares an die Seite stellen kann. ${ }^{42}$ Die Leidener Handschrift entstand 1372 im Auftrag Herzog Albrechts II. von Braunschweig-Grubenhagen. Die Sprache der Handschrift ist hessisch-thüringisch, der Schreiber war aber nach Ausweis des Kolophons und der Bildinschriften ein Niederdeutscher:

\section{[...] vnde heft ghescreuen \\ her Jan uon brunswik monek tho amelunges born $[\ldots]^{43}$}

Ein ,Wigalois'-Fragment des 14. Jahrhunderts (Nr. 56) wird heute im Reichsarchiv in Oslo aufbewahrt. Es war Rückenheftblatt einer Vogteirechnung von 1633 aus dem Ryfylke bei Stavanger. Mit gebotener Vorsicht kann man auch diese mitteldeutsche Handschrift als einen Beweis für das Interesse des Nordens an der oberdeutschen Artusdichtung werten. Im alemannischen Raum bezeugt Rudolf von Ems im ,Alexander' die ,Crône‘ (Alex., V. 3219ff.).

Bernhard Kratz stieß 1976 alle Vermutungen über Heinrichs Biographie um; ${ }^{44}$ anschließend konnte FRITZ PETER KNAPP immerhin sehr viele Indizien für

${ }^{39}$ Cormeau [Anm. 5], S. 181-187; Kern [Anm. 6], S. 133f.

${ }^{40}$ Der Ehrenbrief des Püterich von Reichertshausen. Hg. von Fritz Belkan und Rudolf Wolkan. Weimar 1920, S. 26, Str. 98: Fünfe Lanzelunt,/ der ich nur einen han; S. 26, Str. 102 sam hat auch Lanzilot von Säzenhofen/ aus welisch Ulrich dichtet, / das mag man lesen schon in allen hofen. Zu den fünf ,Lanzelot'-Romanen könnten natürlich auch eine mehrbändige Ausgabe des ,Prosa-Lancelot' und Füetrers Bearbeitung gehören.

${ }^{41}$ Zusammenstellung der Überlieferung mit Abb.: Heinrich von dem Türlin, Diu Krone, hg. von Klaus Zatloukal. Göppingen 1982 (Litterae 95).

${ }^{42}$ Von den klassischen Werken drang anhand von nachweisbaren Handschriften nur Wolframs ,Parzival" bis in das niederdeutsche Sprachgebiet vor; Schirok [Anm. 29], S. 53, Nr. 71. Um ein zutreffendes Bild zu bekommen, müßten aber noch die außerliterarischen Zeugnisse aus dem niederdeutschen Raum (Gawan- und Tristan-Teppiche, Turniere etc.) einbezogen werden. Ebenso müßte überprüft werden, ob mitteldeutsche Handschriften auf niederdeutschem Boden geschrieben und gelesen wurden.

${ }^{43}$ Wirnt von Grafenberg, Wigalois der Ritter mit dem Rade. Hg. von J. M. M. Kapteyn. Bd. 1 Text. Bonn 1926 (Rheinische Beitr. und Hülfsbücher zur germanischen Philologie und Volkskunde. Bd. 9), S. $29^{\star}-43^{\star}$, hier S. $29^{\star}$.

${ }^{44}$ Bernhard Kratz, Zur Biographie Heinrichs von dem Türlin. Amsterdamer Beitr. z. Älteren Germanistik 11 (1976), S. 123-167. 
eine Entstehung der ,Crône' im Auftrag der Andechs-Meranier zusammentragen (breite Kenntnis der französischen Literatur, schnelle Bekanntheit im staufischen Südwesten). ${ }^{45}$ Die Überlieferung stützt diesen Befund nicht, spricht aber auch nicht dagegen, weil die Andechs-Meranier im Mannesstamm schon 1248 aussterben; zur Entstehungszeit muß man noch mit einer stark normierten Schriftsprache rechnen; die spätere Überlieferung ist dann mittelbairisch.

Mit Recht hat JoAchim Heinzle im Anschluß an Cormeaus Untersuchungen Heinrichs Werk pointiert als „Literaturquiz“ bezeichnet, ${ }^{46}$ um so erstaunlicher ist seine geographisch weite, wenn auch quantitativ nicht umfangreiche Überlieferung. Die großzügige Anlage der überlieferten Handschriftenreste spricht für hochmögende Gönner (HARTMUt BECKERS). ${ }^{47}$ Will man diesem Interessentenkreis auf die Spur kommen, bietet der IV. Leich des Tannhäusers Anhaltspunkte. Dort treten neben anderen literarischen Gestalten auch viele bekannte Helden des Artusromans, nur in vertauschten Rollen auf, ein Ratespiel, das noch in heutigen Quizsendungen sehr beliebt ist. Ich zitiere als Beispiel die Strophen 14 und 15:

Her Wigamur vor Kamvoleis
wol tet erz, als wirz han vernomen;
gen dem so hielt her Wigoleis
der was den froun ze dienste komen.
Tristan erwarp die künegin
von Marroch, als wir hoeren sagen.
ein moerin was diu heidenin.
der alden suln wir hie gedagen ${ }^{48}$

Wigamur kämpft anstelle Gahmurets im Wolframschen Turnier vor Kanvoleis. Tristan warb um eine moerinne, wiederum wie Gahmuret, von dem wir kurz zuvor erfahren, daz Gamuret als müezic saz.

Diese sinnentstellenden literarischen Anspielungen setzen ein in der höfischen Literatur erfahrenes Publikum voraus, das in der Lage war, das Spiel mit literarischen Gestalten und Orten nachzuvollziehen. Vorausgesetzt, der IV. Leich gehörte zum ständigen Repertoire Tannhäusers, und dagegen spricht wohl nichts, so können wir nach den Untersuchungen JоAснім BUMKEs am sechsten Leich ablesen, wo wir dieses Publikum in der zweiten Hälfte des 13. Jahrhunderts

\footnotetext{
${ }^{45}$ Fritz Peter KnAPP, Heinrich von dem Türlin. Literarische Beziehungen und mögliche Auftraggeber, dichterische Selbsteinschätzung und Zielsetzung. In: Peter KräMER (Hg.), Die mittelalterliche Literatur in Kärnten. Wien 1980 (Wiener Arbeiten zur germanischen Altertumskunde und Philologie. 16), S. 145-187.

${ }^{46}$ JoACHim HeinZlE, Vom hohen zum späten Mittelalter. T. 2. Wandlungen und Neuansätze im 13. Jahrhundert (1220/1230-1280/1290). Königstein/Ts. 1984. (Geschichte der dt. Literatur von den Anfängen bis zum Beginn der Neuzeit. Bd. 2, T. 2), S. 138; Cormeau [Anm. 5], S. 224.

${ }^{47}$ Hartmut Beckers, Kölner Bruchstücke der, Crone' Heinrichs von dem Türlin und des ,Väterbuchs'. ZfdA 103 (1974), S. 125-134, hier S. 128.

${ }^{48}$ TANnhäuser, Die lyrischen Gedichte der Handschriften C und J. Hg. von Helmut Lomnitzer u. UlRICH MÜLleR. Göppingen 1973 (Litterae 13), S. 36.
} 
antreffen: ${ }^{49}$ im Umkreis der großen Territorialherren im östlichen Deutschland. Zurück zur Überlieferung: Beim Pleier, dem ,Wigamur ' und dem ,Gauriel von Muntabel' des Konrad von Stoffeln wird die Überlieferung schmaler.

Aufgrund von Reimuntersuchungen hält man den Pleier für einen Österreicher. Alle vor 1400 entstandenen Handschriften, ein umfangreiches, Garel'-Fragment (Nr. 13) und das Dietfurter, Tandareis'-Fragment (Nr. 15), sind bairischösterreichisch. Das gilt auch für die um 1400 entstandene vollständige ,Garel'Handschrift (Nr. 14). Im südbairischen Raum belegen die ,Garel'-Fresken auf Runkelstein Kenntnis des Pleierschen Werkes, ${ }^{50}$ im Böhmischen die tschechische ,Tandareis'-Übersetzung. ${ }^{51}$ Seine Resonanz scheint bis 1400 auf den südöstlichen Bereich beschränkt gewesen zu sein. Die frühe ,Wigamur'-Überlieferung ist ebenfalls auf den bayerischen Raum konzentriert. Das um 1300 entstandene Fragment (Nr. 25) stammt aus dem schwäbisch-ostfränkisch-bayerischen Grenzraum, das um 1350 entstandene (Nr. 26 u. Abb. 17) erlaubt keine genauere Lokalisierung; es ist bairisch. Der einzige frühe Textzeuge des , Gauriel von Muntabel` (Nr. 9 u. Abb. 18-19) stammt aus der 2. Hälfte des 14. Jahrhunderts und zeigt bairische Lautung. ${ }^{52}$ Das gilt für ein nach Fertigstellung des Aufsatzes (wieder-)entdecktes zweites Fragment ebenfalls. ${ }^{53}$

Diese Zusammenschau erlaubt mir nun generelle Aussagen: Die Überlieferung der vorgestellten nachklassischen Artusromane bis 1400 ist schmal. Der Pleiersche ,Meleranz' und Strickers ,Daniel' fehlen ganz, alle anderen Romane sind in der Regel nur ein- oder zweimal vor 1400 überliefert und dann fragmentarisch. Die einzige Ausnahme macht Ulrichs ,Lanzelet' mit einer vollständigen Handschrift und der breitesten Überlieferung neben der, Crône', wobei die quantitative und geographische Verbreitung des ,Lanzelet' im Widerspruch zu seiner Wirkung steht. Dieser widersprüchliche Befund im Fall des ,Lanzelet' gilt - blickt man auf die klassischen Artusromane - extrem für Hartmanns ,Erec ${ }^{6}{ }^{54}$ Bei allen

\footnotetext{
${ }^{49}$ Bumke [Anm. 36], S. 191-228.

${ }^{50}$ Walter Haug, Einleitung. In: Runkelstein. Die Wandmalereien des Sommerhauses. Wiesbaden 1982, S. 9-14, hier S. 10.

${ }^{51}$ Der altčechische Tandariuš nach den 3 überlieferten Handschriften mit Einleitung und Wortregister. Hg. von Ulrich BamborschKe. Berlin 1982 (Veröffentlichungen der Abteilung für slavische Sprachen und Literaturen des Osteuropa-Instituts an der Freien Universität Berlin Bd. 49.). Die drei Handschriften stammen aus dem 15. Jahrhundert, die Entstehungszeit des Werkes setzt BAMBORSCHKE in die Mitte des 14. Jahrhunderts (S. 61). Der unbekannte Verfasser kürzte das Werk des Pleiers auf knapp 2000 Verse.

${ }^{52}$ Friedrich Keinz, Aus dem ,Gauriel von Muntabel'. Germania 31 (1886), S. 85-87; Gauriel von Muntabel [Anm. 13], S. XXVIf. Püterich von Reichertshausen nennt im Ehrenbrief [Anm. 40] den Ritter Ulrich von Flädnitz aus der Steiermark als Besitzer einer ,Gauriel'-Handschrift (Str. 91-93): da findt man es, sonst weiß ichs nit bekhennet, vgl. PeTER-JÖRG BeCKer, Handschriften und Frühdrucke mittelhochdeutscher Epen. Wiesbaden 1977, S. 204f.

${ }^{53}$ Nach Fertigstellung des Aufsatzes stieß ich in München auf ein weiteres Fragment (München, SB, cgm 5249(9b) des, Gauriel von Muntabel'. Leidinger entdeckte und identifizierte es im Jahre 1930. Bis vor wenigen Jahren lag es unentdeckt in seinem Nachlaß. Zu den kodikologischen Daten s. Tabelle Nr. 9a. Eine ausführliche Beschreibung mit Textabdruck erscheint demnächst in der ZfdA.

${ }^{54}$ Hartmanns ,Erec ${ }^{6}$ wird nur in einer Handschrift des frühen 16. Jahrhunderts vollständig und in
} 
anderen Romanen deckt sich die geringe literarische Resonanz mit der räumlich begrenzten Verbreitung, sie werden wohl den Sprung aus dem Dialektbereich, in dem sie entstanden, nie oder erst nach 1400 geschafft haben. Viele der nach dem 1. Viertel des 13. Jahrhunderts entstandenen Romane stammen aus dem östlichen Deutschland, der ,Edolanz', der ,Wigamur', die Pleierschen Artusromane aus dem Südosten, ,Segremors‘, ,Manuel und Amande“ und ,Abor und das Meerweib“ aus Mitteldeutschland. Damit bestätigt sich die Feststellung JoAchim Bumkes: „Der Schwerpunkt des literarischen Geschehens hat sich in der zweiten Hälfte des 13. Jahrhunderts nach Osten verlagert, und dort bestimmten die Höfe der großen Territorialherren den literarischen Ton. “55

II.

Zum Sonderfall, Wigalois“

Kein anderer Artusroman, ausgenommen Wolframs ,Parzival', erreichte die Überlieferungszahlen des ,Wigalois‘ Wirnts von Grafenberg. In der Überlieferung des nachklassischen Artusromans nimmt der, Wigalois‘ einen herausragenden Platz ein.

Vom ,Wigalois“ existieren 20 Fragmente und eine Handschrift aus dem 13. Jahrhundert, drei Handschriften und 8 Fragmente des 14. Jahrhunderts und neun Handschriften des 15 . Jahrhunderts, also insgesamt 41 Handschriften. ${ }^{56}$ Wolframs ,Parzival' erreicht etwas mehr als das Doppelte (86 Handschriften und einen Druck). ${ }^{57}$ Ebenso wie beim , Wigalois‘ stammt die Mehrzahl der ,Parzival'Handschriften aus dem 13. Jahrhundert (44) und nimmt über das 14. Jahrhundert (32) bis ins 15. Jahrhundert (10) kontinuierlich ab, wobei die Zahl der vollständigen Handschriften die der Fragmente erst im 15. Jh. übersteigt (13. Jh.: 5 : 39; 14. Jh.: $3: 29 ; 15$. Jh.: $7: 3)$. Es wäre allerdings verfehlt, aus dieser Entwicklung

drei fragmentarischen Handschriften aus dem 13. und 14. Jahrhundert überliefert. Vgl. Hartmann von Aue, Erec. 6. Aufl. bes. von Christoph Cormeau u. Kurt Gärtner. Tübingen 1985 (ATB 39), S. IX-XIV.

${ }^{55}$ Bumke [Anm. 36], S. 190.

${ }^{56}$ Die letzte umfassende Zusammenstellung der, Wigalois'-Überlieferung bot Heribert A. Hilgers, Materialien zur Überlieferung von Wirnts ,Wigalois‘. PBB (Tüb.) 93 (1971), S. 228-288; seither erfolgten zwei Neufunde: Oskar Pausch, Eine Zwettler Überlieferung des, Wigalois‘. ZfdA 108 (1979), S. 340-345 (Nr. 47); A. Janko, Zwei, Wigalois'-Fragmente aus Ljubljana. Acta Neophilologica 15 (1982), S. 3-15 (Nr. 38). Hierbei handelt es sich um zwei Blätter einer Handschrift, also mithin nur um eine fragmentarische Handschrift. - Die noch von HiLgers als verschollen gemeldeten Fragmente der ehemaligen Preußischen Staatsbibliothek (Nr. 35-36) befinden sich in der Biblioteka Jagiellońska (vgl. WOLfGang Milde: Deutsche Handschriften in der Universitätsbibliothek Krakau. Wolfenbütteler Barock-Nachrichten 11 [1984], S. 76-80, hier S. 78 u. 80). Ich bereite einen Abdruck sowie eine text- und überlieferungsgeschichtliche Einordnung der beiden Fragmente vor, wobei das Hauptinteresse den ungewöhnlichen kodikologischen Daten der Nr. 36 gewidmet sein wird.

${ }^{57}$ Die letzte Zusammenstellung der ,Parzival'-Überlieferung stammt von ScHIROK [Anm. 29], S. $30-56$. 
zu schließen, daß die meisten ,Parzival'-Handschriften bzw. ,Wigalois'-Handschriften im 13. Jahrhundert entstanden sind. Ein Blick auf den Beschreibstoff der Fragmente zeigt, daß es, von ganz seltenen Ausnahmen abgesehen, Pergament ist. ${ }^{58}$ Folglich wird die Zahl der Totalverluste von Handschriften kontinuierlich mit der Verbreitung des Papiers gestiegen sein.

Veldekes ,Eneit“ mit 7 Handschriften und 5 Fragmenten, Gottfrieds, Tristan“ mit 11 Handschriften und 16 Fragmenten und Hartmanns, Iwein ' mit insgesamt 32 Handschriften und Fragmenten bleiben deutlich dahinter zurück.

Sicherlich darf man die Häufigkeit der Überlieferung nicht zum alleinigen Gradmesser für Bekanntheit und Beliebtheit machen, doch bezeugt beim, Wigalois' nicht nur die Quantität, sondern auch die literarische Resonanz dessen außerordentliche Verbreitung. ${ }^{59}$ Ein Zeugnis dafür gibt Hugo von Trimberg, magister und rector scolarum am Bamberger St. Gangolfstift, in seinem ,Renner':

Alsô sint bekant durch tiutschiu lant

$\hat{E}$ rec, $\hat{I}$ wan und Tristrant,

Künic Ruother und her Parcifâl,

Wigalois, der grôzen schal

Hât bejaget und hôhen prîs:

Swer des geloubt, der ist unwîs $\hat{s}^{60}$

Was machte Wirnts Werk zu einem Bestseller? Hierauf geben die Handschriften leider keine Antwort: Der Held ohne Krise bewährt die angeborenen adligen Tugenden in einer Welt, deren Gefahren aus eigener Kraft nicht mehr in jedem Fall gemeistert werden können. Nur ungebrochenes Gottvertrauen gepaart mit dem selbstverständlichen Festhalten an den höfischen Normen garantiert den Erfolg. Diese spannend verpackte adlige Lebenslehre traf den Nerv der feudalen Welt. Schon Christoph Cormeau sah in der ,ausdrücklich religiösen Einstellung " das entscheidende Erfolgskriterium, ${ }^{61}$ und JoAchiм HeINZLE arbeitete einen religiösen Grundzug als literarischen Trend im 13. Jahrhundert heraus. ${ }^{62}$

In diesem Punkt begegnen sich Wolframs ,Parzival' und Wirnts ,Wigalois“, nur Wirnts Werk war „leichtere Kost“ und stand einem heilsgeschichtlichen

${ }^{58}$ Die beiden einzigen Papierfragmente unseres Untersuchungsbereichs sind Nr. 9a u. 17.

${ }^{59}$ Ein Beispiel für das extreme Auseinanderklaffen von Bekanntheit und handschriftlicher Überlieferung ist wiederum Hartmanns ,Erec'. Nur in einer einzigen Handschrift und drei Fragmenten überliefert, werden Erec, Enite und das verligen immer wieder zitiert, vgl. u. a. PeTER KeRN, Reflexe des literarischen Gesprächs über Hartmanns ,Erec' in der deutschen Dichtung des Mittelalters. In: Artusrittertum im späten Mittelalter [Anm. 7], S. 126-137.

${ }^{60}$ Hugo von Trimberg, Der Renner. Hg. von Gustav EhrismanN. Bd. 1. Tübingen 1908 (Bibl. lit. Ver. 247), V. 1221-1226.

${ }^{61}$ Cormeau [Anm. 5], S. 122.

${ }^{62}$ Heinzle [Anm. 46], s. S. 171 u. ö. Die religiöse Komponente betont Klaus Grubmüller in seiner kürzlich erschienenen, Wigalois'-Interpretation ebenfalls. Er deutet den Weg des Wigalois als Entfaltung des generellen Typus des christlichen Herrschers mit deutlicher Betonung der Geblütsheiligkeit (Artusroman und Heilsbringerethos. Zum, Wigalois' des Wirnt von Grafenberg. PBB 107 [1985], S. 218-239, hier S. 238). 
Verständnis nicht offen. Die heilsgeschichtliche Dimension des ,Parzival' hat einen kollektiven Bezug, die christliche Morallehre des, Wigalois' bleibt individuell umsetzbar und war für den einzelnen leichter konsumierbar. Gegenüber seinen Nachfolgern setzt sich Wirnts Werk durch eine geringere Neigung ab, mit den literarischen Vorgaben spielerisch umzugehen.

Diese Unterschiede gegenüber Vorgängern und Nachfolgern hinterließen offenbar auch Spuren in der Überlieferung, dort dominieren unaufwendige, schmucklose, sauber geschriebene, kleine und kleinste Formate. ${ }^{63}$

III.

Wie sieht es mit den Fundorten der Fragmente aus? Von 13 der 53 fragmentarisch vorliegenden Handschriften wissen wir nichts über Fundort und Makulierungszeit, ${ }^{64}$ über weitere 7 immerhin, daß sie als Umschläge oder Spiegel von Buchdeckeln dienten. ${ }^{65}$ Wann diese Bücher gedruckt und eingebunden wurden oder ob es sich dabei noch um Handschriften handelt, erfahren wir allerdings nicht.

Einen interessanten Fall stellen hingegen die mittelhochdeutschen ,Cligès'Fragmente dar. Das erste, Züricher Bruchstück fand Albert Bachmann 1887 in einer Inkunabel, die ursprünglich wohl der Kartause Buxheim gehörte. ${ }^{66}$ Es handelt sich um das ,Catholicon' des Johannes Balbus in der 1486 bei Anton Koberger gedruckten Ausgabe. 1969 stellte VizkelETy weitere Fragmente derselben Handschrift vor, die man bei der Durchsicht der Inkunabelbestände der Erzdiözesanbibliothek in Kalocsa fand. Sie steckten im Einband eines Straßburger Frühdrucks von Thomas' ,Summa contra gentiles' aus dem Jahre 1472. Durch einen Vergleich der neuen Bruchstücke mit den Zürichern konnte VizKeLETY an der Art der Verwendung zweifelsfrei erkennen, daß beide Einbände aus einer Buchbinderwerkstatt stammen müssen. 1977 entdeckten GRÖCHENIG und PASCHER die vorerst letzten Fragmente dieser bairischen,Cligès'-Handschrift in einer Inkunabel des Klosters St. Paul im Lavanttal. Sie meldeten allerdings Zweifel an VizKeletys Vermutung an, daß die, Cligès'-Handschrift in einer Buchbinderwerkstatt makuliert wurde, denn der St. Pauler Einband paßt nicht zu dem der reichverzierten Kalocsaer Inkunabel. Sie vermuten hingegen, daß ein wandernder Buchbinder die Handschrift zu Einbandzwecken verbrauchte. ${ }^{67}$ Dieses Beispiel demonstriert, wie eine alte Pergamenthandschrift in einer Werkstatt

\footnotetext{
${ }^{63}$ Vgl. die Nr. 28, 29, 31, 32, 33, 35, 36, 37, 40, 41, 42, 43, 44, 45, 46, 52, 53, 54, 57. Die Aufzählung schließt nur Handschriften ein, deren tatsächliche oder erschließbare Höhe $200 \mathrm{~mm}$ nicht übersteigt. Nur die Nr. 58 übersteigt $300 \mathrm{~mm}(320-330 \times 235)$.

${ }^{64}$ Nr. 1, 3, 9, 20, 22, 36, 38, 45, 46, 47, 51, 52, 55.

${ }^{65}$ Nr. 7, 18, 25, 27, 28, 29, 43.

${ }^{66}$ Albert Bachmann, Bruchstücke eines mhd. Cligès. ZfdA 32 (1887), S. 124-127; Leo Cunibert MoHLberG, Katalog der Handschriften der Zentralbibliothek Zürich. I. Mittelalterliche Handschriften. Zürich 1951, S. 277f.

${ }^{67}$ Gröchenig/Pascher [Anm. 17], S. 23.
} 
oder von einem Buchbinder kontinuierlich makuliert wurde. Einen ähnlich gelagerten Fall lernen wir bei den ,Manuel und Amande'-Fragmenten kennen, die Hans-Hugo Steinhoff ${ }^{68}$ soeben um ein weiteres Pergamentblatt ergänzen konnte. Dieses Pergamentblatt fand man wie die anderen auch im Franziskanerkloster Schwaz, alle Fragmente gehören $\mathrm{zu}$ einer Handschrift im Oktavformat $(150 \times 110 \mathrm{~mm})$. Obwohl wir die gesamte Erzählung von ,Manuel und Amande nicht kennen, läßt sich sagen, daß die zwei Einzel- und drei Doppelblätter so zusammengehören, da $\beta$ das neugefundene Einzelblatt dem älteren Einzelblatt vorangeht, die drei Doppelblätter überliefern den Schluß der Erzählung. Dieser Erzählablauf paßt nun genau zur zeitlichen Abfolge der Drucke, die man in diese Pergamentblätter einschlug:

Einzelblatt I berichtet von einem Jonas, der unerschrocken auf eine beleidigende Kampfansage reagiert. Es klebte auf dem Einband von Luis de Granadas 'De freqventi communione libellus cum dialogo', gedruckt in Köln 1586. Einzelblatt II enthält den Bericht über eine Dame, die einen Ritter in ihren Dienst aufnimmt. Es schützte einen Kölner Druck des Jahres 1615. Die drei Doppelblätter mit der Hochzeit Manuels und Amandes am Artushof und dem Epilog waren der Einband der dreibändigen 'Agricultura Spiritualis/ oder geistliches Feldtbau/ Das ist Sonntag Predigten' von Franciscus Settelein, gedruckt in Salzburg 1675.

Leider konnte ich bisher nicht ermitteln, wie diese Drucke in die Schwazer Bibliothek gelangten, auch SteINHoff berichtet darüber nichts. Die Verwendung ein und derselben Handschrift für drei chronologisch aufeinanderfolgende Drukke legt aber nahe, auch hier wiederum die kontinuierliche Makulierung einer Handschrift, vermutlich in Schwaz, zu erwarten. ${ }^{69}$ Zwei Fälle systematischer Makulierung, beide liegen mindestens hundert Jahre auseinander: einerseits das späte 15. Jahrhundert, die Zeit um 1500, andererseits das 16. und 17. Jahrhundert. Ordnet man nun die anderen zeitlich fixierbaren Fragmente diesen beiden Zeitstufen zu, so ergibt sich der erstaunliche Befund, daß die Mehrzahl der Bruchstücke, und zwar 20 von $33^{70}$ mit Sicherheit oder zumindest großer Wahrscheinlichkeit erst im 16. und 17. Jahrhundert makuliert wurden. Wir finden sie als Archiveinband des 17. Jahrhunderts in Straßburg/Kärnten, als Einband der Rechnungen der Stadt Plön für die Jahre 1645 und 1646, als Einband einer Ausgabe der ,Sententiae Ciceronis', als Einband einer Sammelausgabe des Jesuiten Petrus Canisius und ebenso unerwartet wie beim Tannhäuser treffen hier Wiga-

\footnotetext{
${ }^{68}$ Steinhoff [Anm. 12], S. 242-245.

${ }^{69}$ Beispiele systematischer Makulierung von Handschriften scheint auch die ,Parzival'-Überlieferung (s.o. die im Amt Wassenburg makulierten, zusammengehörigen ,Segremors'- und ,Parzival'-Fragmente) zu bieten: Schirok [Anm. 29], S. 46, Nr. 42; S. 50, Nr. 60; S. 52, Nr. 68. Diese Makulierungszusammenhänge lassen sich allerdings in vielen Fällen nicht mehr rekonstruieren, weil die Produktion spätmittelalterlicher und frühneuzeitlicher Buchbindereien weit verstreut und stark dezimiert die Zeiten überdauert hat. Andererseits weisen sie einen Weg, systematisch Fragmente mittelhochdeutscher Epen aufzuspüren.

${ }^{70}$ Vor 1525: Nr. 2, 9a, 10, 21, 23, 31, 32, 35, 40, 41, 42, 49, 50; nach 1525: 4, 5, 6, 8, 11, 12, 13, 15 , $16,17,19,26,30,33,37,39(?), 44(?), 54(?), 56,58(?)$.
} 
mur und Wigalois aufeinander. Das, Wigamur'-Bruchstück M war Einbandmakulatur der, Metropolis Salisburgensis“ des Wiguleis Hundt von Lautterbach aus dem Jahre 1620. Ein großer Makulierungsschub setzte, soweit es den vorliegenden Überlieferungsausschnitt betrifft, erst in der Mitte des 16. Jahrhunderts ein und reicht bis in das 17. Jahrhundert. Dieser Befund gilt für etwa $40 \%$ der untersuchten Handschriften, eine zeitliche Bestimmung der Makulierungszeit war nur bei ca. $65 \%$ (33) aller Fragmente möglich. Zu diesem Zeitpunkt war wohl die sprachliche Distanz endgültig unüberbrückbar, wohl auch das Interesse an den arthurischen Stoffen vergangen und der Buchhandel ein wohletabliertes Gewerbe mit erhöhtem Bedarf an Makulatur. Grimmelshausen spöttelt wohl im ,Simplicissimus' nur noch verständnislos über die sprichwörtliche ,milte 'von König Artus. ${ }^{71}$

Auf der anderen Seite belegen die frühen Handschriften fortdauerndes Interesse und fortdauernde Benutzung im 15. Jahrhundert und später. Der Korrektureintrag in der Gießener ,Iwein'-Handschrift B ist allgemein bekannt: 1531 11 Sept. hab ich den defect erfilt aus aim alten buch. Vileicht vil falsch $\left(93^{v}\right) .{ }^{72}$ Ein ,Wigalois'-Fragment wurde von einer Hand des 15. Jahrhunderts nach einer besseren Handschrift korrigiert, ${ }^{73}$ eine Korrektur aus dem späten 15 . oder frühen 16. Jahrhundert finden wir auch im Dietfurter, Tandareis'-Fragment. Dort wurde das aus dem ungeraden Vers versehentlich wiederholte Reimwort wenchen durch das richtige krencken ersetzt. ${ }^{74}$

In der vollständig erhaltenen, Wigalois'-Handschrift A (Nr. 34) aus dem 1. Viertel des 13. Jahrhunderts verweist ein Eintrag aus dem 15. Jahrhundert auf benutzerbedingte Textverluste. Am Ende der 11. Lage steht:

hie ist verlorn des buches ein teil
daz duncket mich des tihterz unheil
frav von Kastel latz ane zorn
ez hat graf cunrat verlorn
ich han gehort daz buch si eur
welt irz kinden leihen so ist bezrunge teur. ${ }^{75}$

Ein gleichlautender Spruch am Ende der 8. Lage ist getilgt, die 12. Lage fehlt. Wir haben es hier, wie WERNER FECHTER schon 1935 mitteilte, vermutlich mit

\footnotetext{
${ }^{71}$ Grimmelshausen, Der Abentheurliche Simplicissimus Teutsch. Hg. von Rolf Tarot. Tübingen 1967. Innerhalb der Auseinandersetzung zwischen „Verschwendung“ und „Geitz“ in der ,Continuatio " wird das Verhalten des Iulus, der der Verschwendungssucht erliegt, so kommentiert: in seinem Losament aber/gieng es zu/wie bey deß Königs Arturi Hof=Haltung / da er täglich viel Schmarotzer nicht schlecht hinweg mit Kraut oder Stüben: Sonder mit theuren frantzösischen Bottagien und spanischen Olla Battriden köstlich tractierte (S. 493).

${ }_{72}^{72}$ Gießen, UB, Nr. 97.

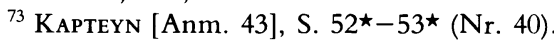

${ }^{74}$ Erich Petzet, Zu ,Tandareis und Flordibel" von dem Pleier. ZfdPh 43 (1911), S. 455f., hier S. 456

${ }^{75}$ KaPteyn [Anm. 43], S. $5^{\star}$.
} 
einer Angehörigen des fränkischen Grafen- und Herrengeschlechts von Castell zu tun. ${ }^{76}$

Anders als im Eingangszitat des Vortrags behauptet, finden wir die meisten zeitlich fixierbaren Fragmente als Makulatur des 16. und des 17. Jahrhunderts und nicht des 15. Dabei handelt es sich mit zwei Ausnahmen, dem ,Lancelot'Bruchstück $m$ und dem wiederentdeckten ,Gauriel'-Fragment, um Pergamentfragmente. Diese Feststellung kann nicht erstaunen, denn Papierrecycling sah und sieht anders aus als Pergamentrecycling. Dies bestätigt auch die Überlieferung der nachklassischen Artusromane im 15. Jahrhundert. Aus dieser Zeit stammen nur vollständige Papierhandschriften. Weltliche Archive, seien es nun städtische oder adlige, makulieren unsere Texte durchgehend erst in der späten Zeit, klösterliche Archive und Bibliotheken setzen mit der Makulierung schon im 15. Jahrhundert ein. ${ }^{77}$ Dort galt wohl schon im 15. Jahrhundert nicht mehr der Weckruf des Abtes Gevrard für seine eingeschlafenen Mönche: Audite, fratres, audite, rem vobis novam et magnam proponam. Rex quidem fuit qui Artus vocabatur. ${ }^{78}$

\section{IV.}

\section{Tabellen, Karten und Abbildungen zur Überlieferung}

Die folgende Tabelle bietet eine Zusammenstellung aller wesentlichen kodikologischen Daten der gegenwärtig bekannten erhaltenen und verschollenen Handschriften, die nachklassische Artusromane vor 1400 überliefern. Die unübliche, tabellarische Darstellungsweise ermöglicht einen direkten Vergleich einzelner Daten quer durch die Gattung. Der chronologische Überblick zeigt, daß die Überlieferung der später im 13. Jahrhundert entstandenen und der fragmentarischen Artusromane erst gegen Ende des 13. Jahrhunderts einsetzt und sich auf die 1. Hälfte des 14. Jahrhunderts konzentriert, dagegen liegen für die früh entstandenen Texte Ulrichs von Zatzikhoven und Wirnts von Grafenberg schon Überlieferungszeugen aus dem ersten Drittel des 13. Jahrhunderts vor. ${ }^{79}$ Sowohl der

${ }^{76}$ Werner Fechter, Das Publikum der mittelhochdeutschen Dichtung. Frankfurt a. M. 1935 (Dt. Forschungen 28), S. 43.

${ }^{77}$ Nicht ein einziges der in Anm. 70 genannten vor 1525 makulierten Fragmente stammt aus einem weltlichen Archiv, acht der spät makulierten jedoch mit Sicherheit (Nr. 4, 6, 8, 13, 17, 19, 37, 56). Die ,Parzival'-Überlieferung stützt diesen Befund: Die Fragmente aus adligen und städtischen Archiven setzen mit einer Ausnahme (Schirok [Anm. 29], S. 48, Nr. 52) erst in der Mitte des 16. Jahrhunderts ein. Vgl. ebd. S. 32 , Nr. 7 (?); S. 10, Nr. 12, 13; S. 34, Nr. 14, 16; S. 47, Nr. 43, 45; S. 48 , Nr. 51 ; S. 49 , Nr. 56 , 57 (?); S. 50 , Nr. 59 ; S. 53 , Nr. 73 ; S. 54 , Nr. 82 , 83 ; S. 55 , Nr. 85.

${ }^{78}$ Caesarius von Heisterbach, Dialogus Miraculorum. Hg. von Joseph Strange I. Köln/ Bonn/ Brüssel 1851, S. 205.

${ }^{79}$ Eine Datierung des,Wigalois' nach 1234, wie sie Volker Mertens (Iwein und Gwigalois - der Weg zur Landesherrschaft. GRM 31 [1981], S. 14-31, hier S. 26) vorschlägt, halte ich aufgrund des Überlieferungsbefundes für unwahrscheinlich. Nicht nur die älteste vollständige Handschrift 
,Lanzelet' (Nr. 22), als auch der ,Wigalois' (Nr. 31, 34, 42, 44) werden noch in der archaischen Form, d. h. einspaltig mit nicht abgesetzten Versen, überliefert. Von den späteren Romanen repräsentieren nur noch der, Wigamur' (Nr. 25) und der ,Loccumer Artusroman' diesen Überlieferungstyp, und beide nehmen damit für die Zeit um 1300 eine Sonderstellung ein. ${ }^{80}$

Die dialektale Einordnung läßt auf einen Blick den Schwerpunkt der Überlieferung im östlichen und südöstlichen Deutschland erkennen (s. Karte I u. II). Nur der ,Lanzelet' Ulrichs und der ,Prosa-Lancelot' laufen diesem Trend zuwider; ihre Überlieferung ist auf den alemannischen und westmitteldeutschen Raum beschränkt. Das gilt auch für den unikal überlieferten, Loccumer Artusroman' und den ,Parcheval'.

Die Dominanz fragmentarischer Überlieferung legte es nahe, dort, wo es möglich war, den Umfang des vollständigen Textes zu rekonstruieren. ${ }^{81}$ Gerade für die umfangreiche fragmentarische, Wigalois'-Überlieferung lassen sich daraus Rückschlüsse ziehen, denn alle vollständigen Handschriften vor 1400 bieten den Text in Einzelüberlieferung. Vergleicht man nun deren Umfang mit den rekonstruierten Blattzahlen der Fragmente, so liegt die Vermutung nahe, daß allgemein Einzelüberlieferung beim ,Wigalois' dominierte. Für diesen Befund spricht zusätzlich die Häufigkeit kleiner und kleinster Formate. Nur die ,Crône‘ Heinrichs von dem Türlin (Nr. 8) und der ,Segremors' (Nr. 19) standen nachweislich in Sammelhandschriften. Ulrichs, Lanzelet' (Nr. 24) und Pleiers, Garel ${ }^{\star}$ (Nr. 14) werden ebenfalls wieder einzeln überliefert. Das Gesamtbild der Überlieferung spricht somit für Dominanz der Einzelüberlieferung bei den nachklassischen Artusromanen. ${ }^{82}$

Prachthandschriften sind nur für die ,Crône'-Überlieferung (Nr. 5-8) und den ,Prosa-Lancelot' (Nr. 16-18) typisch; herausragend und isoliert steht dane-

(Nr. 34, um 1220), sondern auch die frühe fragmentarische Überlieferung (Nr. 31, 36, 42, 43, 44) spricht dagegen. Mehr Wahrscheinlichkeit hat die zeitliche Einordnung, die er in seinem Schlußwort anbietet: „Die Zuschreibung an den spätstaufischen Literaturkreis [...] hängt allerdings nicht an der späten Datierung [...]. Auch in den zwanziger Jahren könnte man sich den ,Wigalois' mit seinen Anspielungen auf die Meranier, Nürnberg, die Schlacht am Welfesholze - Hoyer von Mansfeld - vorstellen, wenngleich der Tod des Fürsten (1204) dann schon recht weit entfernt wäre." (S. 28)

${ }^{80}$ Die ,Wigamur'-Handschrift ist nicht nur vom Anlagetyp her eine Ausnahmeerscheinung. Es handelt sich außerdem um ein Palimpsest. Die ursprüngliche Beschriftung war lateinisch. Leseversuche mit der UV-Lampe ergaben, daß kein fortlaufender Text getilgt wurde. Erkennbar sind nur noch einzelne Wörter, die aber keinen Rückschluß auf den ursprünglichen Text erlauben.

${ }^{81}$ Die Blattzahlen sind Annährungswerte, die aufgrund der Verszahl pro Spalte ermittelt wurden. Dabei wurden Zusätze oder Lücken im fragmentarisch überlieferten Text nicht berücksichtigt und die Verszahl der Ausgabe zugrunde gelegt.

${ }^{82}$ Ein anderes Bild bietet die Überlieferung der arthurischen Versromane im romanischen Raum. Dort werden die nachchrestienschen Texte häufig in Sammelhandschriften vereint (SCHMOLKEHasselmanN [Anm. 9], S. 180). Der Schwerpunkt der Überlieferung liegt dabei ähnlich wie im deutschen Bereich in der Zeit um 1300 und am Anfang des 14. Jahrhunderts; es existieren selten mehr als ein bis zwei Überlieferungszeugen. Handschriften aus dem 15. Jahrhundert, die im deutschen Bereich für alle vollständig bekannten Artusromane existieren, fehlen fast ganz (ebd. S. 179). 


Werk/Bibliothek $^{83} \quad$ Datierung $\quad \begin{aligned} & \text { Schrift- } \\ & \text { dialekt }\end{aligned} \quad$ Hs./Frg. Umfang

Abor und das Meerweib

1. Kopenhagen, Kongelige Bi-

bliotek, Ny kgl. Saml. cod.

$4843,4^{\circ}$

[Ulrich von Türheim], Cligès

2. Kalocsa, Kathedralbibl.,

Ms. 312/a
1. H. 14. Jh. Nordbai- Frg.; 1 Bl., 136 Verse

risch mit

ostfrk. Re-

sten

um $1300 \quad$ Bairisch

Frg.; drei zweispaltige Querstreifen, zwei Längsstreifen eines Blattes; 242 Verse

St. Paul, Stiftsbibl., Sign. $27 / 8$

Frg.; 1 Bl. in zwei Streifen; 143

Verse

Zürich, Zentralbibl., Ms. Z

XIV 12

Frg.; Querstreifen eines Doppelblattes, Längsstreifen eines dritten Bl.; 58 Verse

ben die übergroße Handschrift des ,Segremors‘ (Nr. 19). Aus der, Wigalois'Überlieferung gehören zu diesem Überlieferungstyp die illustrierte Leidener Handschrift (Nr. 53) und das verschollene, mit Raum für Illustrationen versehene Fragment aus Wetzlar (Nr. 58). Neben diesen beiden Handschriften bietet nur noch die Stuttgarter, Wigalois'-Handschrift Federzeichnungen, die aber nicht textbezogen sind. ${ }^{84}$

Die Bezeichnung Anlagetyp bedarf noch einer näheren Erklärung. Es handelt sich dabei um den Versuch, aus der Spaltenanlage der einzelnen Handschriften Rückschlüsse auf bestimmte landschaftliche, zeittypische, stemmatisch bedingte oder schulmäßige Gewohnheiten zu ziehen. Leider entzog sich das Ergebnis bisher einer Systematisierung. Folgende Typen bot das Material:

A - abgesetzte Verse, vorgezogener Anfangsbuchstabe bei An- und Abvers (Abb. 3-4);

${ }^{83}$ Die Angaben in der Tabelle stammen aus der oben zu den jeweiligen Werken zitierten Forschungsliteratur und den vorhandenen Handschriftenkatalogen. Abweichungen beruhen auf Autopsie, Mikrofilmen, Kopien und Bibliotheksanfragen. Die Hilgers-Nummern, die die Umfangsangaben bei der, Wigalois'-Überlieferung ersetzen, beziehen sich auf den Anm. 56 genannten Aufsatz, die Verweise auf Zatloukal auf den Anm. 41 genannten Titel. Gestrichelte Linien trennen Fragmente einer Hs., die in verschiedenen Bibliotheken aufbewahrt werden.

${ }^{84}$ Die Bremer, Wigalois'-Handschrift (Nr. 48) besitzt noch eine grobe Federzeichnung. Alle anderen Handschriften bieten keine Anhaltspunkte für Illustrationen. 


\begin{tabular}{lllllll}
\hline $\begin{array}{l}\text { Umfang } \\
\text { des } \\
\text { vollst. } \\
\text { Textes }\end{array}$ & $\begin{array}{l}\text { Be- } \\
\text { schreib- } \\
\text { stoff }\end{array}$ & $\begin{array}{l}\text { Blattgröße } \\
\text { in mm }\end{array}$ & $\begin{array}{l}\text { Schrift- } \\
\text { spiegel }\end{array}$ & $\begin{array}{l}\text { Spalten- } \\
\text { zahl }\end{array}$ & $\begin{array}{l}\text { Zeilen- } \\
\text { zahl } \\
\text { Anla- } \\
\text { getyp }\end{array}$ & Fundort \\
\hline- & Pg. & $237 \times 200$ & $\begin{array}{l}180 \times 70 \\
\text { pro Spalte }\end{array}$ & 2 & $\begin{array}{l}34 \\
\text { C }\end{array}$ & unbekannt \\
& & & & &
\end{tabular}

\begin{tabular}{|c|c|c|c|c|c|c|}
\hline- & Pg. & $\begin{aligned} 70 & \times 150 \\
60 & \times 145 \\
63 & \times 165 \\
248 & \times 56 \\
248 & \times 54\end{aligned}$ & - & 2 & $\begin{array}{l}36 \\
\mathrm{~A}\end{array}$ & $\begin{array}{l}\text { Thomas von Aquin, De veritate } \\
\text { catholicae fidei. Straßburg: Hein- } \\
\text { ricus Ariminensis } 1472 . \text { Sig.: } \\
\text { 20635; [Kloster; ehem. Kapuzi- } \\
\text { nerkl. Braunau, gegr. 1620] }\end{array}$ \\
\hline - & - & $255 \times 176$ & $178 \times 120$ & - & - & $\begin{array}{l}\text { Cato, Documenta moralia Cato- } \\
\text { nis. Ulm: Johann Zainer um } \\
\text { 1476/78. Sign.: 4. 7. } 11 \text { [Kloster, } \\
\text { ehem. Spital am Pyhrn] }\end{array}$ \\
\hline - & - & $\begin{array}{l}65-68 \times \\
345-352 \\
221 \times 9 / 11\end{array}$ & - & - & - & $\begin{array}{l}\text { Johannes Balbus, Catholicon. } \\
\text { Nürnberg: Anton Koberger } \\
\text { 1486; verschollen [Kloster; Kar- } \\
\text { tause Buxheim] }\end{array}$ \\
\hline
\end{tabular}

B - abgesetzte Verse, Majuskel bei An- und Abvers (Abb. 17);

C - abgesetzte Verse, Anvers vorgezogen (Abb. 9-14);

D - abgesetzte Verse, Anvers mit Majuskel (Abb. 18-19);

E - abgesetzte Verse, keine Hervorhebung von An- oder Abvers (Abb. 15-16);

F - nicht abgesetzte Verse (Abb. 8). ${ }^{85}$

In der Spalte „Fundorte“ finden sich auch Hinweise auf mittelalterliche Besitzer/Benutzer und sonstige Einträge auf den Fragmenten. ${ }^{86}$

${ }^{85}$ Eine Durchsicht der handschriftlichen Überlieferung anderer epischer Texte in Reimpaarversen bestätigte die hier gewonnene Typenbildung; Ergänzungen waren nicht erforderlich. Typ A, B, C treten etwa mit gleicher Häufigkeit auf $(11: 12: 11)$. Nur dreimal vertreten ist Typ D. Eine umfassende Analyse der Anlage von Epenhandschriften müßte die Überlieferung lateinischer und französischer Epentexte miteinbeziehen. Herrn Prof. Dr. N. Henkel verdanke ich den Hinweis, daß die lateinischen Epenhandschriften des Untersuchungszeitraumes vielfach das gleiche Erscheinungsbild bieten wie die deutschen (vgl. Bernd SCHNEIDER, Vergil. Handschriften und Drucke der Herzog August Bibliothek, Wolfenbüttel 1982).

${ }^{86}$ Die Abbildungen dienen vor allem zur Dokumentation der nur fragmentarisch überlieferten Artusromane, da sie nur in dem längst vergriffenen Übungsbuch von MEYER-BENFEY [Anm. 11] annähernd komplett abgedruckt sind. Der, Cligès' sowie der ,Parcheval' wurden nicht aufgenommen, weil von diesen Fragmenten Reproduktionen zur Verfügung stehen (GRÖCHENIG/PASCHER, [Anm. 17]; ZATočıL [Anm. 25]). Die Abbildungen 17, 18 und 19 wurden ergänzt, um alle Anlagetypen mit abgesetzten Reimpaarversen zu dokumentieren. 
Werk/Bibliothek

Datierung Schrift-

Hs./Frg. Umfang

dialekt

Edolanz

um 1300

Bairisch

Frg.; 1 Bl.; 124 Verse

3. Seitenstetten, Stiftsbibl.,

Fragmentenschachtel

4. Wien, NB, cod. s.n. 4001 1. H. 14 Jh. Bairisch $\quad$ Frg.; Doppelblatt e. Lage; 255 Verse

\section{Heinrich von dem Türlin, Crộne um 1300}

5. Berlin, SBPK, Ms. germ.

$2^{\circ} 923,9$

Ostfrän- $\quad$ Frg.; 1 Bl.; 124 Verse;

kisch-Mit- Zatloukal, S. 9

teldt.

- - - - - - --1 (Böhmen)

Schwäbisch-Hall, Stadtarchiv, unsig. [verschollen]

6. Kiel, UB, Ms. K.B. $48^{\mathrm{i}}$ Mitte 14. Jh. Niederdt. Frg.; 1 Doppelbl.; 320 Verse;

nach Zatloukal, S. 9

oberdt.

Vorlage

7. Köln, UBuStB, cod. 5 P 62 1. H. 14. Jh. Ostfrän- $\quad$ Frg.; 1 Bl. (zerschnitten); 183

kisch-Mit- Verse; Zatloukal, S. 9

teldt.

(Böhmen)

8. Linz, OÖ. Landesarchiv, 1. Viertel Mittelbai- $\quad$ Frg.; 4 Bll.; 1191 Verse; ZatLou-

Sch. $3 \mathrm{II} / 4 \mathrm{e}$

14. Jh. risch KAL, S. 9

Wien, NB, cod. 2779 (Wien?) Frg. innerhalb e. Hs.; 40 Bll.;

1-12281

Konrad von Stoffeln,

Gauriel von Muntabel

2. H. 14. Jh. Südbai- Frg.; 1 Bl.; 132 Verse $\triangleq$ risch 1040-1156 mit Abweichungen

9. München, SB, cgm 5249(9a

\begin{tabular}{|c|c|c|c|}
\hline $\begin{array}{l}\text { 9a. München, SB, cgm } \\
5249(9 \mathrm{~b}\end{array}$ & $\begin{array}{l}\text { um } 1373 \\
\text { (WZ Datie- } \\
\text { rung) }\end{array}$ & Bairisch & $\begin{array}{l}\text { Frg.; } 4 \text { Doppelbll.; } 585 \text { Verse } \hat{=} \\
2972-3172 \text { mit Plustext in D }\end{array}$ \\
\hline $\begin{array}{l}\text { Loccumer Artusroman } \\
\text { 10. Loccum, Klosterbibl., } \\
\text { Ms. } 20\end{array}$ & um 1300 & $\begin{array}{l}\text { Mittelnie- } \\
\text { derdt. }\end{array}$ & $\begin{array}{l}\text { Frg.; } 2 \text { stark beschnittene Dop- } \\
\text { pelbll.; } 150 \text { Verse }\end{array}$ \\
\hline $\begin{array}{l}\text { Manuel und Amande } \\
\text { 11. Schwaz, Klosterbibl., Ar- } \\
\text { chiv, Lade O }\end{array}$ & Anf. 14. Jh. & $\begin{array}{l}\text { Nordbai- } \\
\text { risch-Ost- } \\
\text { fränkisch }\end{array}$ & $\begin{array}{l}\text { Frg.; } 3 \text { Doppel- und } 2 \text { Einzelbll.; } \\
283 \text { Verse }\end{array}$ \\
\hline $\begin{array}{l}\text { Parcheval } \\
\text { 12. Prag, Gedenkstätte des nat. } \\
\text { Schrifttums, 392/zl. }\end{array}$ & 2. H. 13. Jh. & $\begin{array}{l}\text { Mittel- } \\
\text { fränkisch }\end{array}$ & $\begin{array}{l}\text { Frg.; } 2 \text { Querstreifen e. Dop- } \\
\text { pelbl.; } 70 \text { Verse }\end{array}$ \\
\hline
\end{tabular}




\begin{tabular}{|c|c|c|c|c|c|c|}
\hline $\begin{array}{l}\text { Umfang } \\
\text { des } \\
\text { vollst. } \\
\text { Textes }\end{array}$ & $\begin{array}{l}\text { Be- } \\
\text { schreib- } \\
\text { stoff }\end{array}$ & $\begin{array}{l}\text { Blattgröße } \\
\text { in } \mathrm{mm}\end{array}$ & $\begin{array}{l}\text { Schrift- } \\
\text { spiegel }\end{array}$ & $\begin{array}{l}\text { Spalten- } \\
\text { zahl }\end{array}$ & $\begin{array}{l}\text { Zeilen- } \\
\text { zahl } \\
\text { Anla- } \\
\text { getyp }\end{array}$ & Fundort \\
\hline- & Pg. & $213 \times 150$ & $165 \times 130$ & 2 & $\begin{array}{l}32 \\
\text { A }\end{array}$ & unbekannt \\
\hline- & Pg. & $\begin{array}{l}231-234 \times \\
157-160\end{array}$ & $175 \times 135$ & 2 & $\begin{array}{l}32 \\
\mathrm{~B}\end{array}$ & $\begin{array}{l}\text { Makulatur auf e. Archiveinband } \\
\text { des 17. Jh.s aus Straßburg/ } \\
\text { Kärnten }\end{array}$ \\
\hline$\star 198$ Bll. & Pg. & $\begin{array}{l}205 \times \\
156-159\end{array}$ & $\begin{array}{l}157 \times \\
125-128\end{array}$ & 2 & $\begin{array}{l}\star 38 \\
\mathrm{~A}\end{array}$ & Ciceronis Sententiae. o. O. u. J. \\
\hline---- & --- & ---- & ----- & --- & - & ---------------- \\
\hline$\star 188$ Bll. & Pg. & $\begin{array}{l}305 \times \\
205-221\end{array}$ & $\begin{array}{l}215-220 \\
\times 150\end{array}$ & 2 & $\begin{array}{l}40 \\
\mathrm{~B}\end{array}$ & $\begin{array}{l}\text { Rechnungen der Stadt Plön über } \\
\text { die Jahre } 1645 \text { u. } 1646\end{array}$ \\
\hline$\star 135$ Bll. & Pg. & $\begin{array}{l}265 \times 190 \\
\star 380 \times \\
250\end{array}$ & $\begin{array}{l}\star 330 \times \\
200\end{array}$ & 2 & $\star 56$ & $\begin{array}{l}\text { Bucheinbände der alten Kölner } \\
\text { Stadtbibl. (Inkunabeln u. Früh- } \\
\text { drucke) }\end{array}$ \\
\hline$\star 99$ Bll. & Pg. & - & - & 3 & $\begin{array}{l}51 \\
\mathrm{E}\end{array}$ & $\begin{array}{l}\text { Urbareinband der Herren von } \\
\text { Jöger (17. Jh.) }\end{array}$ \\
\hline- & - & $355 \times 255$ & $295 \times 207$ & - & - & ab 1358 im Besitz der Turs \\
\hline$\star 32$ Bll. & $\mathrm{Pg}$. & $\begin{array}{l}200-205 \\
\times \\
143-145\end{array}$ & $\begin{array}{l}190 \times \\
125-135 \\
\star 197-200 \\
\times 125-135\end{array}$ & 2 & $\begin{array}{l}\star 34 \\
\mathrm{D}\end{array}$ & unbekannt \\
\hline$\star 39$ Bll. & Pap. & $\begin{array}{l}212-222 \\
\times \\
122-147\end{array}$ & $\begin{array}{l}180-182 \\
\times \\
120-122\end{array}$ & 2 & $\begin{array}{l}35-38 \\
\mathrm{D}\end{array}$ & München, SB, clm 5361 [15. Jh.] \\
\hline- & Pg. & $\begin{array}{l}90 \times 60 \\
\star 150 \times \\
100\end{array}$ & $\begin{array}{l}\text { Schrift- } \\
\text { breite } \star 80\end{array}$ & 1 & $\begin{array}{l}16 \\
F\end{array}$ & $\begin{array}{l}\text { Lat. Gebetbuch um } 1500 \text { [Klo- } \\
\text { ster] }\end{array}$ \\
\hline- & Pg. & $150 \times 110$ & $102 \times 65$ & 1 & $\begin{array}{l}20 \\
\mathrm{C}\end{array}$ & s. S. $238 ; 16 . / 17$. Jh. [Kloster] \\
\hline- & Pg. & $\begin{array}{l}41 \times 196 \\
42 \times 193 \\
\star 240 \times 110\end{array}$ & $\begin{array}{l}40 \times \\
52-59 \\
\star 180 \times 60\end{array}$ & 1 & $\begin{array}{l}34-36 \\
\mathrm{E}\end{array}$ & $\begin{array}{l}\text { unbekannt; } \\
\text { Schriftproben 16./17. Jh. }\end{array}$ \\
\hline
\end{tabular}


Werk/Bibliothek

Datierung

Schrift-

Hs./Frg. Umfang

dialekt

Pleier: Garel

13. Berlin, SBPK, Ms. germ.

$2^{\circ} 923,18$

Innsbruck, UB, Fragm. o. Sig.

(früher Meran, Stadtarchiv)

(t)

limpseste
1. H. 14. Jh. Bairisch Frg.; 1. Doppelbl.;

(Südbai- 15659-15938, 17051-17320; 549 risch?)

Frg.; 7 Doppelbll. (teilw. frgm.); 3813 Verse

Frg.; 2 Einzelbll.; 6754-6997;

8005-8263; 504 Verse

14. Linz, OÖ. Landesarchiv, um 1400 Mittelbai- Hs.

Schlüsselberger Archiv, Hs. risch

96/IV/54

\section{Pleier, Tandareis}

15. Dietfurt, Franziskanerkloster, unsig.

\section{Mitte 14. Jh. Mittelbai- Frg.; 1 Bl.; 16060-16219; 160} risch Verse

\section{Prosa-Lancelot}

16. Amorbach, Fürstl. Leiningsches Archiv, unsig.
Ende 13. Jh. Ostfrän- Frg.; Reste e. Blattes; KLUge I, S. kisch $\quad 230,16-25$ u. S. 232f., 27-4; 28 Zeilen

Frg.; 1 Bl.; s. KLUGE I S. XLII; fränkisch 175 Zeilen stand $147, \mathrm{Hr}$ deutsch Nr. 1

18. München, SB, cgm $5250(25$
Mitte 13. Jh. Ripuarisch Frg.; 1 Bl.; KLUGE I, S. 409, 21-412, 18; 88 Zeilen

\section{Segremors}

19. Gotha, Forschungsbibl.,

Memb. I 133

Weimar, Staatsarchiv, Reg. 1
1. H. 14. Jh. Mitteldt. (Thüringisch)
Frg.; 1 Doppelblatt; 288 Verse

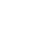

Frg.; 1 Bl.; 144 Verse

\begin{tabular}{llll}
\hline $\begin{array}{l}\text { 20. z. Z. Krakau, Biblioteka } \\
\text { Jagiellońska, Ms. germ. } 4^{\circ} 662\end{array}$ & um 1300 & $\begin{array}{l}\text { Mitteldt. } \\
\text { (Thürin- } \\
\text { gisch od. } \\
\text { westlicher) }\end{array}$ \\
\hline $\begin{array}{l}\text { Ulrich von Zatzikhoven } \\
\text { Lanzelet }\end{array}$ & 1. H. 14. Jh. & Mitteldt. & Frg.; 1 Bl,; 139 Verse \\
$\begin{array}{l}\text { 21. Klagenfurt, UB, Perg.-Hs. } \\
47\end{array}$ & & \\
$\begin{array}{l}\text { Cambridge (Mass.), Hough- } \\
\text { ton Library, Ms. Ger } 80\end{array}$ & - & Frg.; 2 Einzelbll.; $4422-4542 ;$ \\
\end{tabular}




\begin{tabular}{|c|c|c|c|c|c|c|}
\hline $\begin{array}{l}\text { Umfang } \\
\text { des } \\
\text { vollst. } \\
\text { Textes }\end{array}$ & $\begin{array}{l}\text { Be- } \\
\text { schreib- } \\
\text { stoff }\end{array}$ & $\begin{array}{l}\text { Blattgröße } \\
\text { in } \mathrm{mm}\end{array}$ & $\begin{array}{l}\text { Schrift- } \\
\text { spiegel }\end{array}$ & $\begin{array}{l}\text { Spalten- } \\
\text { zahl }\end{array}$ & $\begin{array}{l}\text { Zeilen- } \\
\text { zahl } \\
\text { Anla- } \\
\text { getyp }\end{array}$ & Fundort \\
\hline$\star 79$ Bll. & Pg. & $\begin{array}{l}335 \times \\
240-245\end{array}$ & $\begin{array}{l}280-285 \times \\
215-220\end{array}$ & 3 & $\begin{array}{l}44-47 \\
C\end{array}$ & $\begin{array}{l}\text { Bucheinband aus dem Gerichts- } \\
\text { archiv Meran }\end{array}$ \\
\hline$z----$ & ---- & ------ & - - & ---- & ------ & $\begin{array}{l}\text { Gerichtsprotokolle u. Verfach- } \\
\text { bücher } 1617-1641\end{array}$ \\
\hline- & - & $\begin{array}{l}335-345 \times \\
225-255\end{array}$ & $\begin{array}{l}275-285 \times \\
195-210\end{array}$ & - & $40-45$ & $\begin{array}{l}\text { Tyrolische Landschafft/sachen } \\
\text { Betreffend die Defension [...] im } \\
\text { Monat Martio } 1639\end{array}$ \\
\hline 169 Bll. & Pap. & $280 \times 200$ & $\begin{array}{l}205-212 \times \\
147-163\end{array}$ & 2 & $\begin{array}{l}28-34 \\
\mathrm{~B}\end{array}$ & $\begin{array}{l}\text { Bibliothek des Job Hartmann } \\
\text { von Enenkel (1576-1627); Na- } \\
\text { mensnennungen auf dem letzten } \\
\text { Blatt }\end{array}$ \\
\hline$\star 115$ Bll. & Pg. & $260 \times 182$ & $185 \times 125$ & 2 & $\begin{array}{l}40 \\
\mathrm{D}\end{array}$ & $\begin{array}{l}\text { Johannis Lentuli, Neopolitani } \\
\text { Itali[...] Teutsch vnnd Italiäni- } \\
\text { sche Sprach-Kunst. Augsburg } \\
1650 \text { [Kloster] }\end{array}$ \\
\hline- & Pg. & $\begin{array}{l}120 \times 100 \\
\star 300 \times 235\end{array}$ & $\star 215 \times 185$ & $\star 2$ & $\begin{array}{l}14 \\
\mathrm{ca} . \\
-\end{array}$ & $\begin{array}{l}\text { Mudauer Kirchenrechnung des } \\
\text { Klosters Amorbach von } 1574\end{array}$ \\
\hline- & Pap. & $375 \times 285$ & $315 \times 220$ & 2 & $\begin{array}{l}43-44 \\
-\end{array}$ & $\begin{array}{l}\text { Rechnungseinband aus dem } \\
\text { Waldecker Archiv (17. Jh.) }\end{array}$ \\
\hline- & Pg. & $\begin{array}{l}177 \times 199 \\
\star 300 \times 230\end{array}$ & $\begin{array}{l}157 \times \text { ca. } \\
90 \text { pro } \\
\text { Spalte } \\
\star 230 \times 195\end{array}$ & 2 & $\begin{array}{l}22 \\
\star 31-32 \\
-\end{array}$ & $\begin{array}{l}\text { Einband eines gebundenen } \mathrm{Bu}- \\
\text { ches }\end{array}$ \\
\hline- & Pg. & $\begin{array}{l}475 \times \\
375-365\end{array}$ & $\begin{array}{l}320 \times \\
245-250\end{array}$ & 2 & $\begin{array}{l}36 \\
\mathrm{C}\end{array}$ & $\begin{array}{l}\text { Buchdeckelfund; } 2^{\mathrm{v}} 1543 \text { ampt } \\
\text { wassennburgh (bei Arnstadt) }\end{array}$ \\
\hline- & - & $435 \times 330$ & $\begin{array}{l}310 \times \\
108-113 \\
\text { pro Spalte }\end{array}$ & --- & ---- & $\begin{array}{l}\text { Archiveinband des Amtes Was- } \\
\text { senburg bei Arnstadt (16./17. } \\
\text { Jh.); Sachsen-Ernestinisches } \\
\text { Hausarchiv; } 1^{\mathrm{r}} \text { Wassennburgk }\end{array}$ \\
\hline - & Pg. & $\begin{array}{l}205 \times 141 \\
\star 235 \times 180\end{array}$ & $172 \times 110$ & 2 & $\begin{array}{l}35-36 \\
E\end{array}$ & unbekannt \\
\hline
\end{tabular}

\begin{tabular}{llllll}
\hline 72 Bll. & Pg. & $210 \times 140$ & $170-175 \times 2$ & $29-31$ \\
$130-132$ & $\star 33$ & Klagenfurt, UB, Perg.-Hs. 23, & $\begin{array}{l}\text { Missale (1476); zuvor Urbar } \\
(1373 / 1473 ?) \text { [Kloster] }\end{array}$
\end{tabular}




Werk/Bibliothek Datierung $\quad \begin{aligned} & \text { Schrift- } \\ & \text { dialekt }\end{aligned} \quad$ Hs./Frg. Umfang

22. Oxford, Bodleian Library, 1. Viertel Niederale- $\quad$ Frg.; Querstreifen e. Doppelbl.

Ms. germ. b.3, f. 9-10 13. Jh. mannisch 2259-2285, 2304-2337, 2346-2369, 2389-2411; 98

Verse

\begin{tabular}{|c|c|c|c|}
\hline $\begin{array}{l}\text { 23. Straßburg, StB, unsig. } \\
\text { [verbrannt] }\end{array}$ & um 1300 & $\begin{array}{l}\text { Aleman- } \\
\text { nisch }\end{array}$ & $\begin{array}{l}\text { Frg.; } 2 \text { Bll.; 3089-3214, } \\
\text { 3472-3598; } 255 \text { Verse }\end{array}$ \\
\hline 24. Wien, NB, cod. 2698 & $\begin{array}{l}\text { Anfang } \\
\text { 14. Jh. }\end{array}$ & $\begin{array}{l}\text { Aleman- } \\
\text { nisch }\end{array}$ & Hs.; I + 59 Bll. \\
\hline $\begin{array}{l}\text { Wigamur } \\
\text { 25. München, SB, cgm. } \\
5249(28\end{array}$ & um 1300 & $\begin{array}{l}\text { Bairisch } \\
\text { mit md. } \\
\text { Spuren }\end{array}$ & $\begin{array}{l}\text { Frg.; } 16 \text { Bll. + } 2 \text { Streifen je eines } \\
\text { Blattes; } 1455 \text { Verse }\end{array}$ \\
\hline 26. Wien, NB, cod. s.n. 4433 & $\begin{array}{l}\text { Mitte } 14 . \\
\text { Jh. }\end{array}$ & Bairisch & $\begin{array}{l}\text { Frg.; } 5 \text { Bll.; } 4744-5658 \text { mit Lük- } \\
\text { ken; } 560 \text { Verse }\end{array}$ \\
\hline $\begin{array}{l}\text { Wirnt von Grafenberg, Wigalois } \\
27 . \text { Berlin, SBPK, Ms. germ. } \\
2^{\circ} 747\end{array}$ & $\begin{array}{l}\text { 2. H. } 13 . \\
\text { Jh. }\end{array}$ & Bairisch & $\begin{array}{l}\text { Frg.; } 1 \text { halbes Bl.; Hilgers Nr. 1; } \\
86 \text { Verse }\end{array}$ \\
\hline $\begin{array}{l}\text { 28. Berlin, SBPK, Ms. germ. } \\
2^{\circ} 923,35\end{array}$ & $\begin{array}{l}\text { 2. H. } 13 . \\
\text { Jh. }\end{array}$ & Mitteldt. & $\begin{array}{l}\text { Frg.; } 1 \text { Doppelbl.; HiLgers Nr. 4; } \\
322 \text { Verse }\end{array}$ \\
\hline $\begin{array}{l}\text { 29. Budapest, NB, unsig. [ver- } \\
\text { schollen] }\end{array}$ & $\begin{array}{l}\text { Mitte } 13 . \\
\text { Jh. }\end{array}$ & $\begin{array}{l}\text { Rheinfrän- } \\
\text { kisch } \\
\text { (Hessisch) }\end{array}$ & $\begin{array}{l}\text { Frg.; } 2 \text { Bll. (Stücke e. Doppel- } \\
\text { blatts); Hil GERs Nr. 5; } 133 \text { Verse }\end{array}$ \\
\hline $\begin{array}{l}\text { 30. Feldkirch, Jesuitengymna- } \\
\text { sium, unsig. [verschollen] }\end{array}$ & $\begin{array}{l}\text { 2. H. } 13 . \\
\text { Jh. }\end{array}$ & $\begin{array}{l}\text { Mittelbai- } \\
\text { risch }\end{array}$ & $\begin{array}{l}\text { Frg.; } 2 \text { Bll. (Reste e. Doppelbl.); } \\
\text { HilgERS Nr. 11; } 299 \text { Verse }\end{array}$ \\
\hline $\begin{array}{l}\text { 31. Freiburg i. Br., UB, } \\
\text { Fragm.-Hs. } 445\end{array}$ & $\begin{array}{l}\text { 2. Drittel } \\
\text { 13. Jh. }\end{array}$ & $\begin{array}{l}\text { Ostfrän- } \\
\text { kisch }\end{array}$ & $\begin{array}{l}\text { Frg.; } 2 \text { Bll. (Streifen e. Dop- } \\
\text { pelbl.); HiLgERs Nr. 12; } 117 \\
\text { Verse }\end{array}$ \\
\hline $\begin{array}{l}\text { 32. Freiburg i. Br., UB, } \\
\text { Fragm.-Hs } 513\end{array}$ & $\begin{array}{l}\text { 2. H. } 13 . \\
\text { Jh. }\end{array}$ & $\begin{array}{l}\text { Bairisch } \\
\text { (?) }\end{array}$ & $\begin{array}{l}\text { Frg.; } 1 \text { Doppelbl.; HiLgers Nr. } \\
\text { 13; } 230 \text { Verse }\end{array}$ \\
\hline
\end{tabular}

\begin{tabular}{llll}
\hline $\begin{array}{l}\text { 33. Göttingen, SUB, cod. ms. } \\
\text { philol. } 187\end{array}$ & $\begin{array}{l}\text { 2. H. 13. } \\
\text { Jh. }\end{array}$ & $\begin{array}{l}\text { Aleman- } \\
\text { nisch }\end{array}$ & $\begin{array}{l}\text { Frg.; 2 Bll. (unvollständig); HiL- } \\
\text { GERS Nr. 14; 224 Verse }\end{array}$
\end{tabular}




\begin{tabular}{|c|c|c|c|c|c|c|}
\hline $\begin{array}{l}\text { Umfang } \\
\text { des } \\
\text { vollst. } \\
\text { Textes }\end{array}$ & $\begin{array}{l}\text { Be- } \\
\text { schreib- } \\
\text { stoff }\end{array}$ & $\begin{array}{l}\text { Blattgröße } \\
\text { in } \mathrm{mm}\end{array}$ & $\begin{array}{l}\text { Schrift- } \\
\text { spiegel }\end{array}$ & $\begin{array}{l}\text { Spalten- } \\
\text { zahl }\end{array}$ & $\begin{array}{l}\text { Zeilen- } \\
\text { zahl } \\
\text { Anla- } \\
\text { getyp }\end{array}$ & Fundort \\
\hline $\begin{array}{l}\text { ca. } \star 110 \\
\text { Bll. }\end{array}$ & Pg. & $\begin{array}{l}65-70 \times \\
99 \\
\star 130 \times 99\end{array}$ & $\begin{array}{l}63 \times \\
78-82\end{array}$ & 1 & $\begin{array}{l}13 \\
\star 24 \\
(\stackrel{ }{=} a \\
43 \mathrm{~V} .) \\
\mathrm{F}\end{array}$ & unbekannt \\
\hline$\star 74$ Bll. & Pg. & $\begin{array}{l}\text { Klein } \\
\text { Quart }\end{array}$ & - & 2 & $31-32$ & $\begin{array}{l}\text { Straßburg, Johanniterbibl., A } \\
107\end{array}$ \\
\hline $58 \mathrm{Bll}$. & Pg. & $252 \times 170$ & $\begin{array}{l}208-212 \\
\times 140\end{array}$ & 2 & $\begin{array}{l}40 \\
\mathrm{E}\end{array}$ & Ambraser Bibliothek \\
\hline $\begin{array}{l}\text { ca. } \star 79 \\
\text { Bll. }\end{array}$ & Pg. & $\begin{array}{l}168-170 \\
\times \\
115-121\end{array}$ & $\begin{array}{l}138-140 \\
\times 82-85\end{array}$ & 1 & $\begin{array}{l}28-29 \\
F\end{array}$ & $\begin{array}{l}\text { Diplomatarium des Zisterzien- } \\
\text { serklosters Kaisheim }\end{array}$ \\
\hline$\star 49$ Bll. & Pg. & $187 \times 150$ & $155 \times 110$ & 2 & $\begin{array}{l}30-31 \\
\star 32 \\
\text { B }\end{array}$ & $\begin{array}{l}\text { Wiguleis Hundt zu Lautterbach, } \\
\text { Metropolis Salisburgensis. Mün- } \\
\text { chen } 1620 . \text { [Kloster] }\end{array}$ \\
\hline$\star 69$ Bll. & Pg. & $\begin{array}{l}275 \times 57 \\
\star 275 \times \\
180\end{array}$ & $\begin{array}{l}235 \times 60 \\
\text { pro Spalte }\end{array}$ & 2 & $\begin{array}{l}43 \\
\mathrm{~A}\end{array}$ & Buchdeckel \\
\hline$\star 74$ Bll. & Pg. & $170 \times 130$ & $\begin{array}{l}145-150 \\
\times 110\end{array}$ & 2 & $\begin{array}{l}40-41 \\
E\end{array}$ & $\begin{array}{l}\text { Druck der Starhembergischen } \\
\text { Bibliothek [acc. 1890, } 6062 \mathrm{der} \\
\text { kgl. Bibl. Berlin] (GW 5896) }\end{array}$ \\
\hline ^87 Bll. & Pg. & Quart & $160 \times 115$ & 2 & $\begin{array}{l}\star 34 \\
\mathrm{C}\end{array}$ & leerer Einbanddeckel \\
\hline ^67 Bll. & Pg. & unbekannt & unbekannt & 2 & $\begin{array}{l}\star 44 \\
36-37 \\
C\end{array}$ & $\begin{array}{l}\text { Sammelband der Schriften des } \\
\text { Petrus Canisius }\end{array}$ \\
\hline$\star 98$ Bll. & Pg. & $\begin{array}{l}60 \times 105 \\
\star 150 \times \\
105\end{array}$ & $\begin{array}{l}60 \times 80 \\
\star 120 \times 80\end{array}$ & 1 & $\begin{array}{l}\star 32 \triangleq \\
\star 60-61 \mathrm{~V} \\
\mathrm{~F}\end{array}$ & $\begin{array}{l}\text { Laurentius Valla, Elegantiae lin- } \\
\text { guae latinae. o. O. u.J. [Erst- } \\
\text { druck 1471] }\end{array}$ \\
\hline ‡98 Bll. & Pg. & $\begin{array}{l}139-158 \\
\times 131\end{array}$ & $\begin{array}{l}130-147 \\
\times 115\end{array}$ & 2 & $\begin{array}{l}\star 30-31 \\
\mathrm{~A}\end{array}$ & $\begin{array}{l}\text { unbekannt; zw. } 1^{\mathrm{v}} \text { u. } 2^{\mathrm{r}} \text { heralo- } \\
\text { gium eterne sapientie }(\text { Hd. des } 15 \text {. } \\
\text { Jh.; evt. Seuse, Horologium sa- } \\
\text { pientie) }\end{array}$ \\
\hline 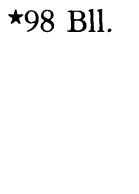 & Pg. & $\begin{array}{l}155 \times 100 \\
\star 200 \times 140\end{array}$ & $\begin{array}{l}150 \times 93 \\
\text { Bl. } 1(4 \\
\text { Zeilen } \\
\text { fehlen) }\end{array}$ & 2 & $\begin{array}{l}26 u .30 \\
\star 30 \\
\mathrm{~B}\end{array}$ & $\begin{array}{l}1^{\mathrm{r}} \text { Catonis disticha moralia. } \\
\text { Quoad graece. Apophthegmata } \\
\text { seu dicta Graeciae Sapientium } \\
\text { cum scholijs Erasmi. [u. a. Basel } \\
\text { 1533, 1534; Köln 1571, 1575] }\end{array}$ \\
\hline
\end{tabular}


Werk/Bibliothek

Datierung Schrift- Hs./Frg. Umfang

dialekt

34. Köln, Histor. Archiv, cod. 1. Viertel Bairisch $\quad$ Hs.; 118 Bll.; Hilgers Nr. 18

W. 6*

13. Jh.

35. z.Z. Krakau, Biblioteka Ja- um 1300 Bairisch giellońska, Ms. germ. $4^{\circ} 672$

Frg.; 2 beschädigte Doppelbll.;

Hilgers Nr. 2; 307 Verse

\begin{tabular}{|c|c|c|c|}
\hline $\begin{array}{l}\text { 36. z. Z. Krakau, Biblioteka Ja- } \\
\text { giellońska, Ms. germ. } 4^{\circ} 1689\end{array}$ & $\begin{array}{l}\text { 2. Drittel } \\
\text { 13. Jh: }\end{array}$ & Bairisch & $\begin{array}{l}\text { Frg.; } 8 \text { Bll.; HiLGERS Nr. 5; Kor- } \\
\text { rekt: } 3689-4089,5998-6384 ; \\
788 \text { Verse }\end{array}$ \\
\hline $\begin{array}{l}\text { 37. Linz, OÖ. Landesarchiv, } \\
\text { Buchdeckelfunde Sch } 3, \text { Nr. II/ } \\
\text { 4c }\end{array}$ & um 1300 & Bairisch & $\begin{array}{l}\text { Frg.; } 2 \text { Doppelbll.; HiLgers Nr. } \\
\text { 21; } 528 \text { Verse }\end{array}$ \\
\hline $\begin{array}{l}\text { 38. Ljubljana, NB u. UB, Ms. } \\
1079 \text {, št. } 76\end{array}$ & $\begin{array}{l}\text { 2. H. } 13 . \\
\text { Jh. }\end{array}$ & Bairisch & $\begin{array}{l}\text { Frg.; } 2 \text { Bll. (beschnitten); } \\
\text { 2948-3119, 3807-3978; } 344 \\
\text { Verse }\end{array}$ \\
\hline 39. München, SB, cgm 190 I & um 1300 & Bairisch & $\begin{array}{l}\text { Frg.; } 1 \text { Doppelbl.; HiLgers Nr. } \\
\text { 24; } 256 \text { Verse }\end{array}$ \\
\hline 40. München, SB, cgm 190 II & um 1300 & $\begin{array}{l}\text { Nordöstl. } \\
\text { Rd. des } \\
\text { Oberdt. }\end{array}$ & $\begin{array}{l}\text { Frg.; } 1 \text { Doppelbl.; HiLgers Nr. } \\
\text { 25; } 352 \text { Verse }\end{array}$ \\
\hline $\begin{array}{l}\text { 41. Prag, Státní knihovna, } \\
\text { Frag. germ. } 36\end{array}$ & $\begin{array}{l}\text { Mitte } 13 \text {. } \\
\text { Jh. }\end{array}$ & $\begin{array}{l}\text { Nordöstl. } \\
\text { Rd. des } \\
\text { Oberdt. }\end{array}$ & $\begin{array}{l}\text { Frg.; } 1 \text { Bl.; Hilgers Nr. 30; } 102 \\
\text { Verse }\end{array}$ \\
\hline $\begin{array}{l}\text { 42. Vorau, Stiftsbibl., cod. } 118 \\
\text { A }\end{array}$ & $\begin{array}{l}\text { 2. Drittel } \\
\text { 13. Jh. }\end{array}$ & Bairisch & $\begin{array}{l}\text { Frg.; } 5 \text { Doppelbll. (teilw. unvoll- } \\
\text { ständig) }+2 \text { Streifen; HILGERS } \\
\text { Nr. 33; } 1200 \text { Verse }\end{array}$ \\
\hline 43. Wien, NB, cod. s. n. 339 & $\begin{array}{l}\text { 2. Drittel } \\
\text { 13. Jh. }\end{array}$ & $\begin{array}{l}\text { Mittel- } \\
\text { deutsch }\end{array}$ & $\begin{array}{l}\text { Frg.; } 1 \text { Doppelbl. (unvollstän- } \\
\text { dig); HilgERS Nr. 36; } 232 \text { Verse }\end{array}$ \\
\hline 44. Wien, NB, cod. 14612 & $\begin{array}{l}\text { 1. Viertel } \\
\text { 13. Jh. } \\
(1210- \\
1220)\end{array}$ & Bairisch & $\begin{array}{l}\text { Frg.; } 3 \text { Doppelbll.; HiLGERs Nr. } \\
\text { 35; } 665 \text { Verse }\end{array}$ \\
\hline $\begin{array}{l}\text { New Haven, Yale University, } \\
\text { Beinecke Library, MS 481, no. } \\
113\end{array}$ & - & - & $\begin{array}{l}\text { Frg.; } 2 \text { Bll.; } 5589-5701 \text {, } \\
\text { 9849-9965; } 230 \text { Verse }\end{array}$ \\
\hline
\end{tabular}




\begin{tabular}{|c|c|c|c|c|c|c|}
\hline $\begin{array}{l}\text { Umfang } \\
\text { des } \\
\text { vollst. } \\
\text { Textes }\end{array}$ & $\begin{array}{l}\text { Be- } \\
\text { schreib- } \\
\text { stoff }\end{array}$ & $\begin{array}{l}\text { Blattgröße } \\
\text { in } \mathrm{mm}\end{array}$ & $\begin{array}{l}\text { Schrift- } \\
\text { spiegel }\end{array}$ & $\begin{array}{l}\text { Spalten- } \\
\text { zahl }\end{array}$ & $\begin{array}{l}\text { Zeilen- } \\
\text { zahl } \\
\text { Anla- } \\
\text { getyp }\end{array}$ & Fundort \\
\hline 118 Bll. & Pg. & $210 \times 145$ & $\begin{array}{l}\text { 1. Hd. } \\
165-175 \\
\times \\
100-110 \\
2 . \mathrm{Hd} . \\
170-175 \times \\
110-115\end{array}$ & 1 & $\begin{array}{l}\text { 1. } H d . \\
27-28 \\
2 . H d . \\
24 \stackrel{\wedge}{ } \\
42-46 V . \\
\text { F }\end{array}$ & $\begin{array}{l}\text { s. S. 239f.; Schloßbibliothek } \\
\text { Blankenheim }\end{array}$ \\
\hline 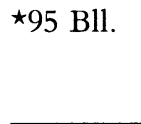 & Pg. & $\begin{array}{l}145 \times 140 \\
\star 171 \times \\
140\end{array}$ & $\begin{array}{l}\star 143 \times \\
110\end{array}$ & 2 & $\begin{array}{l}\max .29 \\
\star 31 \\
\mathrm{~A}\end{array}$ & $\begin{array}{l}\text { Buchdeckel; dt.-lat. Rezepte (15. } \\
\text { Jh.) }\end{array}$ \\
\hline $\begin{array}{l}\star_{\mathrm{ca}} \text {. } \\
120 \mathrm{Bll} .\end{array}$ & Pg. & $196 \times 75$ & $186 \times 43$ & 1 & $\begin{array}{l}47-52 \\
\text { A }\end{array}$ & unbekannt \\
\hline ^89 Bll. & Pg. & $198 \times 140$ & $153 \times 110$ & 2 & $\begin{array}{l}33 \\
\mathrm{C}\end{array}$ & $\begin{array}{l}\text { Herzoglich-Coburgisches Ar- } \\
\text { chiv Greinburg/Donau, Register- } \\
\text { band, 17. Jh. }\end{array}$ \\
\hline *69 Bll. & Pg. & $\begin{array}{l}210 \times 140 \\
\star 225 \times \\
155\end{array}$ & $195 \times 125$ & 2 & $\begin{array}{l}43 \\
\mathrm{~A}\end{array}$ & unbekannt; $2^{\mathrm{v}}$ Jacobus 1474 \\
\hline$\star 92$ Bll. & Pg. & $212 \times 150$ & $160 \times 127$ & 2 & $\begin{array}{l}32 \\
\mathrm{~B}\end{array}$ & $\begin{array}{l}\text { unbekannt; } 1^{\mathrm{r}} \text { fas per aliquem da- } \\
\text { tur, mein dinst, Ich han }\end{array}$ \\
\hline ^67 Bll. & Pg. & $\begin{array}{l}195 \times \\
145-147\end{array}$ & $\begin{array}{l}170-172 \\
\times 135\end{array}$ & 2 & $\begin{array}{l}44 \\
\mathrm{C}\end{array}$ & $\begin{array}{l}\text { Inkunabel aus Benediktbeuren } \\
\text { [Kloster]; } 2^{\circ} \text { Inc. s. a. } 767\end{array}$ \\
\hline$\star 109$ Bll. & Pg. & $\begin{array}{l}145 \times 112 \\
\star 170 \times \\
130\end{array}$ & $\begin{array}{l}135 \times 100 \\
\star 140 \times \\
100\end{array}$ & 2 & $\begin{array}{l}25-26 \\
\star 27 \\
\text { A }\end{array}$ & $\begin{array}{l}\text { Inkunabel }(1486 / 87) ; 1^{\mathrm{v}} \text { Melodie } \\
\text { eines Sanctus sanctus }(15 . \mathrm{Jh} .)\end{array}$ \\
\hline ‡98 Bll. & Pg. & $150 \times 100$ & $\begin{array}{l}\text { ca. } 120 \times \\
73\end{array}$ & 1 & $\begin{array}{l}29 \\
\stackrel{=}{\mathrm{F}} 60 \mathrm{~V}\end{array}$ & $\begin{array}{l}\text { Hs. } 157 \text { der Stiftsbibliothek aus } \\
\text { der 2. H. d. 15.Jh.s (Kirchen- } \\
\text { recht) }\end{array}$ \\
\hline 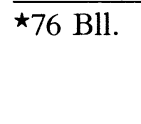 & Pg. & $\begin{array}{l}110 \times 129 \\
\star 190 \times \\
150\end{array}$ & $\begin{array}{l}106 \times \\
108-110 \\
\star 140 \times 110\end{array}$ & 2 & $\begin{array}{l}29 \\
\star 39 \\
\mathrm{E}\end{array}$ & $\begin{array}{l}\text { Einbandmakulatur; durchgehend } \\
\text { Minuskeln am Versanfang }\end{array}$ \\
\hline$\star 100 \mathrm{Bll}$. & Pg. & $\begin{array}{l}165 \times \\
100-115\end{array}$ & $\begin{array}{l}130-135 \\
\times 85-90\end{array}$ & 1 & $\begin{array}{l}31-33 \\
\hat{=} 58- \\
60 \mathrm{~V} \\
\mathrm{~F}\end{array}$ & $\begin{array}{l}\text { aus der Kartause Gaming, Nö; f. } \\
3^{\mathrm{v}} \text { Antonius Faber } 1510 ; \text { heute: } \\
\text { ÖNB, cod. } 1347 \text { u. Frühdruck } \\
\text { des Vocabularius Ex quo }\end{array}$ \\
\hline- & - & $\begin{array}{l}149 / 150 \times \\
97-101\end{array}$ & $\begin{array}{l}134-137 \\
\times 83-86\end{array}$ & - & --- & unbekannt \\
\hline
\end{tabular}




Werk/Bibliothek Datierung $\begin{aligned} & \text { Schrift- } \\ & \text { dialekt }\end{aligned} \quad$ Hs./Frg. Umfang

\begin{tabular}{|c|c|c|c|}
\hline $\begin{array}{l}\text { 45. Wolfenbüttel, HAB, cod. } \\
404.9 \text { (8) Novi }\end{array}$ & um 1300 & $\begin{array}{l}\text { Nordöstl. } \\
\text { Grenzge- } \\
\text { biet des } \\
\text { Oberdt. }\end{array}$ & $\begin{array}{l}\text { Frg.; } 1 \text { Doppel- und } 1 \text { Einzelbl. } \\
\text { (unvollst.); HilgERs Nr. 39; } 230 \\
\text { Verse }\end{array}$ \\
\hline
\end{tabular}

\begin{tabular}{lcll}
\hline $\begin{array}{l}\text { 46. Wolfenbüttel, HAB, cod. } \\
\text { 404.9 (9)Novi }\end{array}$ & um 1300 & $\begin{array}{l}\text { Nordöstl. } \\
\text { Grenzge- } \\
\text { biet des } \\
\text { Oberdt. }\end{array}$ & $\begin{array}{l}\text { Frg.; 1 Doppelbl. (4 Stücke, un- } \\
\text { vollst.); Hilgers Nr. 40; 230 } \\
\text { Verse }\end{array}$ \\
\hline $\begin{array}{l}\text { 47. Zwettl, Stiftsbibl., Frag- } \\
\text { mentenschachtel }\end{array}$ & um 1300 & $\begin{array}{l}\text { Mitteldt. } \\
\text { mit bair. }\end{array}$ & $\begin{array}{l}\text { Frg.; 1 Bl. (teilw. fragm.); } \\
\text { 9037-9165; 128 Verse } \\
\text { Spuren } \\
\text { (Böhmen?) }\end{array}$ \\
\hline 48. Bremen, SUB, Ms. b. 42 1356 & $\begin{array}{l}\text { Aleman- } \\
\text { nisch }\end{array}$ & Hs.; 75 Bll.; HilgERs Nr. 6
\end{tabular}

\begin{tabular}{|c|c|c|c|}
\hline $\begin{array}{l}\text { 49. Einsiedeln, Stiftsbibl., un- } \\
\text { sig. [verschollen] }\end{array}$ & $\begin{array}{l}\text { 2. H. } 14 . \\
\text { Jh. }\end{array}$ & $\begin{array}{l}\text { Aleman- } \\
\text { nisch }\end{array}$ & Frg.; 10 Bll.; Hilgers Nr. 10 \\
\hline $\begin{array}{l}\text { 50. Halle, UBuLB, Qu. Cod. } \\
101 \text { Spiegel }\end{array}$ & $\begin{array}{l}\text { Anf. } 14 . \\
\text { Jh. }\end{array}$ & $\begin{array}{l}\text { Nordöstl. } \\
\text { Grenzge- } \\
\text { biet des } \\
\text { Oberdt. }\end{array}$ & $\begin{array}{l}\text { Frg.; } 2 \text { Bll. (teilw. fragm.); HiL- } \\
\text { GERS Nr. 15; } 271 \text { Verse }\end{array}$ \\
\hline $\begin{array}{l}\text { 51. Innsbruck, Ferdinandeum, } \\
\text { FB 1519/VIII }\end{array}$ & $\begin{array}{l}\text { Anf. } 14 . \\
\text { Jh. }\end{array}$ & $\begin{array}{l}\text { Südbai- } \\
\text { risch }\end{array}$ & $\begin{array}{l}\text { Frg.; } 1 \text { Doppelbl. (beschnitten); } \\
\text { Hilgers Nr. 17; } 320 \text { Verse }\end{array}$ \\
\hline $\begin{array}{l}\text { 52. Kremsier, ehem. Archiv, } \\
\text { unsig. [verschollen] }\end{array}$ & $\begin{array}{l}\text { 2. H. } 14 . \\
\text { Jh. }\end{array}$ & $\begin{array}{l}\text { Mittelbair. } \\
\text { mit md. } \\
\text { Spuren }\end{array}$ & $\begin{array}{l}\text { Frg.; } 1 \text { Doppelbl.; Hilgers Nr. } \\
\text { 19; } 241 \text { Verse }\end{array}$ \\
\hline München, SB, cgm 5249(72 & - & - & $\begin{array}{l}\text { Frg.; } 1 \text { Bl. (leichter Textverl.); } \\
\text { HILGERS Nr. 23; } 122 \text { Verse }\end{array}$ \\
\hline 53. Leiden, UB, cod. Ltk. 537 & 1372 & $\begin{array}{l}\text { Mitteldt. } \\
\text { (Thüring.) } \\
\text { mit nie- } \\
\text { derdt. } \\
\text { Elem. }\end{array}$ & $\begin{array}{l}\text { Hs.; } 115 \text { Bll. (118 Bll.); HILGERS } \\
\text { Nr. } 20\end{array}$ \\
\hline
\end{tabular}




\begin{tabular}{|c|c|c|c|c|c|c|}
\hline $\begin{array}{l}\text { Umfang } \\
\text { des } \\
\text { vollst. } \\
\text { Textes }\end{array}$ & $\begin{array}{l}\text { Be- } \\
\text { schreib- } \\
\text { stoff }\end{array}$ & $\begin{array}{l}\text { Blattgröße } \\
\text { in } \mathrm{mm}\end{array}$ & $\begin{array}{l}\text { Schrift- } \\
\text { spiegel }\end{array}$ & $\begin{array}{l}\text { Spalten- } \\
\text { zahl }\end{array}$ & $\begin{array}{l}\text { Zeilen- } \\
\text { zahl } \\
\text { Anla- } \\
\text { getyp }\end{array}$ & Fundort \\
\hline *66 Bll. & Pg. & $\begin{array}{l}80 \times 120 \\
40 \times 85 \\
\star 160 \times \\
130\end{array}$ & $\begin{array}{l}71 \times 102 \\
\star 140 \times \\
102\end{array}$ & 2 & $\begin{array}{l}22-23 \\
u . \\
12-13 \\
\star 44-45 \\
\text { B }\end{array}$ & $\begin{array}{l}\text { unbekannt; gemeinsame Schreib- } \\
\text { stube mit } 46\end{array}$ \\
\hline
\end{tabular}

\begin{tabular}{|c|c|c|c|c|c|c|}
\hline$\star 66$ Bll. & Pg. & $\begin{array}{l}45 \times 95 \\
45 \times 75 \\
\star 135 \times 95\end{array}$ & $\begin{array}{l}38 \times 75 \\
\star 115 \times 75\end{array}$ & 2 & $\begin{array}{l}14-18 \\
\star 44-46 \\
\text { B }\end{array}$ & $\begin{array}{l}\text { unbekannt; gemeinsame Schreib- } \\
\text { stube mit } 45\end{array}$ \\
\hline
\end{tabular}

\begin{tabular}{|c|c|c|c|c|c|c|}
\hline *92 Bll. & Pg. & $223 \times 130$ & $\begin{array}{l}175-182 \\
\times 126 \\
\star 175-182 \\
\times 136\end{array}$ & 2 & $\begin{array}{l}32 \\
\mathrm{~B}\end{array}$ & unbekannt \\
\hline 75 Bll. & Pap. & $206 \times 147$ & $170 \times 120$ & 2 & $\begin{array}{l}32-41 \\
\text { B }\end{array}$ & $\begin{array}{l}\text { Burchart von amwil, fritz jacob von } \\
\text { amwil (Schweizer Ministerialen- } \\
\text { geschlecht); Anna von Helms- } \\
\text { dorff, Klosterfrau zu Dießenho- } \\
\text { fen; Melchior von Haiminsfeld } \\
\text { gen. Goldast ( } † 1635)\end{array}$ \\
\hline
\end{tabular}

$\begin{array}{llllll}\star 74 \text { Bll. } & \text { Pg. unbekannt unbekannt } 2 & 39-40 & \text { Missale der Stiftsbibliothek }\end{array}$

\begin{tabular}{|c|c|c|c|c|c|c|}
\hline ^87 Bll. & Pg. & $\begin{array}{l}215 \times 135 \\
210 \times 160\end{array}$ & $169 \times 130$ & 2 & $\begin{array}{l}34 \\
\mathrm{C}\end{array}$ & $\begin{array}{l}\text { Magdeburger Domvikar Johann } \\
\text { Boningk ( } † \text { 1481); Prämonstra- } \\
\text { tenserkloster St. Wiperti Qu. } \\
\text { Cod. } 101 \text { (entst. um 1455) }\end{array}$ \\
\hline
\end{tabular}

\begin{tabular}{|c|c|c|c|c|c|c|}
\hline ^74 Bll. & Pg. & $\begin{array}{l}207 \times 154 \\
\star 220 \times \\
160\end{array}$ & $190 \times 135$ & 2 & $\begin{array}{l}37-40 \\
40 \\
C\end{array}$ & unbekannt \\
\hline
\end{tabular}

\begin{tabular}{|c|c|c|c|c|c|c|}
\hline $\begin{array}{l}\text { ca. } \star 98 \\
\text { Bll. }\end{array}$ & $\mathrm{Pg}$. & Oktav & - & 1 & $30-31$ & $\begin{array}{l}\text { Kloster Heinrichau Schlesien; } \\
\text { pro Zeile ein Reimpaar }\end{array}$ \\
\hline
\end{tabular}

115 Bll. $\quad$ Pg. $241 \times 167 \quad 182 \times 136 \quad 2 \quad 26-29 \quad$ Herzog Albrecht II. von BraunA schweig-Grubenhagen (1361-1384); 47 Illustrationen 
Werk/Bibliothek

Datierung Schrift- Hs./Frg. Umfang

dialekt

\begin{tabular}{llll}
\hline 54. München, SB, cgm 190 III & $\begin{array}{l}\text { Mitte 14. } \\
\text { Jh. }\end{array}$ & $\begin{array}{l}\text { Aleman- } \\
\text { nisch }\end{array}$ & $\begin{array}{l}\text { Frg.; 1 Doppelbl. (unvollst.); } \\
\text { HILGERS Nr. 26; 157 Verse }\end{array}$
\end{tabular}

55. Nürnberg, GNM, Hs 6797 Mitte 14. Aleman- $\quad$ Frg.; 1 Doppelbl. (teilweise

Jh. nisch frgm.); Hilgers Nr. 27; 370

Verse

56. Oslo, Riksarkivet, Gam- $\quad$ 1. H. 14. Mittel- $\quad$ Frg.; 1 halbes Bl. (quer); Hilgers

melnorske membranfragment Jh. deutsch Nr. 28; 48 Verse

nr. 94

57. Stuttgart, LB, cod. HB $\quad 1361-\quad$ Schwä- $\quad$ Hs.; 87 Bll.; Hilgers Nr. 32 XIII. 5 $1364(\mathrm{Wz})$ bisch

58. Wetzlar, Staatsarchiv, 1. H. 14. Jh. (?)

Rheinfrän-

Frg.; 1 Doppelbl. (teilweise

Mscr. VIII ex litt. B 1644/5228

[verschollen]

kisch

frgm.); Hilgers Nr. 34; 272

Verse 


\begin{tabular}{|c|c|c|c|c|c|c|}
\hline $\begin{array}{l}\text { Umfang } \\
\text { des } \\
\text { vollst. } \\
\text { Textes }\end{array}$ & $\begin{array}{l}\text { Be- } \\
\text { schreib- } \\
\text { stoff }\end{array}$ & $\begin{array}{l}\text { Blattgröße } \\
\text { in } \mathrm{mm}\end{array}$ & $\begin{array}{l}\text { Schrift- } \\
\text { spiegel }\end{array}$ & $\begin{array}{l}\text { Spalten- } \\
\text { zahl }\end{array}$ & $\begin{array}{l}\text { Zeilen- } \\
\text { zahl } \\
\text { Anla- } \\
\text { getyp }\end{array}$ & Fundort \\
\hline ^98 Bll. & Pg. & $\begin{array}{l}135 \times 133 \\
\star 185 \times \\
136-140\end{array}$ & $\begin{array}{l}121 \times 115 \\
\star 145 \times \\
115\end{array}$ & 2 & $\begin{array}{l}26-27 \\
\star 30 \\
\mathrm{~B}\end{array}$ & $\begin{array}{l}\text { unbekannt; } 2^{\mathrm{r}} \text { Caspar Ambiel } \\
\text { (Vorbesitzer); Wappen (dreige- } \\
\text { teiltes Feld mit Löwen?) }\end{array}$ \\
\hline ^63 Bll. & Pg. & $\begin{array}{l}220-225 \\
\times 150\end{array}$ & $200 \times 135$ & 2 & $\begin{array}{l}40-48 \\
\mathrm{E}\end{array}$ & $\begin{array}{l}1849 \text { Schloßbibliothek Aufseß; } \\
\text { mehrfach ein Reimpaar pro Zeile }\end{array}$ \\
\hline ^87 Bll. & Pg. & $\begin{array}{l}107-111 \\
\times 200 \\
\star 290 \times \\
210\end{array}$ & $\begin{array}{l}80-84 \times \\
145 \\
\star 240 \times \\
145\end{array}$ & 2 & $\begin{array}{l}12 \\
\star 34 \\
\mathrm{E}\end{array}$ & $\begin{array}{l}\text { Ryfylke bei Stavanger, Vogtei- } \\
\text { rechnung von } 1633\end{array}$ \\
\hline 87 Bll. & Pap. & $190 \times 140$ & $\begin{array}{l}165-170 \\
\times \\
120-125\end{array}$ & 2 & $\begin{array}{l}31-34 \\
\mathrm{~B}\end{array}$ & - \\
\hline $\begin{array}{l}\star 74-86 \\
\text { Bll. }\end{array}$ & Pg. & $\begin{array}{l}\star 320-330 \\
\times 235\end{array}$ & $235 \times 162$ & 2 & $\star 40$ & $\begin{array}{l}\text { Reichskammergericht; } 3 \times \\
\text { zwölfzeiliger Raum für Illustra- } \\
\text { tionen }\end{array}$ \\
\hline
\end{tabular}




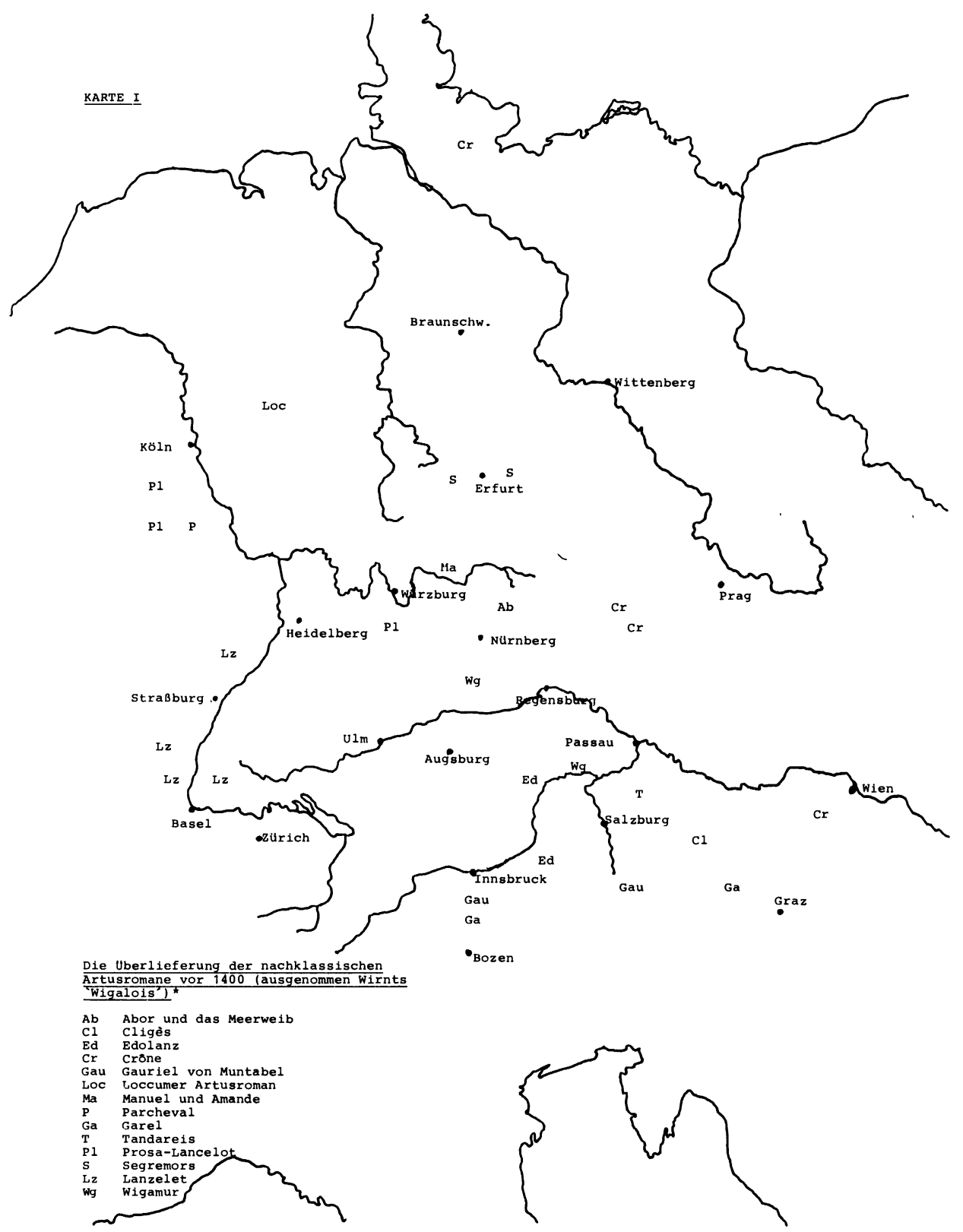

* Nicht näher eingrenzbare Handschriften sind im Mittelpunkt des jeweiligen Dialektbereichs zentriert. 

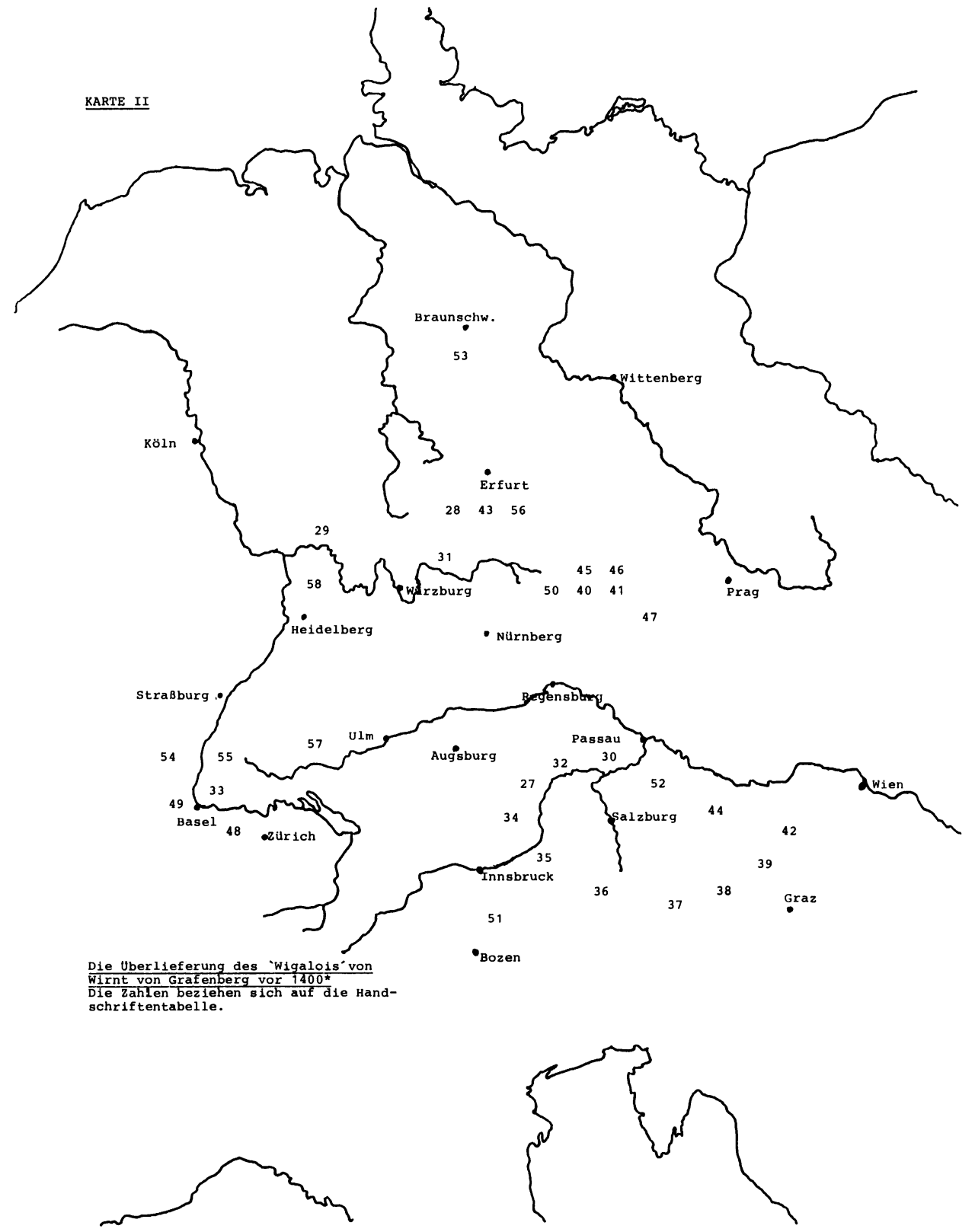

*Nicht naher eingrenzbare Handschriften sind im Mittelpunkt des jeweiligen Dialektbereichs zentriert. 


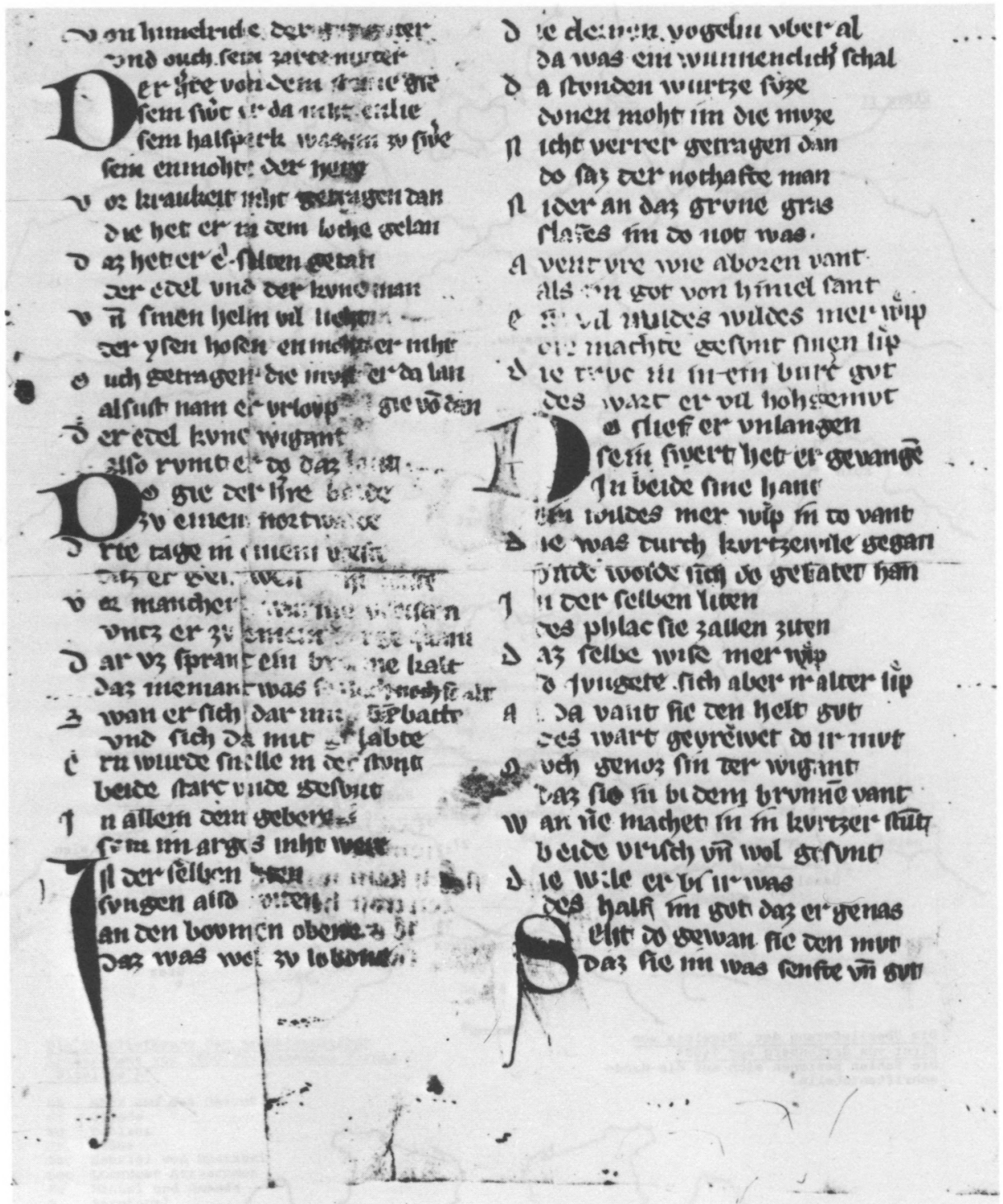

Abb. 1: Abor und das Meerweib, 1 ${ }^{\mathrm{r}}$ C-Typ, Nr. 1. Kopenhagen, Kongelige Bibliotek, Ny kgl. Saml. $4843,4^{\circ}$. 


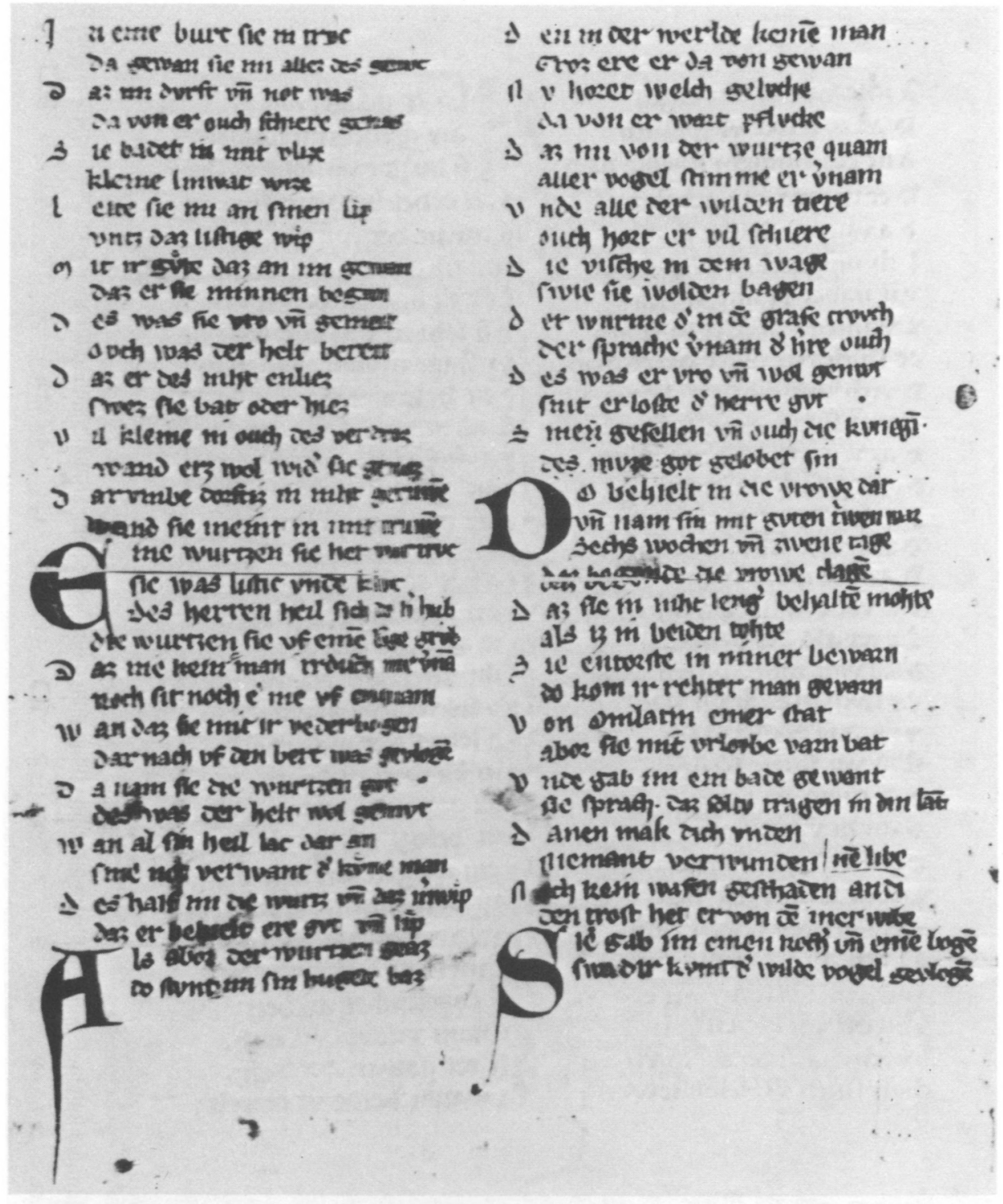

Abb. 2: Abor und das Meerweib, 1v, C-Typ, Nr. 1. Kopenhagen, Kongelige Bibliotek, Ny kgl. Saml. $4843,4^{\circ}$. 


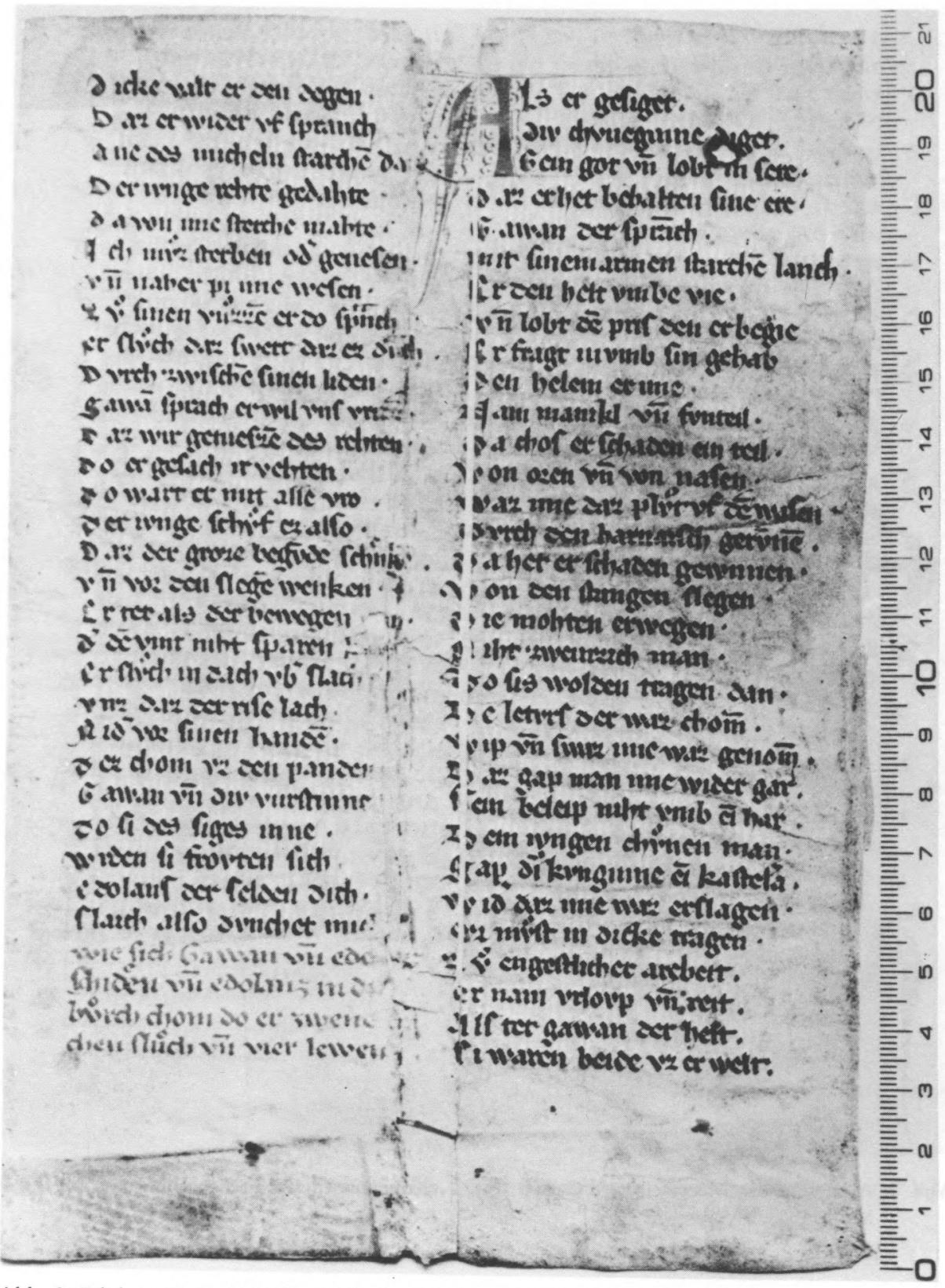

Abb. 3: Edolanz, 1 ${ }^{\text {r }}$ A-Typ, Nr. 3. Seitenstetten, Stiftsbibl., Fragmentenschachtel. 


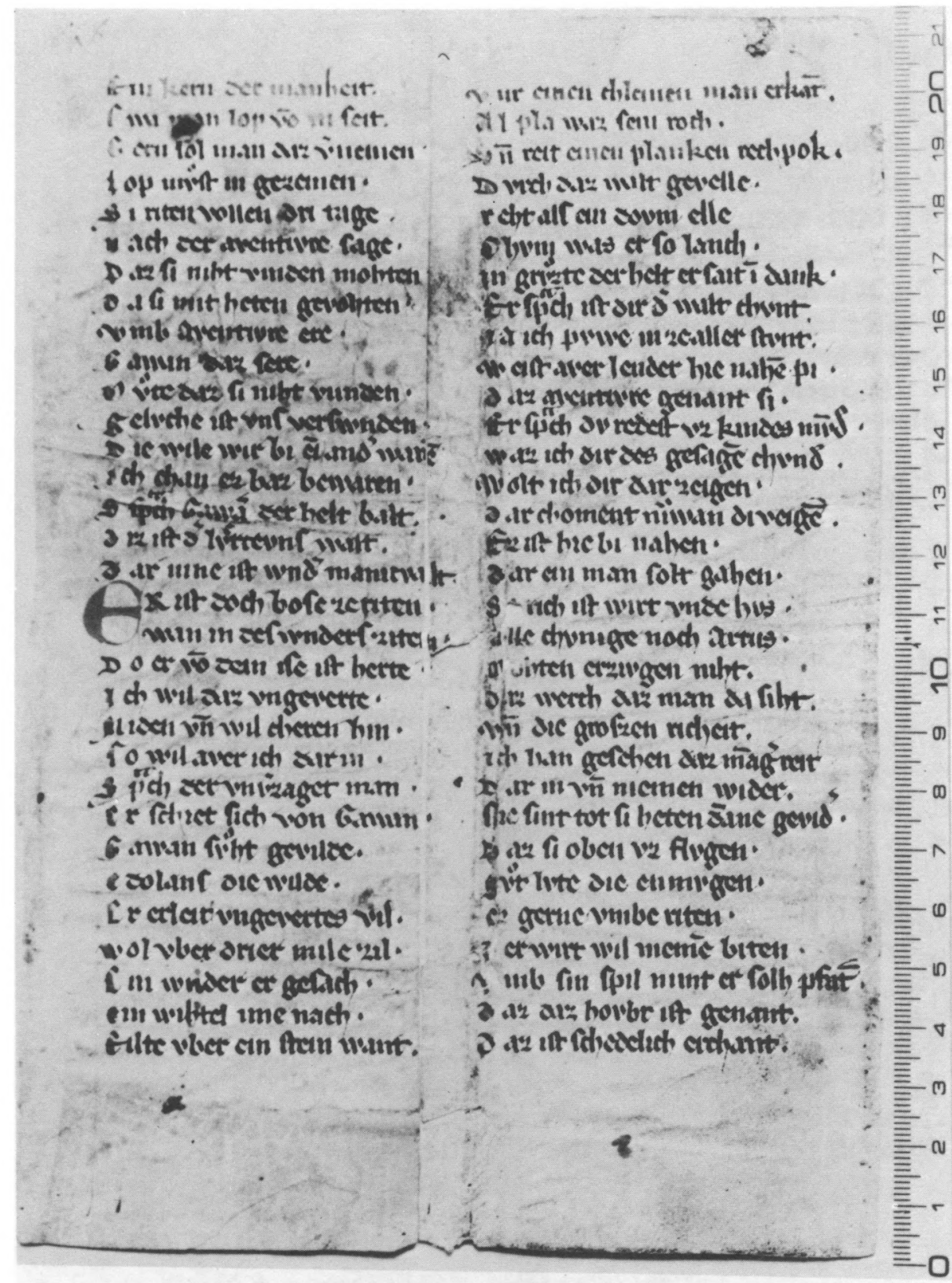

Abb. 4: Edolanz, 1 , A-Typ, Nr. 3. Seitenstetten, Stiftsbibl., Fragmentenschachtel. 


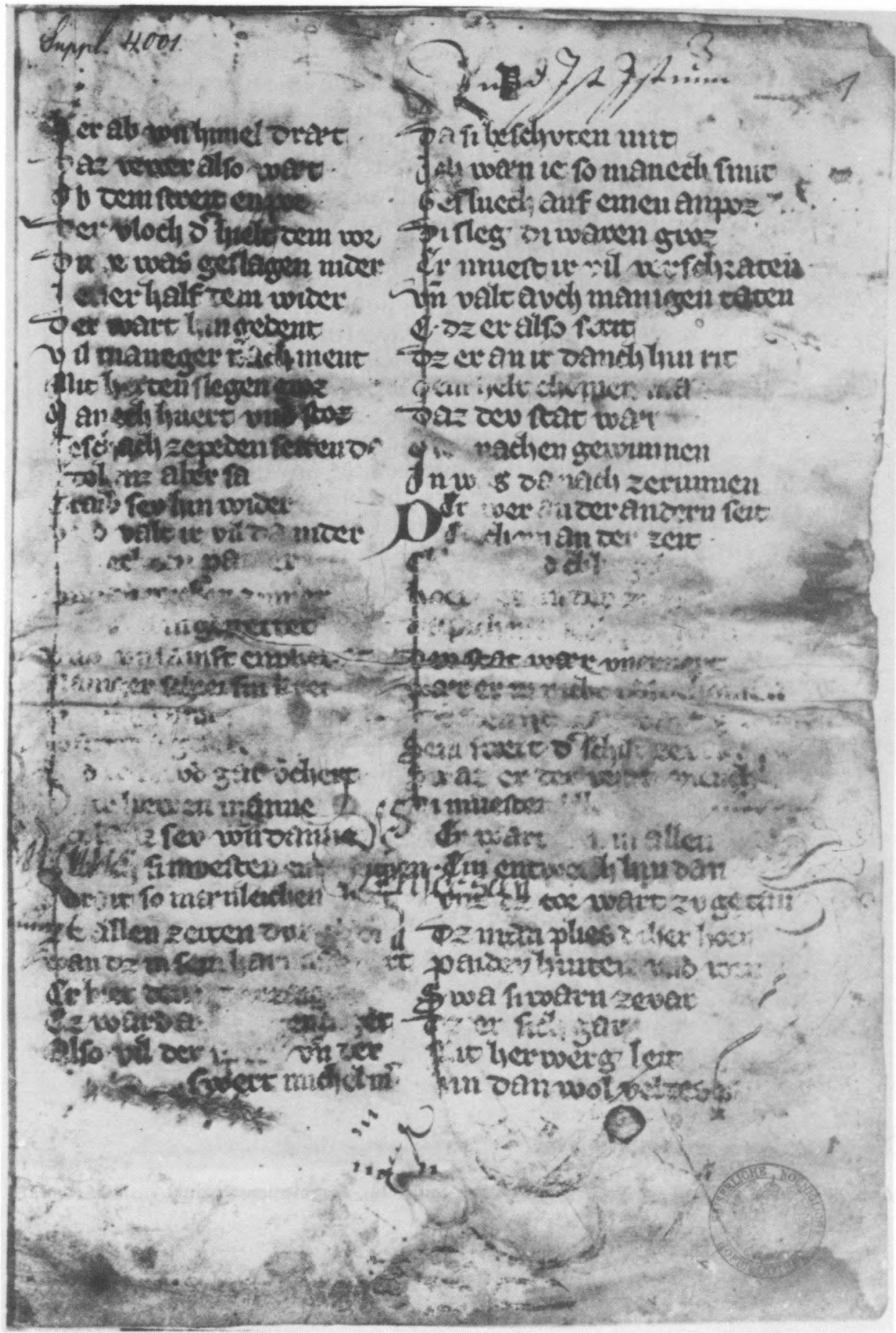

Abb. 5: Edolanz, 1' ${ }^{\text {, }}$ B-Typ, Nr. 4. Wien, NB, cod. s.n. 4001. 


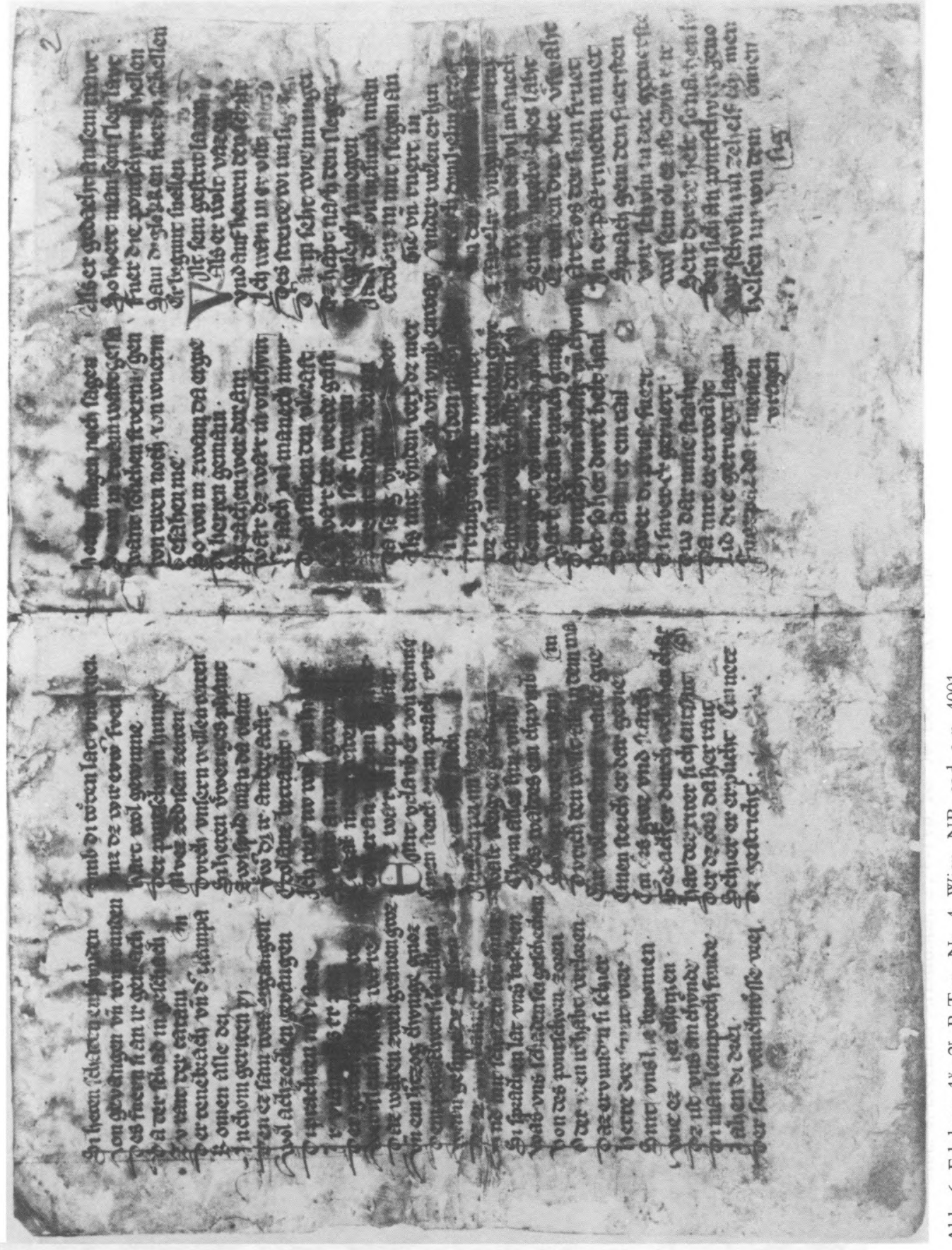




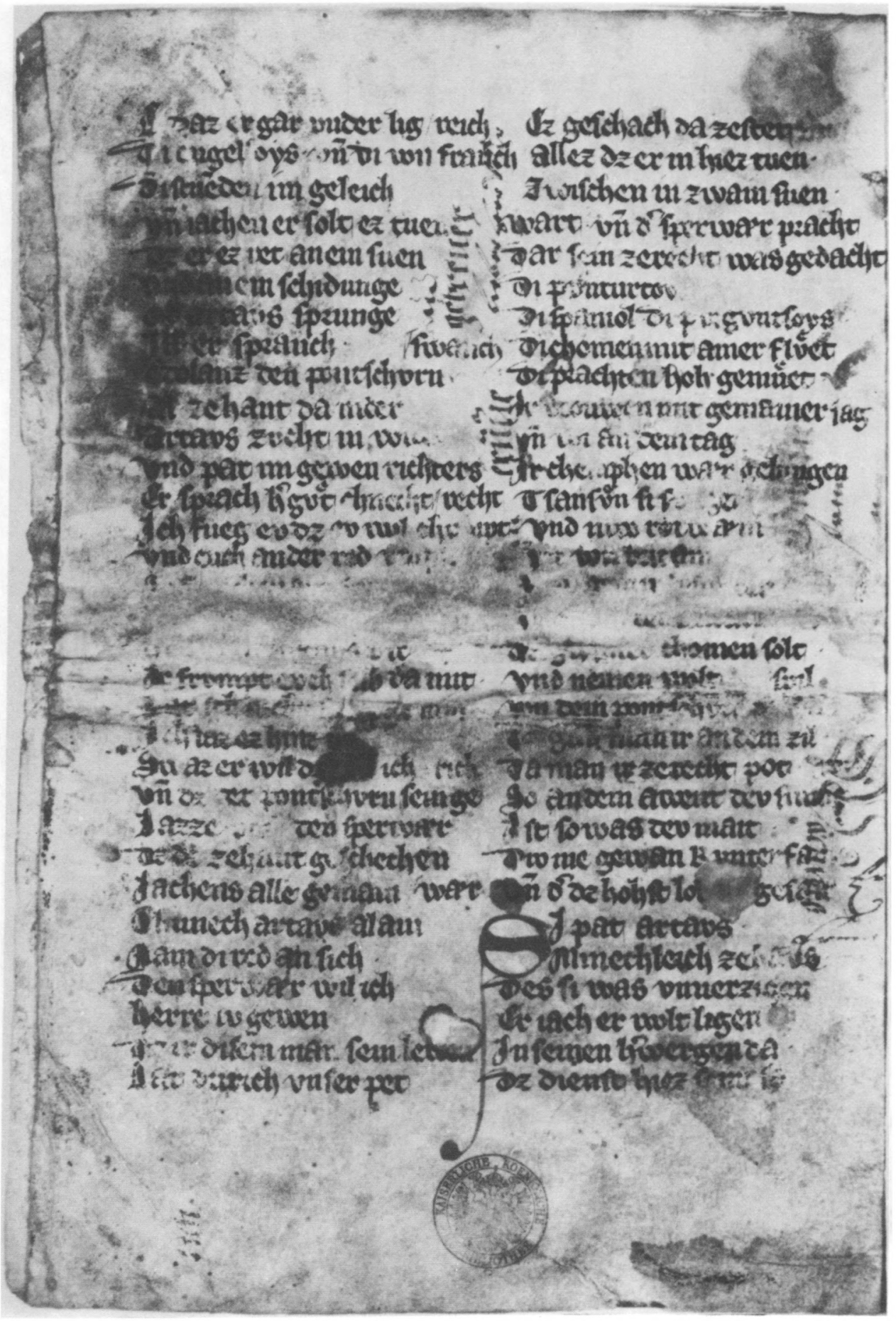

Abb. 7: Edolanz, 2v, B-Typ, Nr. 4. Wien, NB, cod. s.n. 4001. 


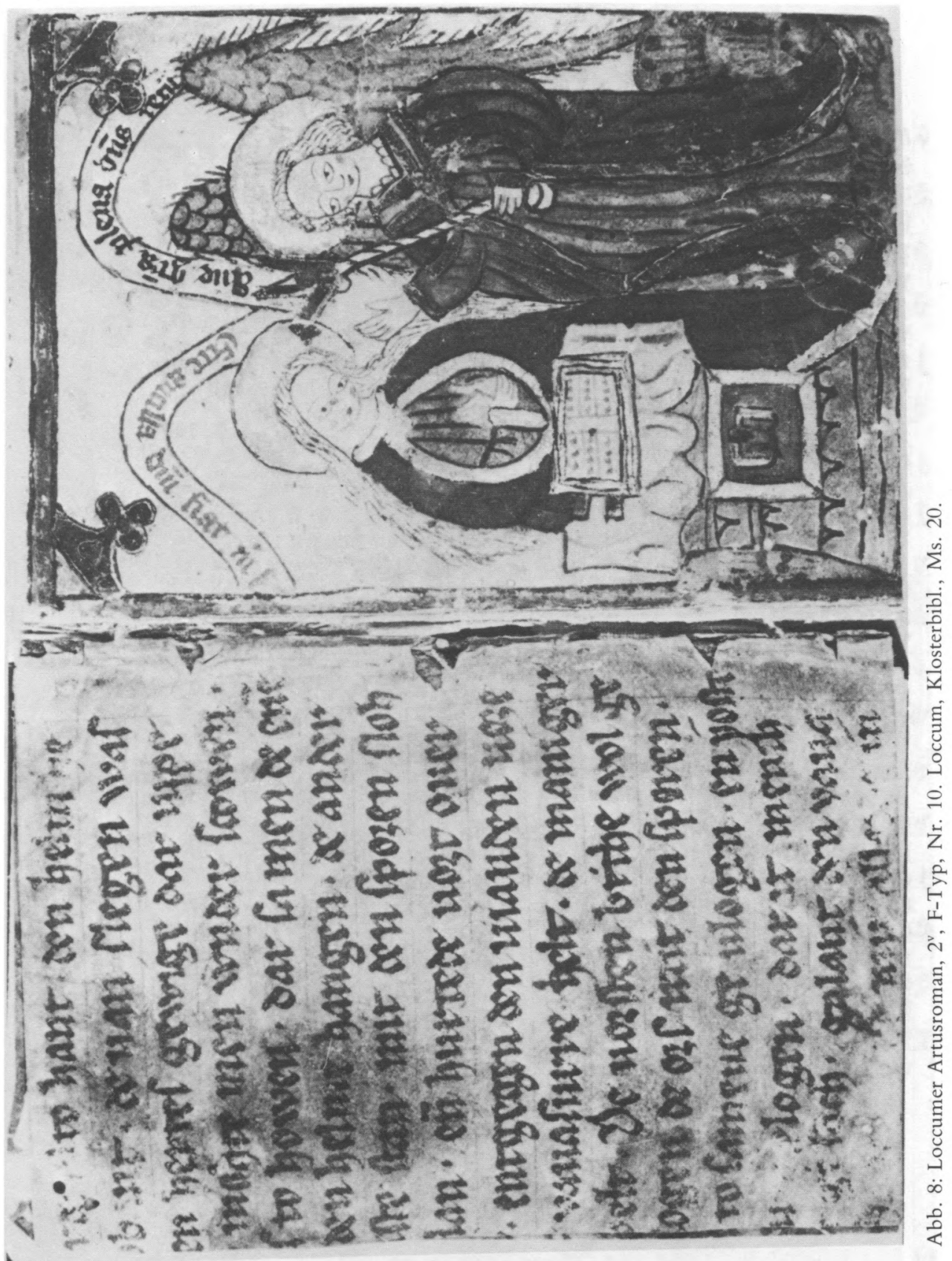


G anvane wu tener not.

so wer vulitgetid min tor.

sin lekent ite moter dan min.

fwliose veturt matgrion.

spad) cr anden tritum itunt.

jot our wan gawome laver

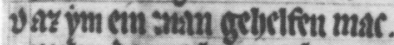

vitm dante biten vort one.

j di rue mogene vitu mir ot:.

Inalgrum fikn wer firt.

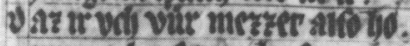

yuur adde fly moty to:

j r fie zu vens zo are wetr. sie ut ygar'zu bert.

1 t'fir vit soz vî villane.

zodj ovnket xe mur zo kmanc.

$\checkmark$ itt der lip nodi to muve

vaz to vordye dat nim vir thin

an viloctivenuts.

wan ob v mitictungs.

solukr beterthatp vitir lozn.

calte vezret v. vurtwan.

wert vै getcosen unxe bate.

viveit etn fitgetane vatr.

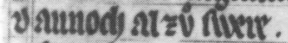

fo wlger miner Int

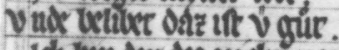

Jol bm ore des metyr neritr.

J di wil pers rituretum.

odr ibi wil b' namen firikn.

p) u caget mi won oer ngent.

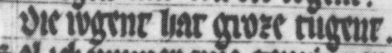

sol id iommer vis grovinitien.

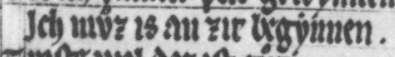

ctoitr wi dar ut gilt.

oút twot madjet lioen múr.
Vuxix terter an man.

Jil) wil obts mir gor gan.

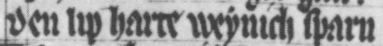

Gor rudie midi lewoan. Jib wil nemelidien vant. (i) Wil unwe Theten. Jre fult alot ud termiten. f $v$ ud oviker ato vivine. Wat damer obidjes ma arir kome.

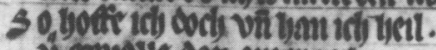
v grvatic ors anytr mil.

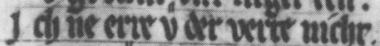
swar value da grencite.

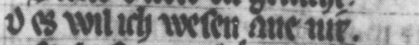

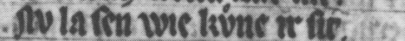

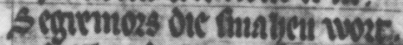
vic bet dallerr givogej

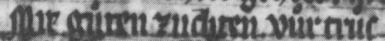

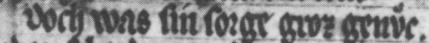

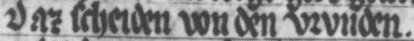
vie da vmme tounden.

vủger timimener vno letr. So twbme on sice fin tuantyent.

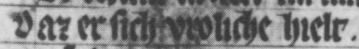

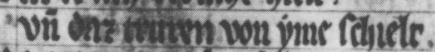

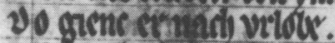
ation

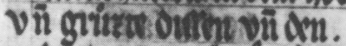

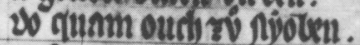

ost fronen undrat tongen. 20 fie gar frtwingm.

sin critiver lietr.

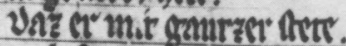

v utof tiem wast voltr grom. sin lip. In gure in telet. b ct fipadi votumx zu me far.

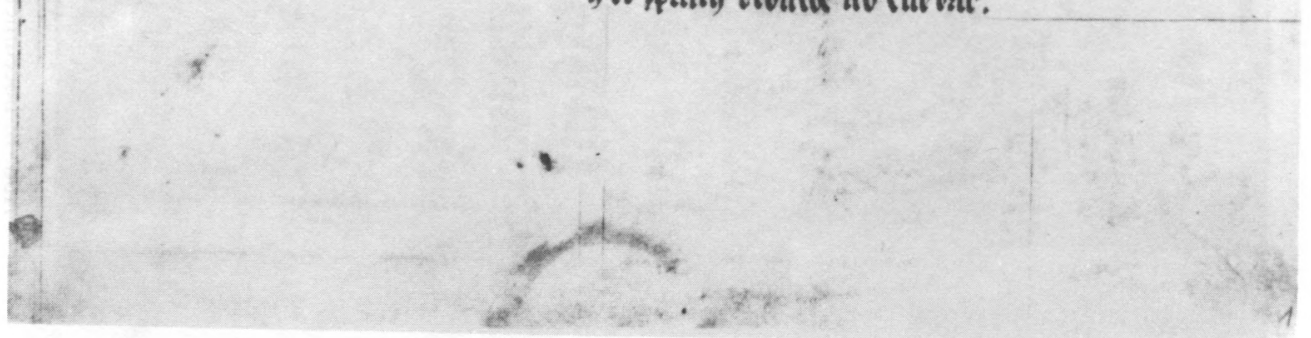

Abb. 9: Segremors, 1, C-Typ, Nr. 19. Weimar, Staatsarchiv, Reg. 1. 
menen diruen ats udb Uar.

J di bin of minem ware.

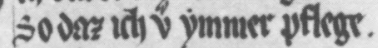

visnett mir truluen. Je fille ynmer bunven. A n mivnem hetrzen minm!.

Jit vate won om batron.

pine zumuthdie vare swar di lumum werd gekare.

so fot v. dat grwirzen fin. varz in al con orenine min.

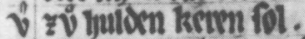
jo bedard id river therr wod.

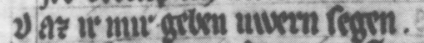

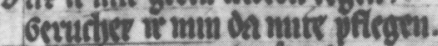
vncesemere ur mit githo? So wind bobes miver is.

vй nur ne mac geforden mode. mar vild daz grvowemen idte.

$j$ rlyaber glit gunt wn mit.

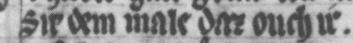

mur o bole grmuer thiger. word dan vily wn mit vitrtager.

so kvendidi vnivirzes tiogen.

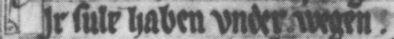

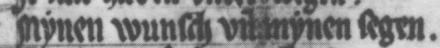

of 9 e crore trote ór minder.

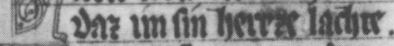

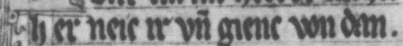

Al boger was or minne kan

vis minuse to vetre mausgen mive.

2vin fie fir gruade tie.

mume ore ger funertern.

vndr viritchen dem ferteren.

minne dersurtide.

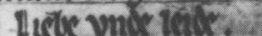

menus ore fler wundr. Vinde ligles dee will gromot.

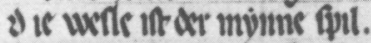
stumine fie ature vurbounden wil.

y $\mathrm{ctl}$ man wen vigemadis. so kan fie fullie fadis.

2) ถะ fie trutte rnvinder. ปar man m $x$ vindor.

2) en twoth . Ar con man gewert. alles os if hetrer cort.

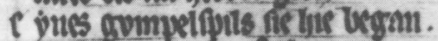

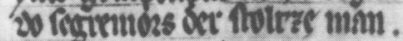

von ar wervebuiuen geme. vit ur vilob virtienr. 20 bandix ore minur. ster mager mu tr fimer.

( yusen minken grodar so dar fie mir alvivele tane. vin groadier waz fie netr. str outre nutre betr.

sidi antr grwatr gegrion. vitur genaden vidie teren.

V นี mur oicnet welo varu. we fie fict) mivdote truartin. 2) az manz ur motor milfrusud. sir groadier ob uti um fretr. imvines kilrinotrs perwats. Jim grtwher afele bas sir er mir ro bole itt.

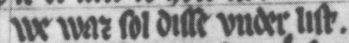
Gedodire fie abur fam zu tour.

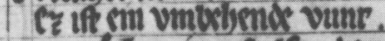
war múd ar im gelyelín vare. Jet) wene mir grzene baz.

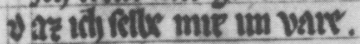
vin tî) in Indes leweare.

Abb. 10: Segremors, 1v, C-Typ, Nr. 19. Weimar, Staatsarchiv, Reg. 1. 


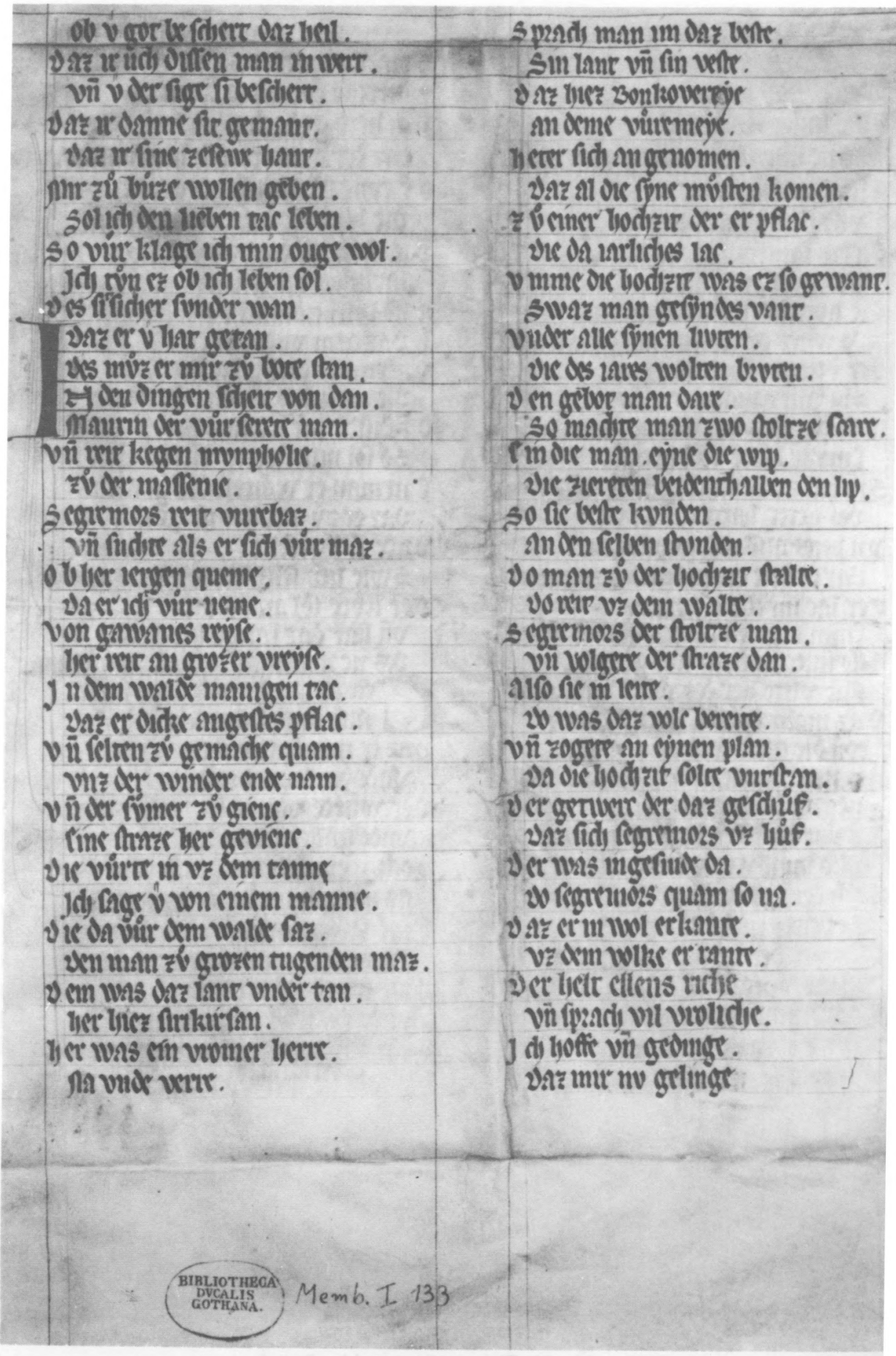

Abb. 11: Segremors, 1, C-Typ, Nr. 19. Gotha, Forschungsbibl., Memb. I 133. 


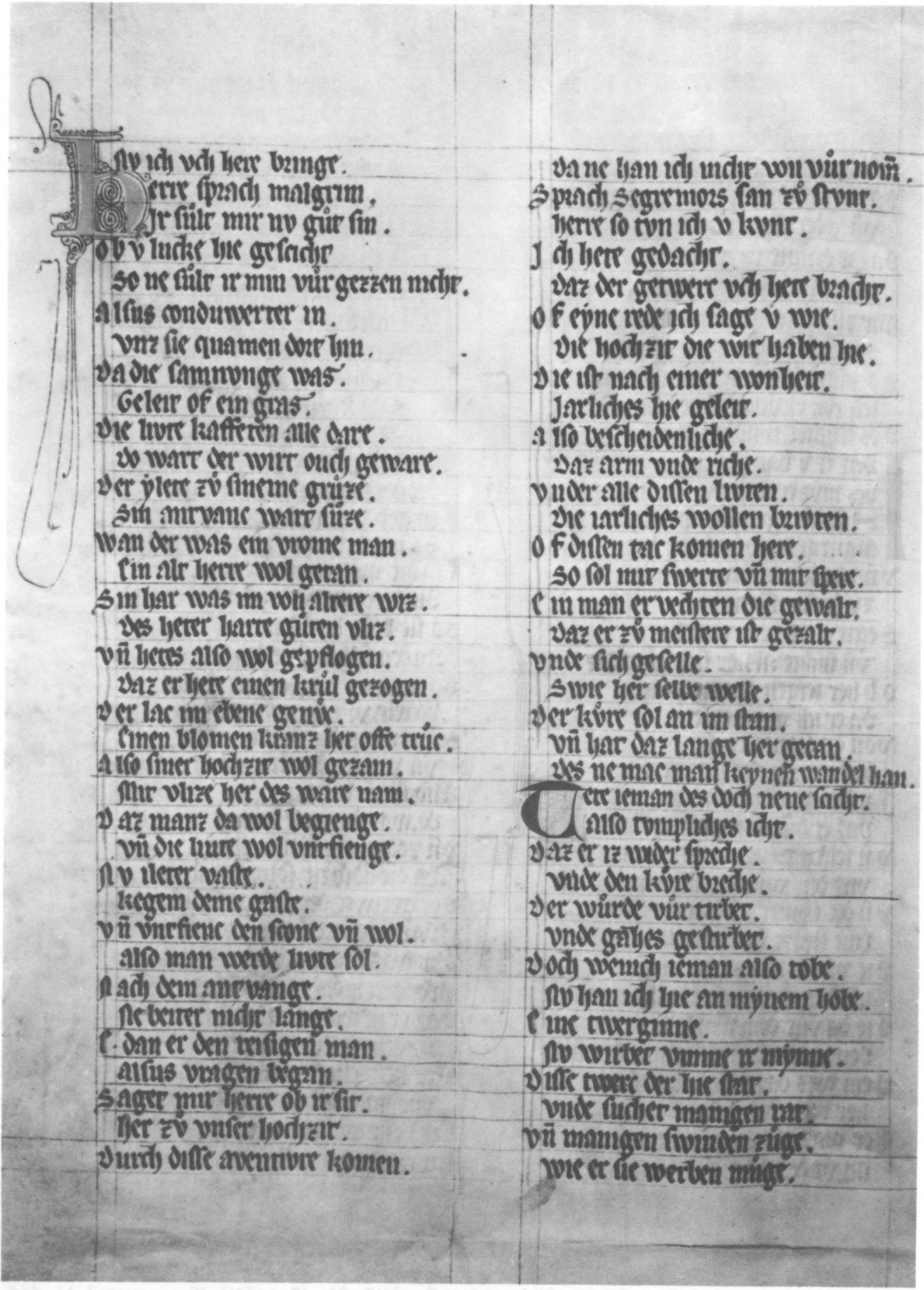

Abb. 12: Segremors, 1v, C-Typ, Nr. 19. Gotha, Forschungsbibl., Memb. I 133. 
ก ข vil tod $\cup$ fagen me. lis lie cin witkr indom is

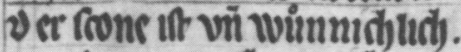
vnd aller zurbert mib. 9) a it ctvidi mris. katmentr lise em fixs 1) is was da wite wonlaste. flur ur willectr lamet. 6 crifif tie daz der tetix ylan. Gebloer ymener me tol tran.

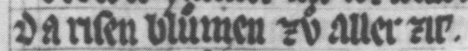
vie wgere-fingren wide ther. a n mamern ruzen one. vis andite tit to frons. Da: da gur nufm netr. ob anc tietrer finker. De liver da weren miliom. es mudier fie wol grtuoten. wam dant lut vor ctuar. vì giter kivrezculte (tant. mam imidjut vanot vinden. Lufr won gitem whroen. Gưrn ruci won witeren. soldx ern mam de zar da kutrzen. so finceilyed wol am vnder lite. var bi tonode miten ninder uts. cinctar alo grumene. vic bat dar zu gracrute.

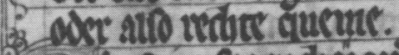

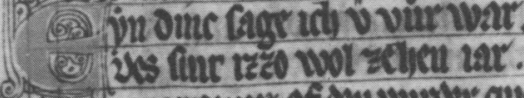

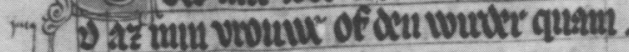
vílíd daz an $12 m$. 2) az fir da wectren wolde. ve wik fie leben olox. vñ ince da wrtken cinten tîm. sten anger nodb mamger ftium Nidir germalen limdx. vii lites den von grvend. von marmethevie moven. mamgen fleyin turen. s ลzก mm otun ma daz wrr. Jie vber tall vĩ uber ber.

v stre tragrn mn felim. Jab unenc idis uxrtats mugr fin. y at fididem grlldie. vatr unde ritie. wan fie bar giuts our marbr. 20 dre tovim was willm bader. $\$$ o lent min vimur viur. 2 suxr ur uivme gent. 2)az fis ọa blicter. 2) a mir nincture fluts. viilyere dat kunden woitr.

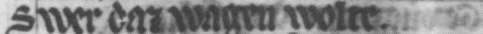
2ar der tronich folitr.

of omplan:

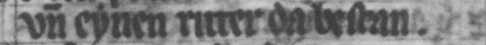

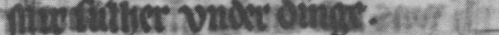

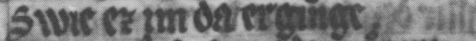

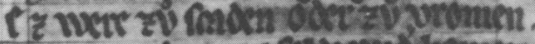
Dar er ninuter coloc wid iconicn. wan firch the atro grtwe: aler cine folcr on logen tor.: vndr dre ine fege teme. Jar de zu we queme

vnicutor mietroa. vitz thdoro oatua:

$14 \mathrm{~cm}$ modo 4 vî fiverueces to monme:

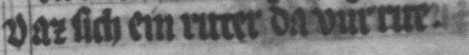




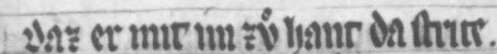

Vี D) ละ Mroclucke vundx.

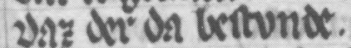

2

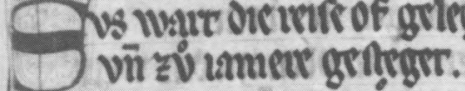

wamlinewas mut grituc. are notolibene vitu trie.

2) az fir dar cuamm.

vĩ ore alemtive namen.

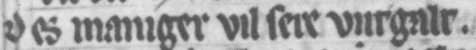

cin turtet on Thet grinoale.

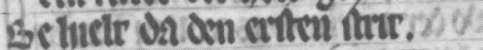

vid vas Da inanige zit.

2) az im me wart wiór viren. vin watt worly orcke belhitrm.

is cr. Wats cin vurte wolgrloen. zจ์ allen thignden ve nkzorn.

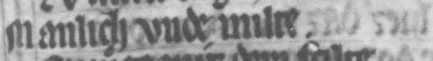

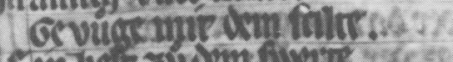
cin ber zy am fiotio.

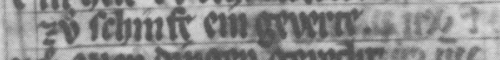

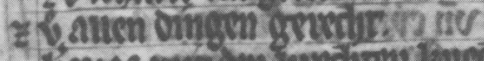

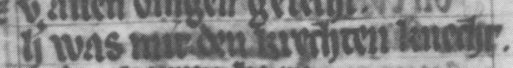

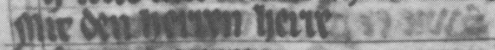

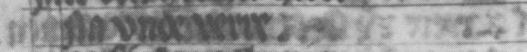

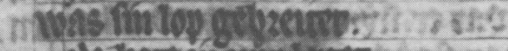
2b berr mur tints. S m mantin tocter vi fín. of fis grome viguvin.

2) az cr ouidotere una er bere lue vituen them Jnamgme turter strilaton. os twanes gitur eliationor.

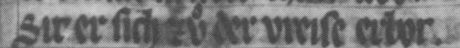

yo minte st nuerten denluy. ato wincle ber oaz wow. mir tazket suxntwir.

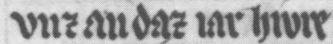

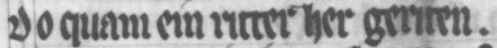
atre thmer mir un uadi belas firm. ver was cín ttare man als rr fir. von tm wate sin fo betre hyr.

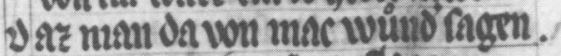
ขa wart Grmoalt mólagm.

vî der an fogr da grtum. atrite uv ort vevanuen man.

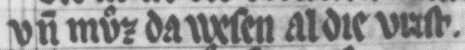
die er venvite foger itt. an fus grtanc vitutr. Genetise unuet ther.

sol ce v ro vol etgan.

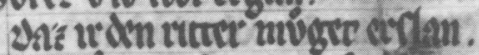
so mizer ut fellor da uretar 8. Itrre was oaz mox.

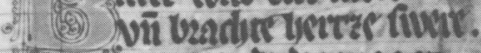

इ cui itur vude de magy

- sir watm lond mach vit zager. wan aloge mic gercadi. Jaz modyte fid vit vatuad). Gelichm dure inde. ats watm ticnach lent: vort um symen komen. 20 firbirten vite nouten. ats in karnojtruintach Jaz inzu cdimatirge

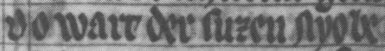

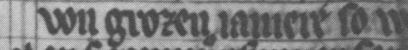
2)ละ tie vuvartionten

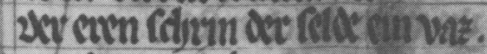
2) tearvine wouryume 


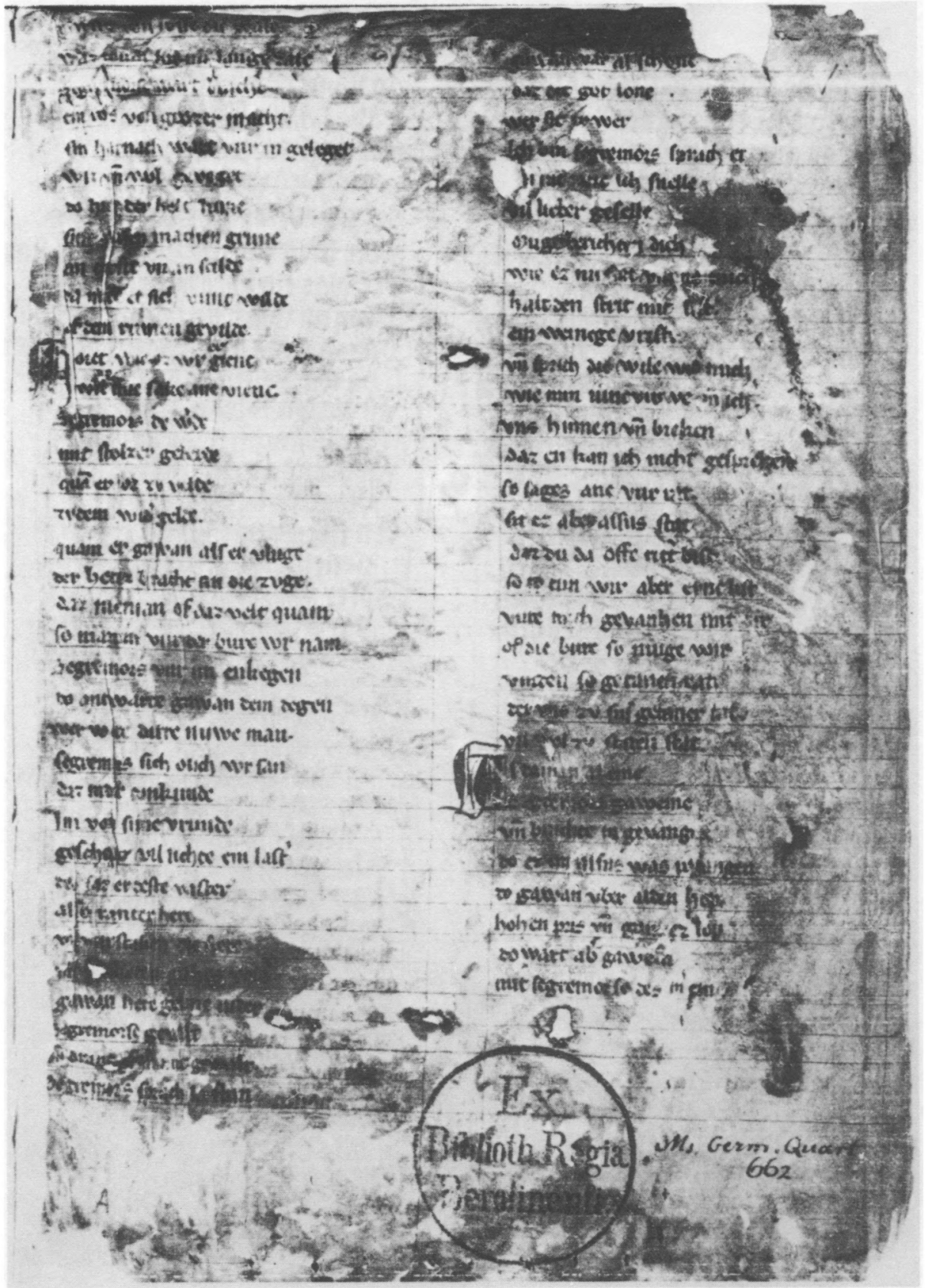

Abb. 15: Segremors, 1, E-Typ, Nr. 20. z. Z. Krakau, Biblioteka Jagiellońska, Ms. germ. $4^{\circ} 662$. 


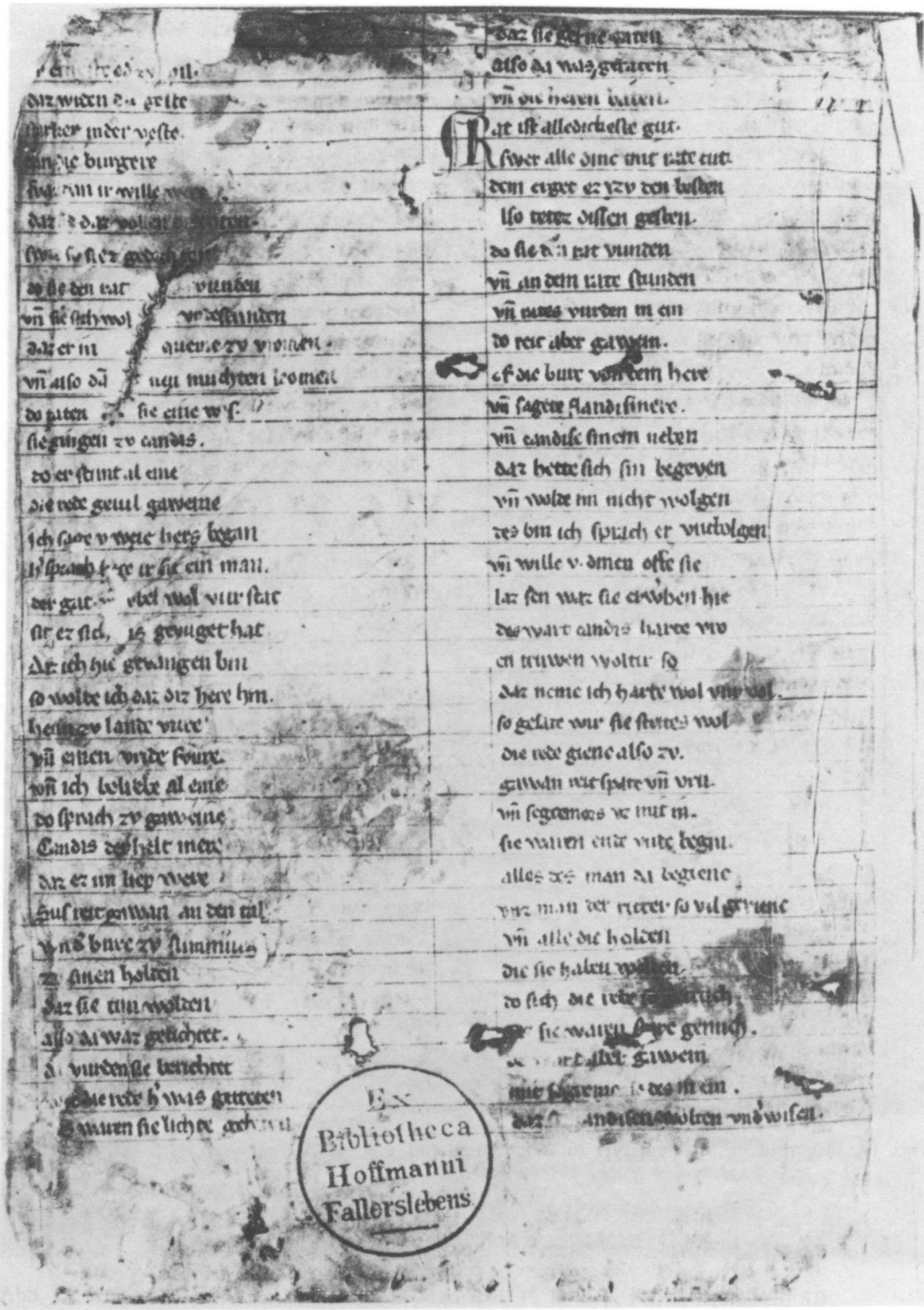

Abb. 16: Segremors, 1v, E-Typ, Nr. 20. z. Z. Krakau, Biblioteka Jagiellońska, Ms. germ. $4^{\circ} 662$. 


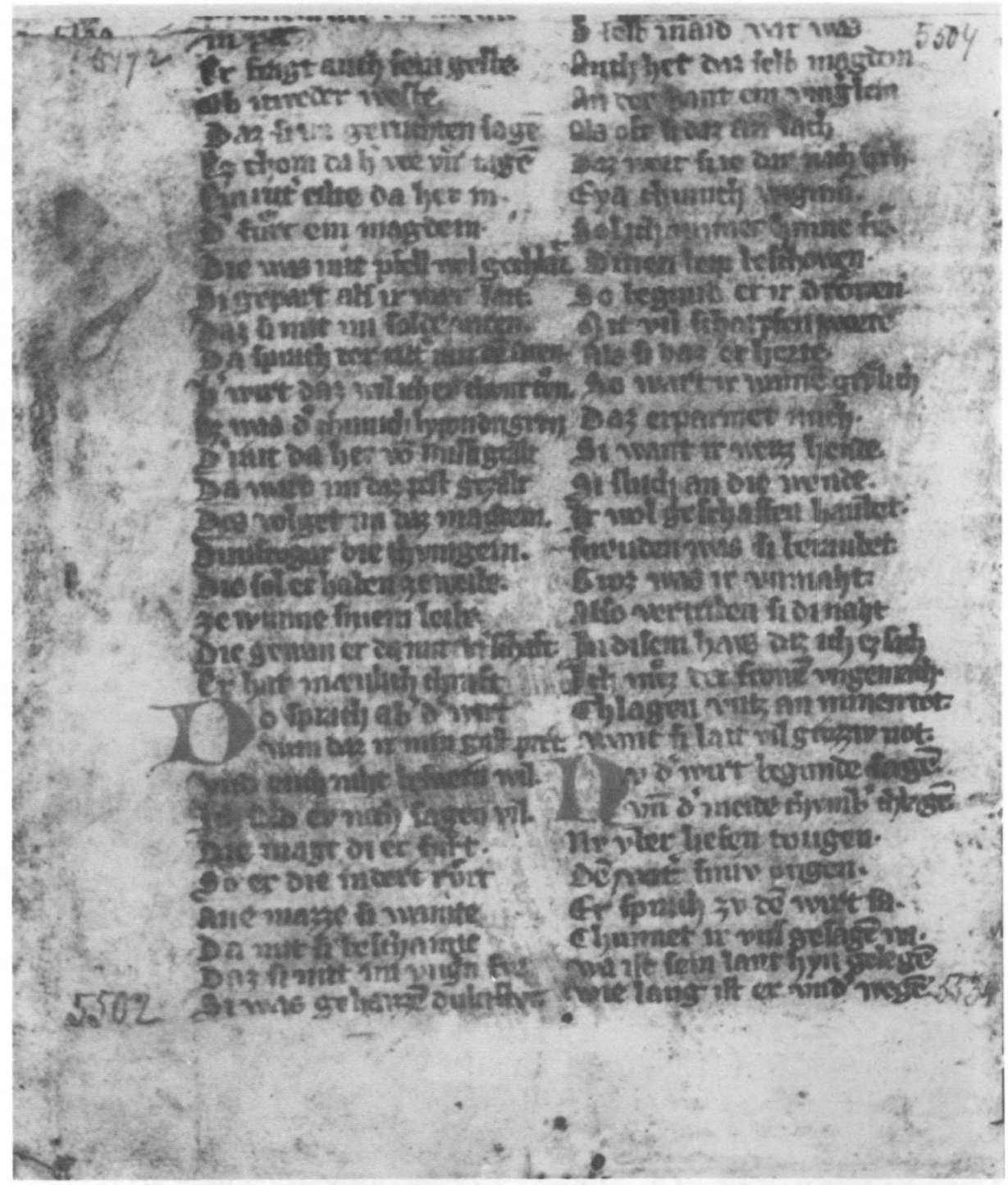

Abb. 17: Wigamur, 4 , B-Typ, Nr. 26. Wien, NB, cod. s.n. 4433. 


\section{5

$$
1040=110960 \text { Cgm } 5249
$$

Fi auf ún ander tacty

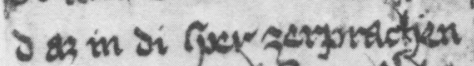
ons in zaveute wor g hant alto (was wient teint bersente

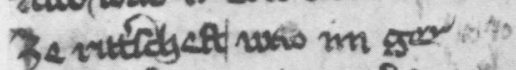

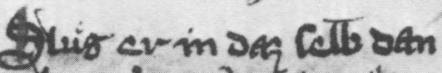
$10 \%$

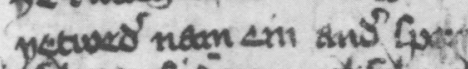

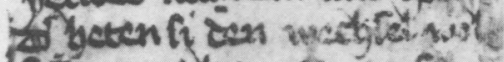

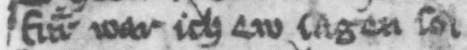
1बh wetn nol sin wos miln tete se grefyereen Yritgel viuter in fotucen is to fi oi Cimm nevtlue 82 uns s abent sne sic bogrey s th matwon nu mữ ss getgen clgatm

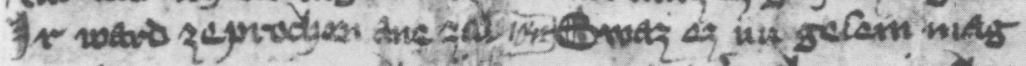

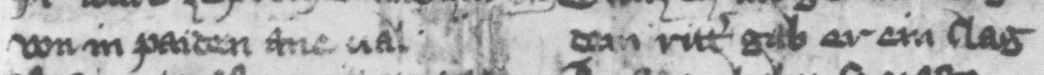

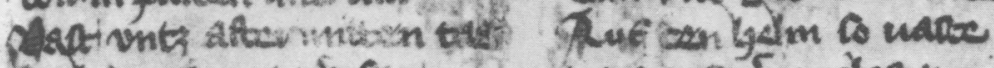

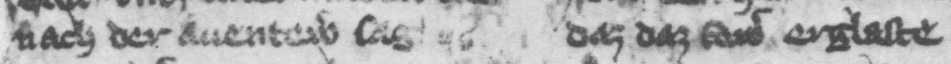
Go vadý tiubt pettagen.

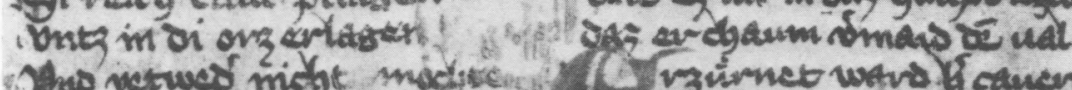

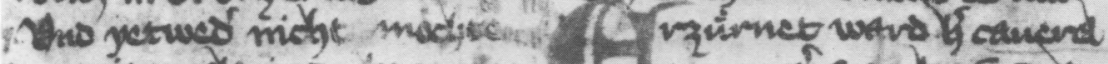

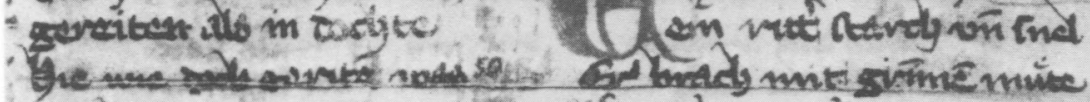

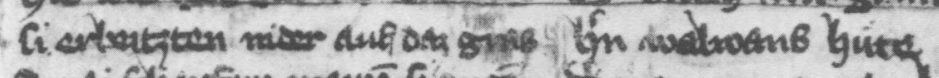

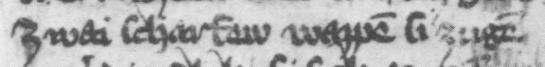

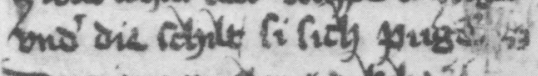

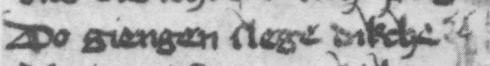
ots in si fewers gotidyc sobren balm priatrien

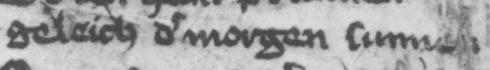
Sea con vitar- bod gemut ptivenelyalten aes blist in rame or duiz noa oño dyine nef wid ctriess gotutrem fyelm Cimot las orin cen midm

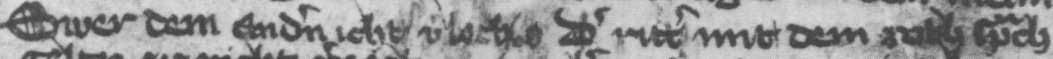

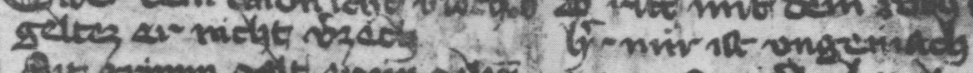

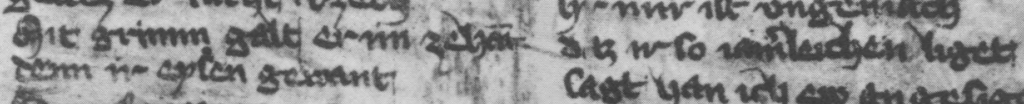

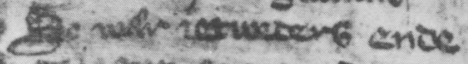
Ecisger fin ansing henos

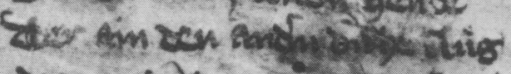

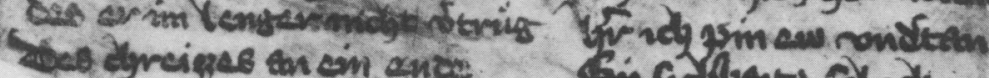
Cate yan rody an angronget

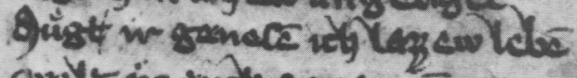
rude in suct seudng 8 dx

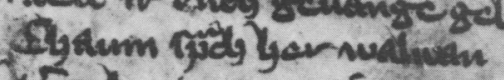

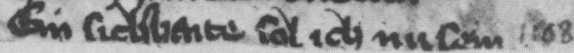

Abb. 18: Konrad von Stoffeln, Gauriel von Muntabel, 1' , D-Typ, Nr. 9. München, SB, com 5249(9a. 


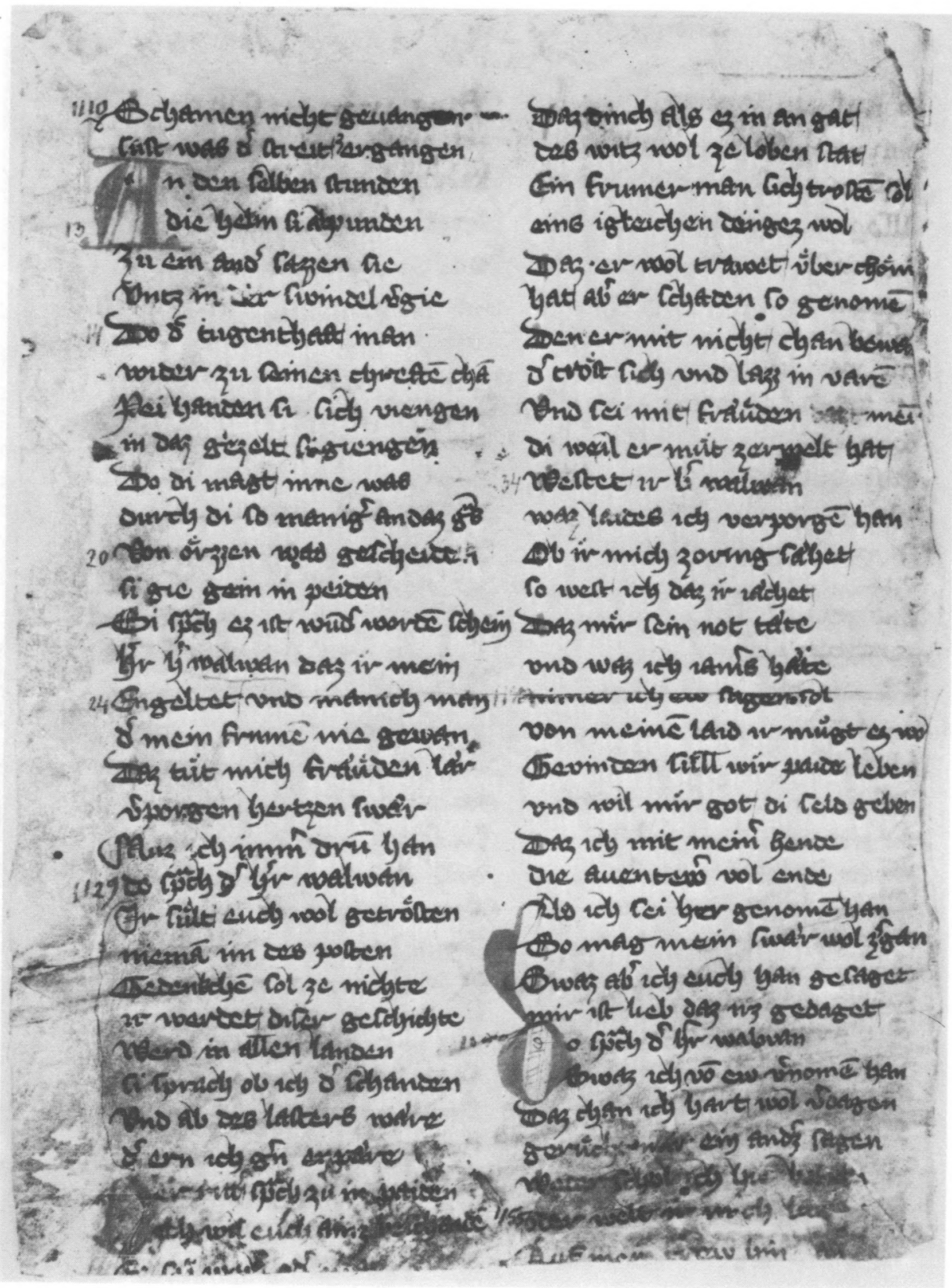

Abb. 19: Konrad von Stoffeln, Gauriel von Muntabel, 1v, D-Typ. Nr. 9. München, SB, cgm 5249(9a. 


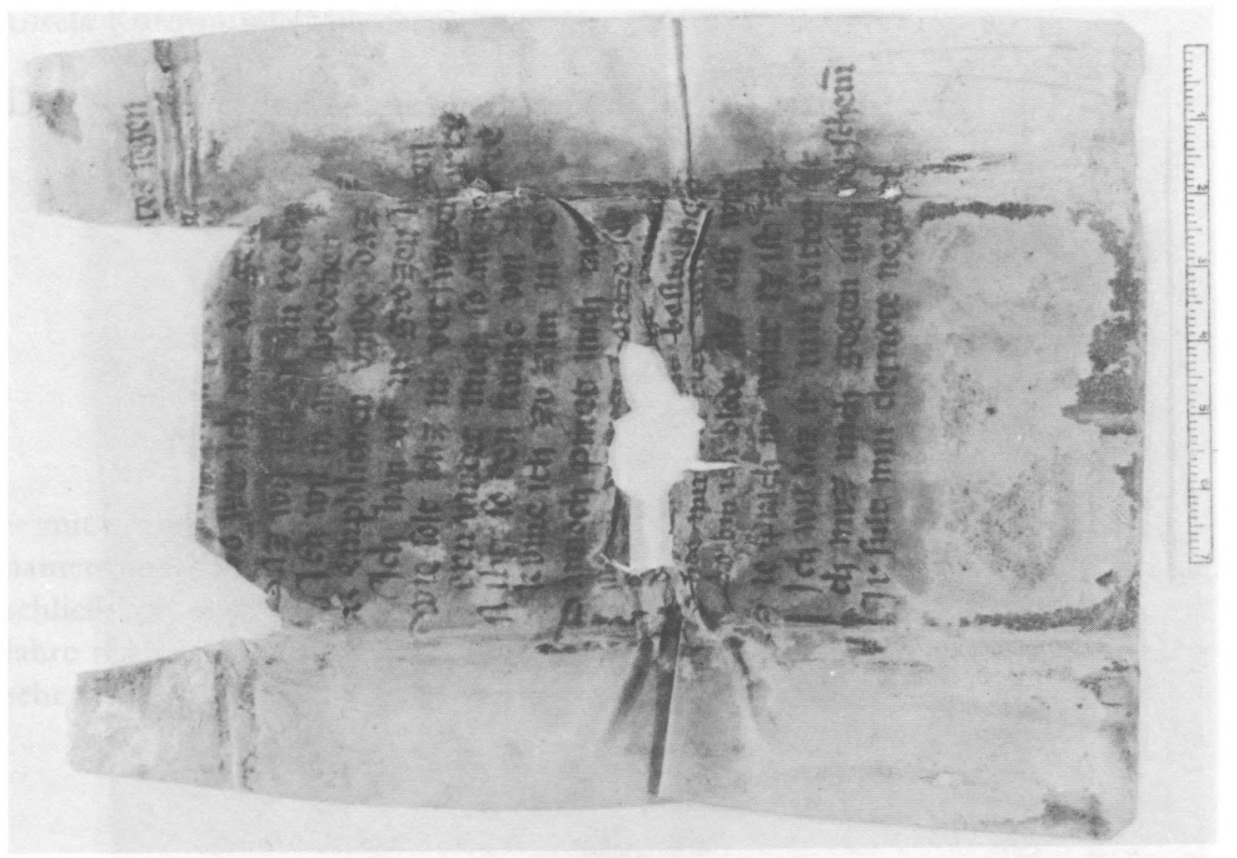

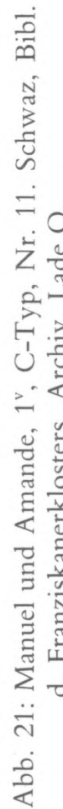

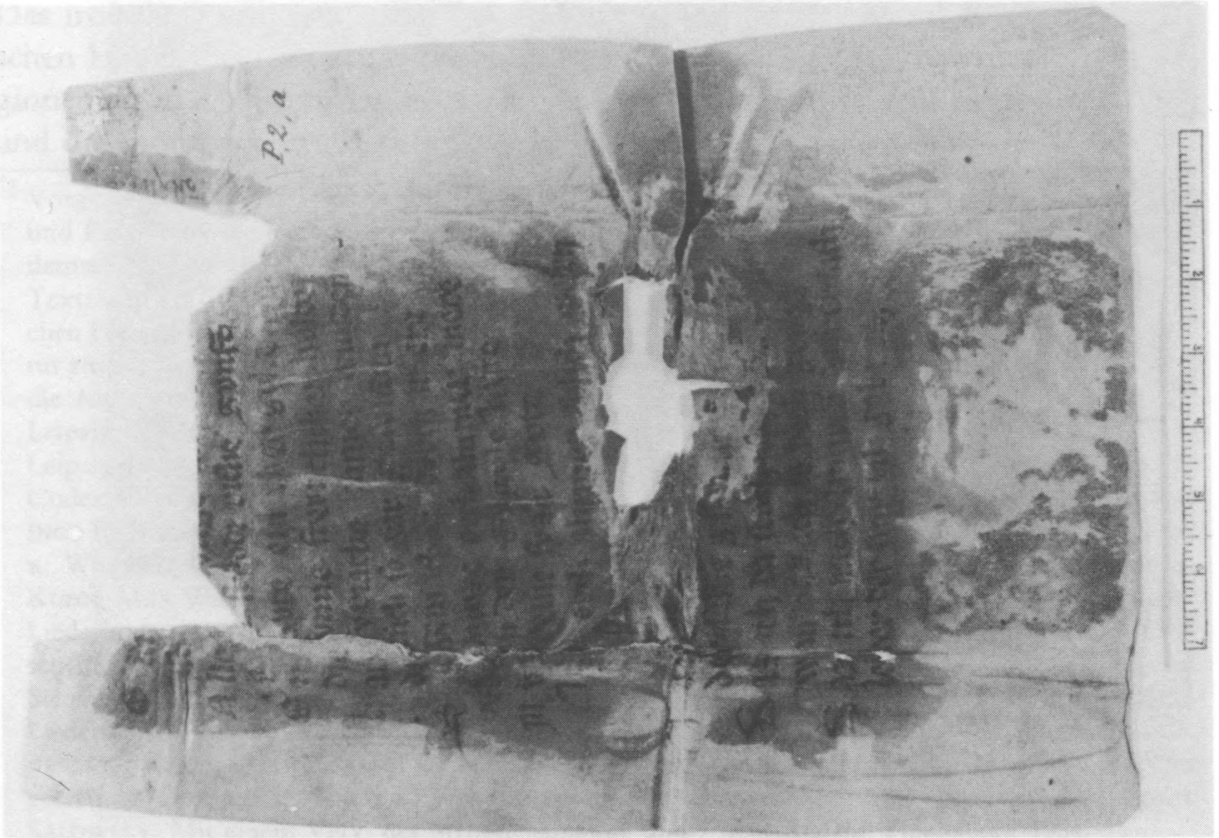

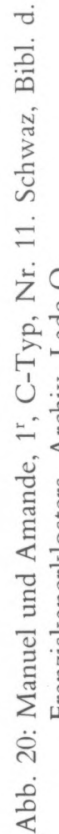




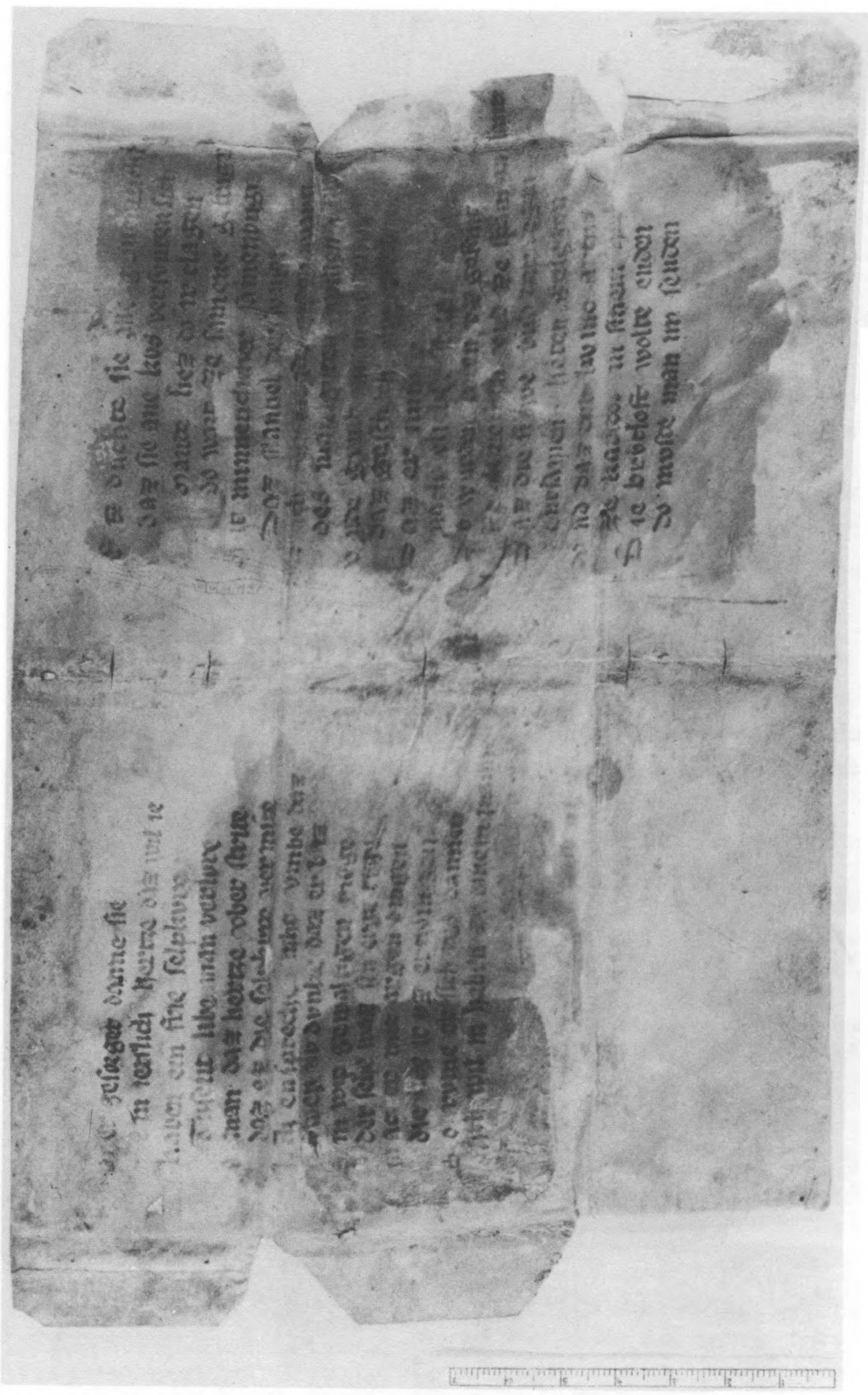

Abb. 22: Manuel und Amande, $7^{\text {v }}$ u. 2 $2^{r}$, C-Typ, Nr. 11. Schwaz, Bibl. d. Franziskanerklosters, Archiv, Lade O. 